\title{
ANALYSIS OF THE SEASONAL PERFORMANCE OF \\ HYBRID LIQUID DESICCANT COOLING SYSTEMS
}

by

FRIEDRICH SICK

A thesis submitted in partial fulfillment of the requirements for the degree of

MASTER OF SCIENCE

(Chemical Engineering)

\author{
at the \\ UNIVERSITY OF WISCONSIN-MADISON
}

1986 


\section{ANALYSIS OF THE SEASONAL PERFORMANCE OF HYBRID LIQUID DESICCANT COOLING SYSTEMS}

by Friedrich Sick

Under the Supervision of Professors John A. Duffie and Sanford A. Klein

In conventional air conditioning systems, the air is dehumidified by low temperature condensing of the water vapor which is a thermodynamically non-optimal process. Liquid desiccant cooling components separate sensible and latent loads, i.e. cooling and dehumidification, respectively. Thus, the thermodynamic process for conditioning the air from the ambient to the desired state can be optimized. However, liquid desiccant systems require more equipment and different types of energy inputs, namely cooling, heating, and electricity. These energies may be supplied by a number of different devices, such as a chiller, a heat pump, a cogenerator, a boiler, solar collectors, or combinations of the above. The combination of conventional and liquid desiccant air conditioning equipment forms a hybrid liquid desiccant system. One such system is installed at the Science Museum in Richmond, VA (SMVA).

A simulation model for the liquid desiccant component of a hybrid system was developed. An analysis of experimental test data taken at the SMVA was conducted. 
The liquid desiccant component was examined and the sensitivity of its seasonal performance to changes in principal component variables was identified. Seasonal simulations were performed on different operation modes of a hybrid liquid desiccant cooling system. The results were analyzed in terms of estimated operational costs and compared to the equivalent cost estimation of a conventional cooling system. The study showed that the investigated liquid desiccant configuration usually will not lower the costs of operation. A suggestion for an improved system is made. 


\section{ACKNOWLEDGEMENTS}

In this apparently most important part of my thesis (according to the expected number of its readers), I want to express my thanks to those who, directly or indirectly, helped producing all the following pages.

I am particularly indebted to my advisors, Professor John A. Duffie and Professor Sanford A. Klein. Jack's encouragement and help in whatever matter throughout my whole stay at the University of Wisconsin were a steady and firm support on my way to the "master". Without Sandy's involvement and interest in my project, without his questions, suggestions, and ideas the following pages would look different and may not be worth reading. I thank you both, Jack and Sandy, for leaving me so much freedom in the way I carried out the project.

I appreciated the positive, relaxed, and cooperative atmosphere in the Solar Lab. My fellow graduate students made even long working days and nights enjoyable. I am glad that I found so many friends among and through them. Special thanks go to Ann for proofreading the manuscript of this thesis and for so much more.

All this was made possible by the exemplary organization of an exchange program between the Universitat Stuttgart, West-Germany, and the University of Wisconsin-Madison through Professor Dr.-Ing. Michael Zeitz and Professor W. Harmon Ray. The funds for this pro- 
gram were made available by the German Academic Exchange Service (DAAD). The financial support was continued by the University of Wisconsin, the University of Wisconsin Foundation, and the U.S. Department of Energy.

Thanks go also to my friends in Germany who kept in touch over thousands of miles. And to my sisters Barbara and Franziska who showed so much deep interest in what their "little brother" was doing "da druben in Amerika".

Last, but certainly not least, a special thank you to my mother Dorothea. Your support, encouragement, and help in so many matters were vital to me. 


\section{TABLE OF CONTENTS}

Page

ABSTRACT ....................................... $i$

ACKNOWLEDGEMENTS .............................. iv

LIST OF FIGURES..............................

LIST $O F$ TABLES $\ldots \ldots \ldots \ldots \ldots \ldots \ldots \ldots \ldots \ldots \ldots \ldots \ldots \ldots \ldots \ldots \ldots \ldots \ldots$

NOMENCLATURE ................................. xiv

CHAPTER 1: Introduction......................... 1

1.1 Liquid Desiccant Cooling Systems................. 1

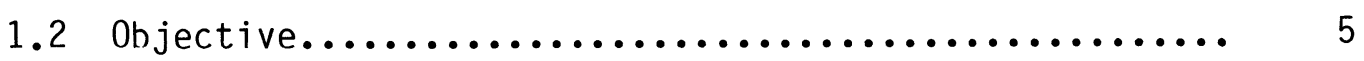

1.3 The System at the Science Museum in Virginia......... 7

CHAPTER 2: Modeling the Liquid Desiccant Component.......... 9

2.1 Modeling Approaches........................ 9

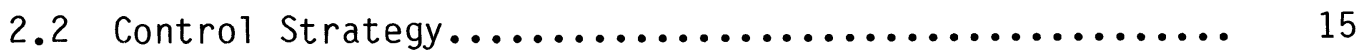

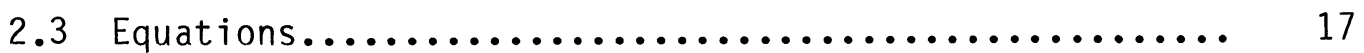

2.4 Solving the Equations...................... 22

2.5 TRNSYS Component Model...................... 27

CHAPTER 3: Experimental Test Data Analysis................ 28

3.1 Data Analysis and Results.................... 28

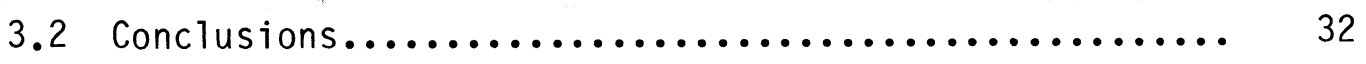

CHAPTER 4: Liquid Desiccant Component Simulation............ 33

4.1 Definition of a Standard Liquid Desiccant Component... 33

4.2 Standard Simulation Results.................... 39 
4.3 Liquid Desiccant Component Rehavior............... 42

4.3.1 Variations in Conditioner Air Flow Rate and

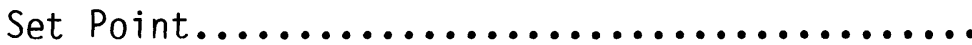

4.3.2 Variations in Regenerator Air Flow Rate and Inlet Conditions.......................

4.3.3 Variations in the Hot Water Source Temperature

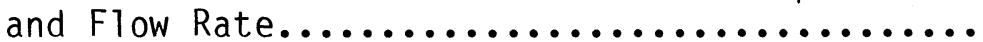

4.3.4 Variations in the Upper Sump Level for the Conditioner Control.

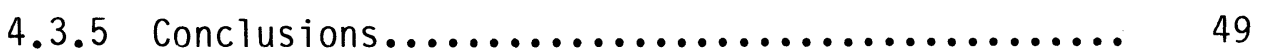

CHAPTER 5: System Simulation and Results.................. 52

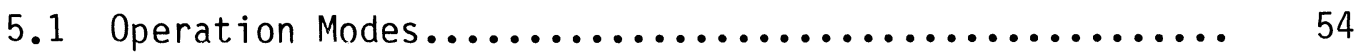

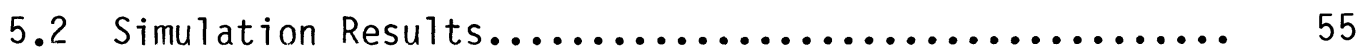

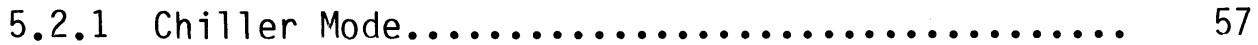

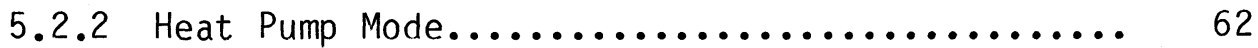

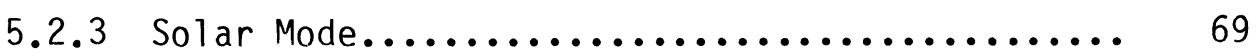

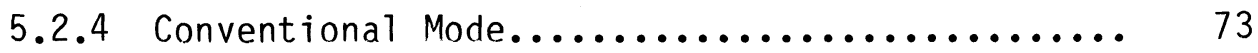

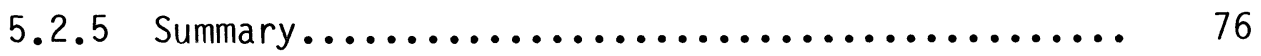

CHAPTER 6: Conclusions and Recommendations............... 81

APPENDIX A: Computer Code Listings for TRNSYS Components...... 87

A.1 Liquid Desiccant Component.................... 87

A.2 Energy Supply Control Component for Chiller Mode..... 110

APPENDIX B: Example Data Sheet as Supplied by TVA.......... 115 
Page

APPENDIX C: Example TRNSYS Decks..................... 117

C.1 TRNSYS Deck for the Chiller Mode................. 117

C.2 TRNSYS Deck for the Solar Mode................. 122

REFERENCES................................... 128 


\section{LIST OF FIGURES}

Figure

Page

1.1 Dehumidification and cooling of air by partial condensation of the water vapor in the air..................

1.2 Schematic of a liquid desiccant air conditioning component.....................................

1.3 Dehumidification and cooling of air by a liquid desiccant.

2.1 Exchange chamber with inlet and outlet variables as applied in the Kathabar model.

2.2 Schematic of the liquid desiccant component with sump (including the locations of system variables).

2.3 Incidence matrix for the liquid desiccant component

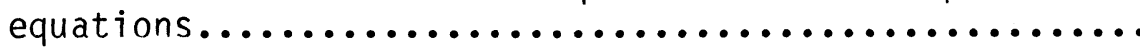

2.4 Partitioned incidence matrix including sump and decision variables for the liquid desiccant component equations.

4.1 Cooling energy delivered by the LD component as function of sump size and timestep for monthly simu-

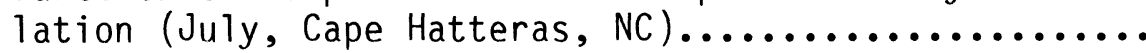

4.2 Daily operating time fractions of conditioner and regenerator and times with no load for monthly base case simulation....................................

4.3 Conditioner inlet and outlet and regenerator outlet humidity for monthly base case simulation..............

4.4 Conditioner inlet and outlet, regenerator outlet, and sump temperature for monthly base case simulation.

4.5 Cooling load and delivered cooling energy for monthly base case simulation.

4.6 Desiccant cooling and heating energy and required auxiliary cooling energy for monthly base case simulation. 
Figure

Page

4.7 Cooling and heating input and required auxiliary cooling energy as function of the conditioner air mass flow

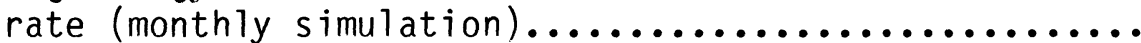

4.8 Cooling and heating input and required auxiliary cooling energy as function of the conditioned air set

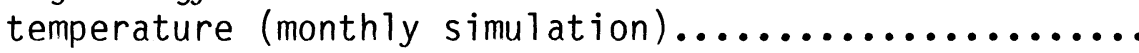

4.9 Cooling and heating input and required auxiliary cooling energy as function of the regenerator air mass flow

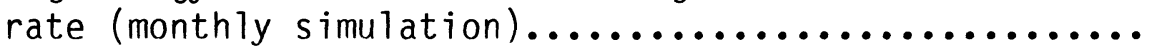

4.10 Cooling and heating input and required auxiliary cooling energy as function of the regenerator air inlet

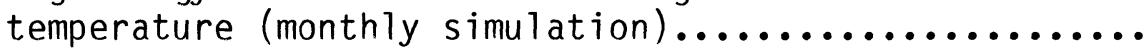

4.11 Cooling and heating input and required auxiliary coolenergy as function of the regenerator air inlet

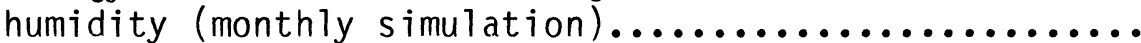

4.12 Cooling and heating input and required auxiliary cooling energy as function of the hot water source temper-

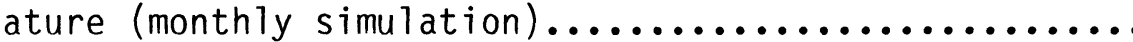

4.13 Cooling and heating input and required auxiliary cooling energy as function of the hot water source flow

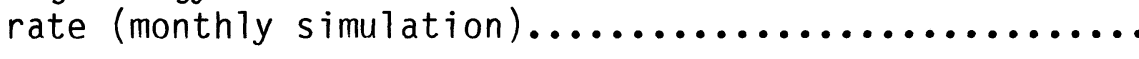

4.14 Cooling and heating input and required auxiliary cooling energy as function of the upper sump level for the conditioner control (monthly simulation).............

5.1 Average load, delivered energy, heating and cooling input for April-0ctober weather conditions of Cape

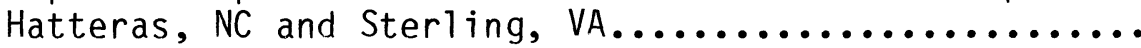

5.2 Average total operational costs of Chiller Mode as function of cogenerator capacity and regeneration

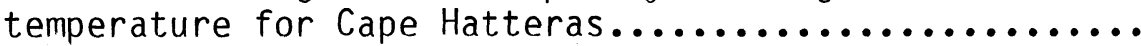

5.3 Average total operational costs of Chiller Mode as function of cogenerator capacity and regeneration

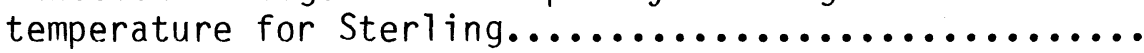


Figure

Page

5.4 Gas, electricity, and total energy consumption of Chiller Mode for Cape Hatteras $\left(60^{\circ} \mathrm{C}\right.$ regeneration

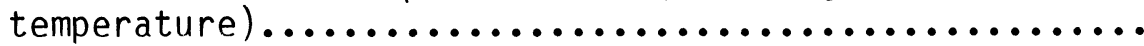

5.5 Gas, electricity, and total operational costs of Chiller Mode for Cape Hatteras $\left(60^{\circ} \mathrm{C}\right.$ regeneration

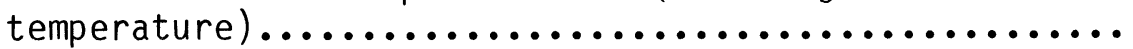

5.6 Gas, electricity, and total energy consumption of Chiller Mode for Sterling $\left(60^{\circ} \mathrm{C}\right.$ regeneration temperature)

5.7 Gas, electricity, and total operational costs of Chiller Mode for Sterling $\left(60^{\circ} \mathrm{C}\right.$ regeneration temperature)

5.8 Cooling and heating energy input versus regeneration temperature varying interchanger UA value (monthly simulation).

5.9 Monthly operating time fractions of conditioner and regenerator versus regeneration temperature...........

5.10 Average total operational costs of Heat Pump Mode as function of cogenerator capacity and regeneration

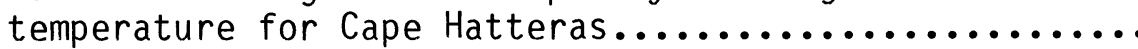

5.11 Average total operational costs of Heat Pump Mode as function of cogenerator capacity and regeneration temperature for Sterling.

5.12 Gas, electricity, and total energy consumption of Heat Pump Mode for Cape Hatteras $\left(60^{\circ} \mathrm{C}\right.$ regeneration temperature)

5.13 Gas, electricity, and total operational costs of Heat Pump Mode for Cape Hatteras $\left(60^{\circ} \mathrm{C}\right.$ regeneration

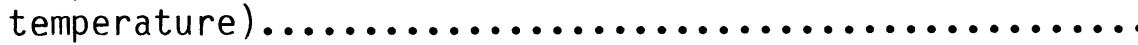

5.14 Gas, electricity, and total energy consumption of Heat Pump Mode for Sterling $\left(60^{\circ} \mathrm{C}\right.$ regeneration temperature)

5.15 Gas, electricity, and total operational costs of Heat Pump Mode for Sterling $\left(60^{\circ} \mathrm{C}\right.$ regeneration temperature) 
5.16 Gas, electricity, and total operational costs of Heat

Pump Mode for Cape Hatteras (electricity rate

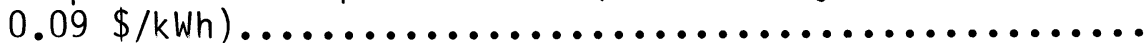

5.17 Gas, electricity, and total operational costs of Heat

Pump Mode for Sterling (electricity rate $0.09 \$ / \mathrm{kWh}$ )...

5.18 Average total operational costs of Solar Mode as function of cogenerator capacity and collector area for Cape Hatteras $\left(60^{\circ} \mathrm{C}\right.$ regeneration temperature $) . .$. .

5.19 Average total operational costs of Solar Mode as function of cogenerator capacity and collector area for Sterling $\left(60^{\circ} \mathrm{C}\right.$ regeneration temperature $) \ldots . \ldots \ldots$

5.20 Average total operational costs of Solar Mode as function of cogenerator capacity and regeneration temperature for Cape Hatteras $\left(500 \mathrm{~m}^{2}\right.$ collector area)..

5.21 Average total operational costs of Solar Mode as function of cogenerator capacity and regeneration temperature for Sterling (500 $\mathrm{m}^{2}$ collector area)......

5.22 Gas, electricity, and total energy consumption of Solar Mode for Cape Hatteras (500 $\mathrm{m}^{2}$ collector area)........ 74

5.23 Gas, electricity, and total operational costs of Solar Mode for Cape Hatteras (500 $\mathrm{m}^{2}$ collector area)........

5.24 Gas, electricity, and total energy consumption of Solar Mode for Sterling $\left(500 \mathrm{~m}^{2}\right.$ collector area)............ 75

5.25 Gas, electricity, and total operational costs of Solar Mode for Sterling $\left(500 \mathrm{~m}^{2}\right.$ collector area)........... 75

5.26 Minimum operational costs for Chiller, Heat Pump, and Solar Mode compared to 2 cost estimations for con-

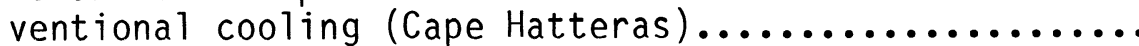

5.27 Minimum operational costs for Chiller, Heat Pump, and Solar Mode compared to 2 cost estimations for conventional cooling (Sterling).

6.1 Schematic of a modified liquid desiccant cooling system 86 


\section{LIST OF TABLES}

Table

$\underline{\text { Page }}$

2.1 Comparison of Kathabar and effectiveness factor model to finite step integration model for conditioner

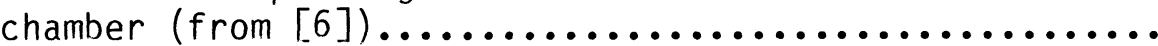

3.1 Energy balance on the desiccant cooler using experimental test data..................................

3.2 Energy balance on the desiccant heater using experimental test data..................................

3.3 Energy balance on the conditioner using experimental

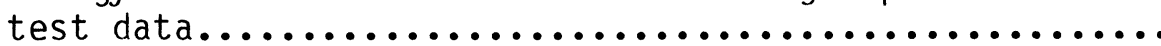

3.4 Check of Kathabar predictions for the conditioner using experimental test data........................... 31

4.1 Liquid desiccant component base case variables........ 34

4.2 Representative component energies and daily operation fractions for different timesteps................. 37

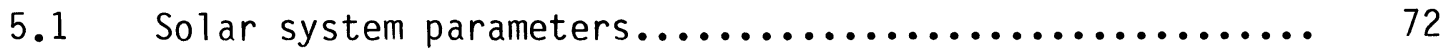

5.2 Estimation of the operational costs of 2 conventional cooling systems. 


\section{NOMENCLATURE}

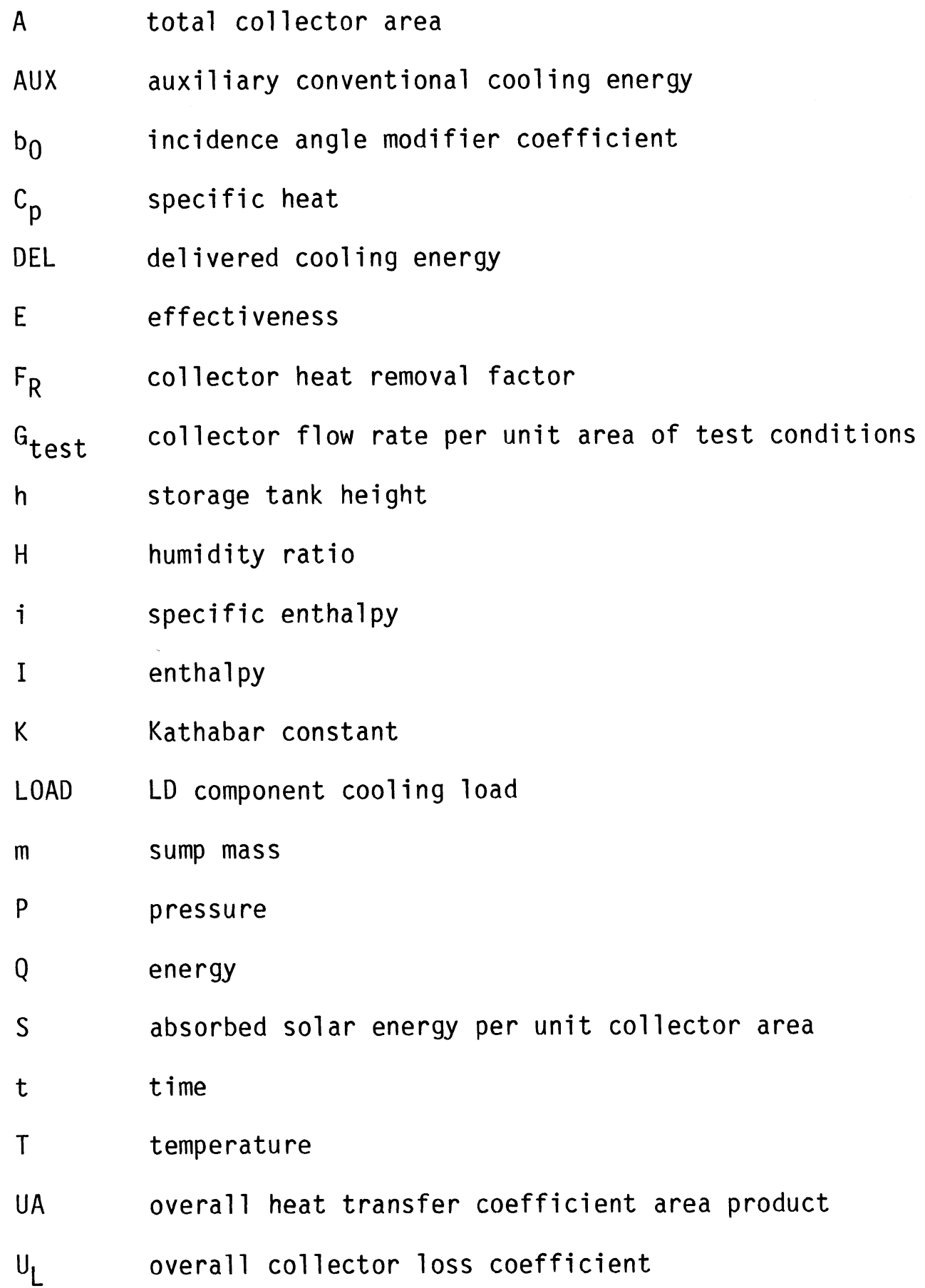


14 cooler water outlet

15 interchanger outlet to conditioner

16 cooler water side

40 conditioner desiccant outlet

41 regenerator desiccant outlet

Superscripts

- rate of change 


\begin{tabular}{|c|c|}
\hline $1 \mathrm{~m}$ & $\log$ mean \\
\hline $\mathrm{m}$ & model \\
\hline $\mathrm{mt}$ & mass transfer \\
\hline$n$ & normal \\
\hline out & outlet \\
\hline $\mathrm{R}$ & regenerator \\
\hline $\mathrm{s}$ & solution \\
\hline set & set point \\
\hline$u$ & upper \\
\hline use & useful \\
\hline w & water \\
\hline 0 & time 0 (initial condition) \\
\hline 1 & regenerator air inlet \\
\hline 2 & regenerator air outlet \\
\hline 3 & regenerator desiccant inlet \\
\hline 4 & conditioner air inlet \\
\hline 5 & conditioner air outlet \\
\hline 6 & conditioner desiccant inlet \\
\hline 7 & regenerator sump outlet \\
\hline 8 & conditioner sump outlet \\
\hline 9 & interchanger outlet to regenerator \\
\hline 11 & heater water inlet \\
\hline 12 & heater water outlet \\
\hline 13 & cooler water inlet \\
\hline
\end{tabular}




$\begin{array}{ll}U_{t} & \text { tank loss coefficient } \\ V & \text { tank volume } \\ W & \text { mass flow rate } \\ \beta & \text { collector slope } \\ \Delta & \text { difference } \\ \varepsilon & \text { error bound } \\ \rho_{g} & \text { ground reflectance } \\ (\tau \alpha) & \text { transmittance-absorptance product } \\ \xi & \text { solution concentration }\end{array}$

\section{Subscripts}$$
\text { a }
$$

$$
\text { air }
$$$$
\text { amb ambient }
$$$$
\text { c cooler }
$$$$
\text { C conditioner }
$$$$
\text { d data }
$$$$
\text { eq equilibrium }
$$$$
\text { h heater }
$$$$
\text { ht heat transfer }
$$$$
i \quad \text { interchanger }
$$$$
\text { in sump inlet }
$$$$
\text { inlet collector inlet }
$$$$
1 \text { lower }
$$

LiCl Lithium-Chloride 


\section{CHAPTER 1: Introduction}

For human comfort and the protection of sensitive objects, it is necessary to condition air in buildings which are located in climates with hot and humid weather conditions. The need to conserve energy and, more directly perceptible, increasing energy costs lead to the demand for energy efficient solutions of technical problems. Conventional air conditioning systems not only consume large amounts of energy, but also condition the air in a thermodynamically non-optimal way. Therefore, they are a promising area for engineers who seek to find new ways to solve old problems in a more economic and energy efficient way.

i.1 Liquid Desiccant Cooling Systems

There are two portions of an air conditioning load called the sensible and the latent load. The sensible load is a reduction of temperature. It originates from heat released by various sources or carried into the building by air infiltration as well as heat conduction through the building envelope. The latent load is a reduction of humidity and due to moisture released by people and transported into the building by air infiltration. Conventional air conditioning systems adjust both temperature and humidity to the desired values by passing outdoor air through cooling coils. The air is cooled down below its dew point such that enough water vapor condenses to meet the humidity specifications. For a typical humidity ratio of 0.007 $\mathrm{kg} / \mathrm{kg}$ this occurs at $9^{\circ} \mathrm{C}$ which is usually below the desired air 
temperature. Therefore the air has to be heated up again. Figure 1.1 illustrates the process on a psychrometric chart. The graph shows that although the air is generally reheated by free waste heat or by mixing with return air, the cooling process itself needs more energy than a thermodynamically optimal process with a direct path from the outdoor air state to the set point. Desiccant systems avoid this disadvantage by splitting up the conditioning task into cooling (sensible load) and dehumidification (1atent load).

In general, a desiccant is any hygroscopic substance, i.e. a substance that removes moisture from humid air when in contact with it. Silica gel is a well-known solid desiccant. A LiCl-water solution is an example for a liquid desiccant (LD). The hygroscopic nature of liquid desiccants allows a physical separation of the latent and sensible loads, although it is possible to combine both processes in one single device, the absorber or conditioner chamber, and handle them simultaneously. Figure 1.2 shows the general configuration for a LD system. Precooled desiccant solution flows countercurrently to the air stream through the conditioner where it absorbs water vapor and cools down the air only to the desired set temperature. The water taken from the air goes into the liquid desiccant solution. In order to maintain its concentration, the salt solution is pumped to a regenerator. The process in the regenerator is reverse to that in the conditioner. Return air from the building absorbs water from the preheated solution which becomes more concentrated and is pumped back to the conditioner. The conditioner and 


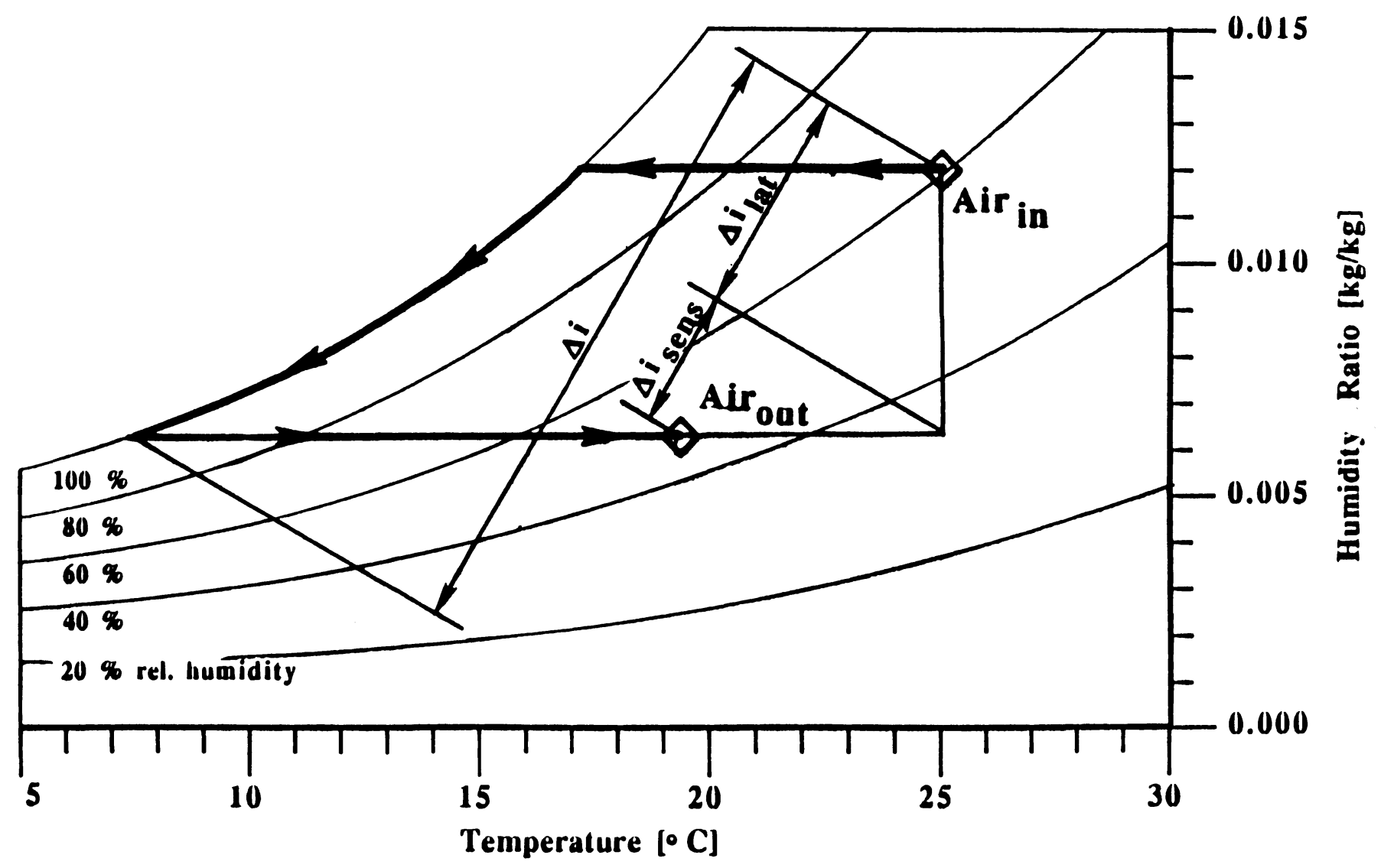

Figure 1.1 Dehumidification and cooling of air by partial condensation of the water vapor in the air 


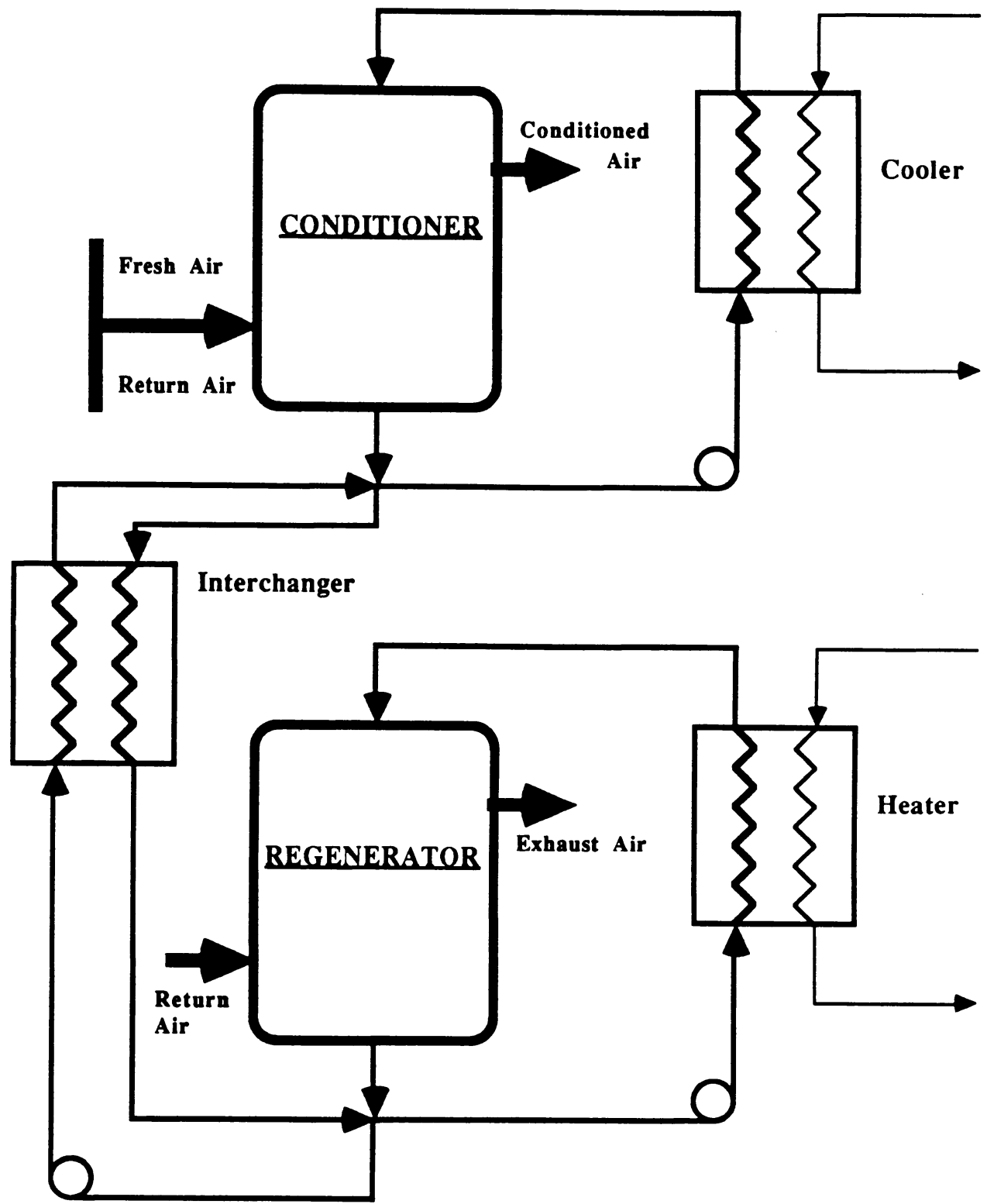

Figure 1.2 Schematic of a liquid desiccant air conditioning component 
the regenerator are connected by a heat exchanger (interchanger). The hot solution leaving the regenerator heats up the cooler desiccant coming from the conditioner. Thus, the solution entering the conditioner cycle is precooled, while the solution flow to the regenerator is preheated. Figure 1.3 illustrates the path of the air in the conditioner. The thermodynamic process is optimal in an energetic sense. However, the graph does not show the regeneration process with the required energy input.

The combination of conventional and LD equipment forms a hybrid liquid desiccant system and is referred to as the LD system, whereas the LD equipment alone is called the LD component.

\subsection{Objective}

LD cooling components need more equipment than conventional ones, mainly because of the need for regeneration. Both cooling and heating energy are required, along with increased parasitic energy due to a larger number of pumps. There are several options for the hot water supply in the regenerator. It is desirable to use a "free" energy source like solar energy or waste heat. So far, a general statement on the operational costs of LD systems compared to conventional ways of air conditioning has not been made. The objective of this study is to find an answer to the question whether LD cooling systems may be less energy consuming and/or less expensive to operate than conventional systems and, if so, under which conditions they are most effective. 


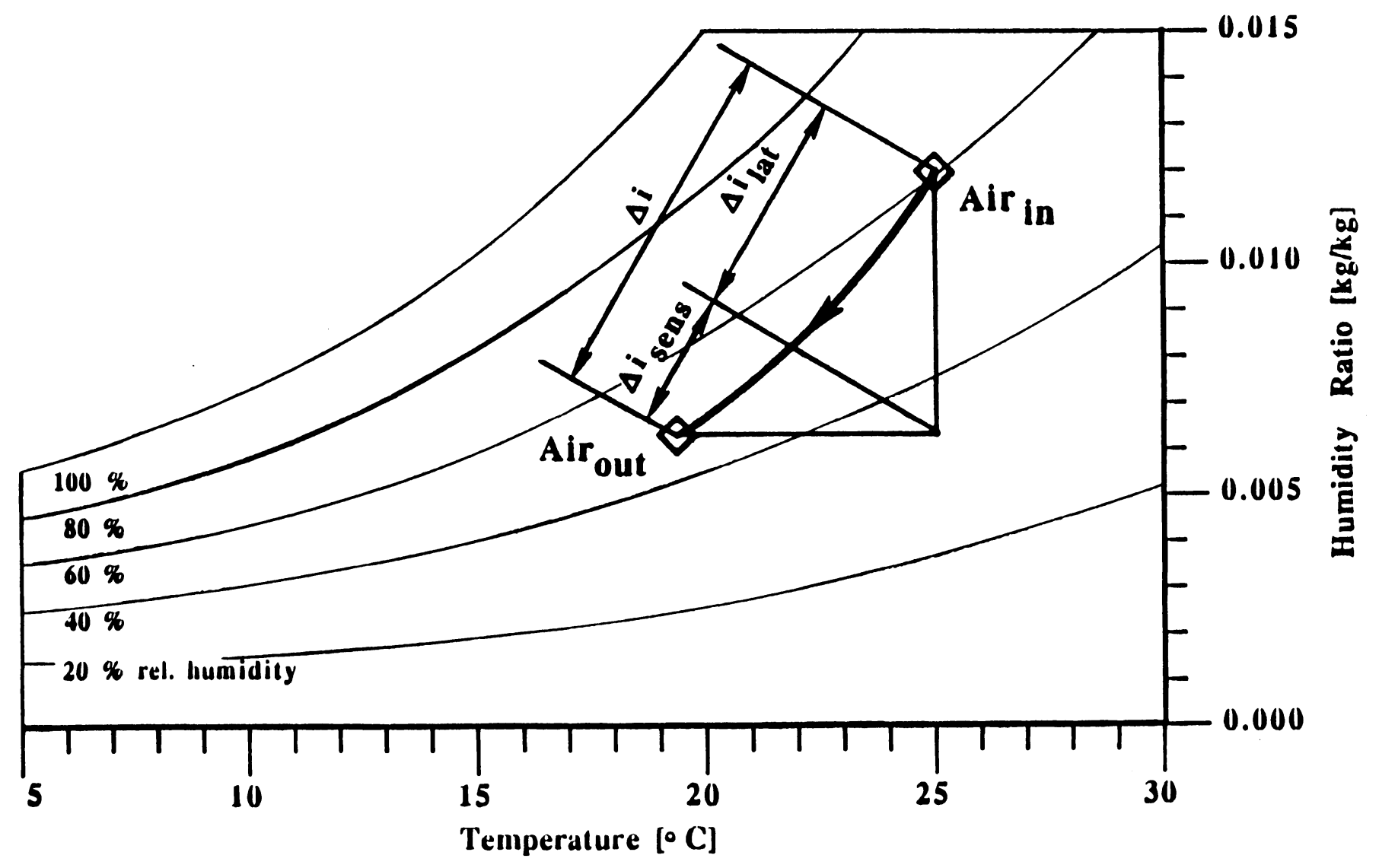

Figure 1.3 Dehumidification and cooling of air by a liquid desiccant 
The basis for the comparisons made in this study are the total operation costs for a cooling season. It is recognized that the initial investment is not included in the comparisons. The first cost of the LD equipment may be higher, but it is possible that the initial investment equals that of more conventional systems $[2,3]$. By comparing operational costs, the heat and electrical energy inputs are reduced to a common denominator. Moreover, it will be easier for the reader to account for different or changing energy rates and their effects on the system comparison.

To make the comparisons discussed above, the performance of LD systems is simulated using records of actual meteorological conditions for an entire cooling season. A model of a LD component with a LiCl-water solution as desiccant (like the one shown in Figure 1.2) has been developed based on mass and energy balances. The systems that have been examined then consist of the LD component and several combinations of equipment for the energy supply. The results are compared with a conventional system which is simulated under the same 1oads.

\subsection{The System at the Science Museum in Virginia (SMVA)}

A LD system as described in Section 1.1 is installed at the Science Museum in Richmond, VA (SMVA) along with a number of additional devices. The available equipment makes a variety of energy supplies possible. A conventional chiller produces cold water for the absorber cycle. Both regeneration heat and electricity can be 
supplied by a gas cogenerator. There is also a heat pump that delivers hot water and simultaneously meets part of the cooling load. A supplementary boiler produces additional heat if needed. Two 5000 gallon tanks are available for hot water storage. The installation of flat plate solar collectors as hot water source has also been considered.

A design description of the SMVA system was presented by Meckler [2]. A steady state analysis of this system has been developed by Buschulte [1]. The system was extensively instrumented and subjected to a comprehensive data collection in various operation modes. However, it turned out that the measured data are questionable as shown in Chapter 3. The present model is of general nature although it resembles the specific LD cycle of the SMVA system as close as possible. It can be easily adjusted to represent any LD component of the same configuration. 


\section{CHAPTER 2: Modeling the Liquid Desiccant Component}

The examination of hybrid liquid desiccant cooling systems by computer simulations requires a mathematical model for the central liquid desiccant (LD) component consisting of the conditioner, the regenerator, the solution heater and cooler, as well as the interchanger. There are a variety of modeling alternatives. Some of them are briefly discussed in the first section of this chapter. The approach used in this study is presented in Sections 2.2 through 2.4. TRNSYS [5] (TRaNsient SYStem) is a modular simulation program developed at the University of Wisconsin Solar Energy Laboratory. It has a library containing models of many energy system components and also allows the use of specific user-written routines. A main program handles the information flow (e.g., mass, energy, temperatures, control signals) between the components and performs the simulation. It receives the definition of the system from a computer file called "deck", which contains a list of the components with parameter specifications and the information about how the components are connected to each other. The LD component model was made TRNSYS compatible.

\subsection{Model ing Approaches}

Buschulte [1] developed two models for the heat and mass exchange in the conditioner and the regenerator of the SMVA system. His equilibrium model uses two effectiveness coefficients, one each for the mass and heat exchange, to correct for real chamber performance after calculating the maximum possible heat and mass flow 
rates. This model is computationally simple, but applicable only in the neighborhood of its design point. A more elaborate model is Buschulte's finite step integration program. However, the amount of computation time needed by this model makes it practically impossible to run simulations of an entire cooling season.

The KATHABAR Engineering Service suggested a simple model for the heat and mass transfer in the two exchange chambers [4]. It consists of only two algebraic equations. Figure 2.1 illustrates the model. The two relationships are:

- The air humidity leaving the conditioner or regenerator is equal to the equilibrium humidity of the desiccant solution at its entering concentration and the leaving air temperature:

$$
H_{\text {out }}=H_{\text {eq }}\left(T_{a, \text { out }}, \xi_{\text {in }}\right)
$$

- The ratio of the difference in temperatures of the inlet streams to the enthalpy difference of the inlet and outlet air is a constant:

$$
\frac{T_{a, \text { out }}-T_{s, \text { in }}}{i_{a, \text { in }}-i_{a, \text { out }}}=k
$$

The value of the constant is a function of the two flow rates. According to Meckler [4], the constant values for the SMVA system are $K_{C}=0.04013 \mathrm{kgk} / \mathrm{kJ}$ for the conditioner and $K_{R}=$ $0.01911 \mathrm{kgK} / \mathrm{kJ}$ for the regenerator. 


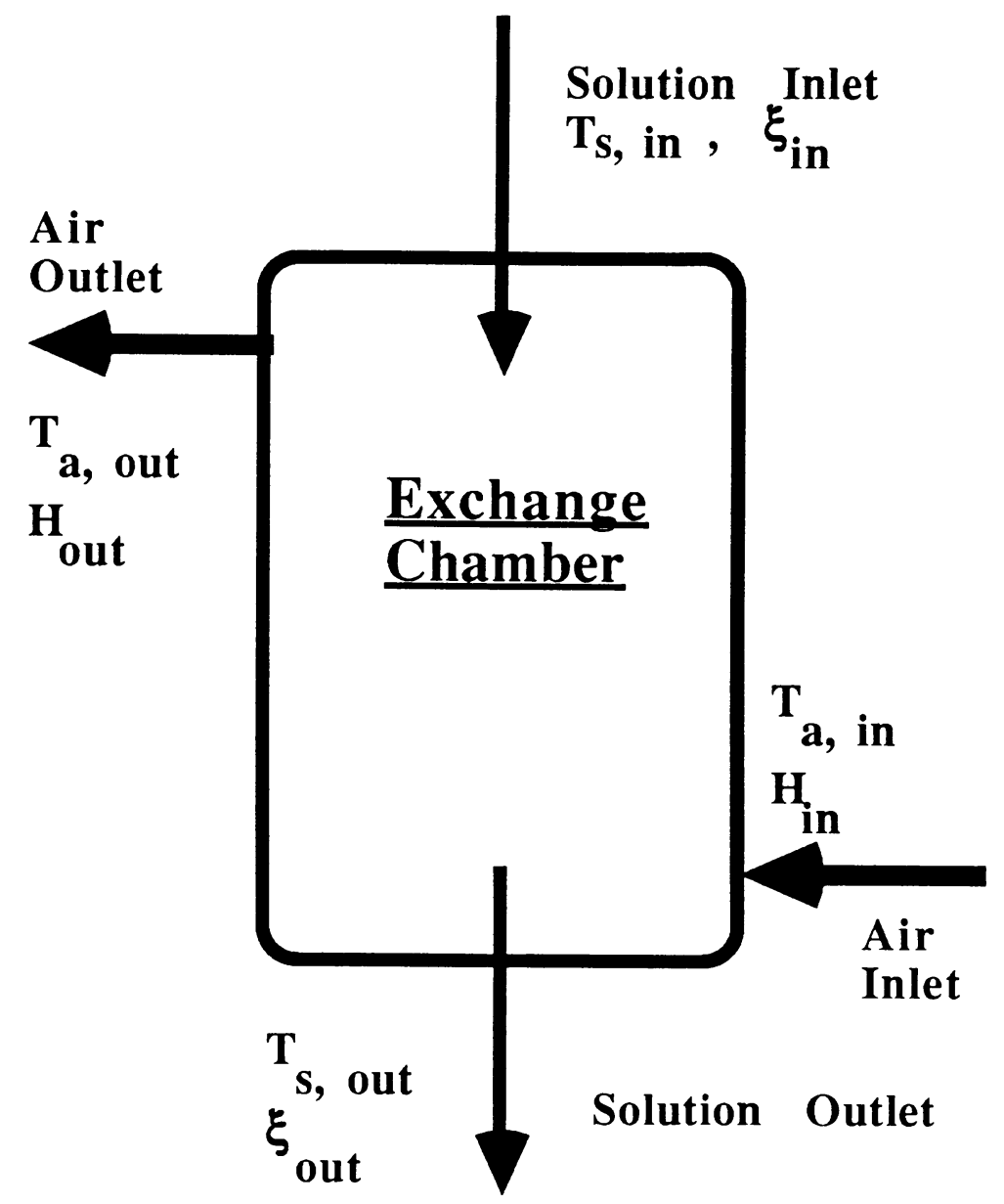

Figure 2.1 Exchange chamber with inlet and outlet variables as applied in the Kathabar model 
Northey [6] compared the effectiveness and the KATHABAR model to Buschulte's finite step integration model. He showed that the KATHABAR model always deviates less from the finite step integration model than the effectiveness approach. For transfer areas and solution to air flow ratios that are as large as those at the SMVA, the KATHABAR predictions are very close to the integration results. Table 2.1 presents some of Northey's evaluations for the simulation of a conditioner with $22 \mathrm{~m}^{2}$ transfer area and a solution to air flow ratio of 9:5. The variable names are taken from Figure 2.2. The finite step integration model used 125 steps and a mass transfer coefficient of $1 \mathrm{~kg} /\left(\mathrm{m}^{2} \mathrm{~s}\right)$. Northey determined a KATHABAR constant of $K_{C}=0.0286$ and effectiveness factors of $E_{m t}=0.965$ for the mass transfer and $E_{h t}=0.911$ for the heat transfer. According to Table 2.1 the percent differences to the finite step integration model of the air outlet state calculated with the KATHABAR model are less than $1 \%$, whereas the effectiveness factor model yields differences between $1.2 \%$ and $4.3 \%$ in this example. The model presented in this thesis includes the KATHABAR equations.

Buschulte modeled each piece of equipment separately and combined these components using TRNSYS. For the central LD component models are needed for the conditioner, the regenerator, three heat exchangers, and two sumps. The modeling strategy applied in this study combines the equations describing all the equipment pieces forming one single LD component model, in order to reduce the necessary computation. 


\begin{tabular}{|c|c|c|c|c|c|c|c|c|c|c|c|c|c|}
\hline \multicolumn{4}{|c|}{ Inlet Conditions } & \multicolumn{10}{|c|}{ Air Outlet Conditions } \\
\hline \multicolumn{2}{|c|}{ Air } & \multicolumn{2}{|c|}{ Solution } & \multicolumn{2}{|c|}{ Step Integration } & \multicolumn{4}{|c|}{ Kathabar Model } & \multicolumn{4}{|c|}{ Effectiveness Factor } \\
\hline $\mathrm{T}_{4}$ & $\mathrm{H}_{4}$ & $T_{6}$ & $\xi_{6}$ & $\mathbf{T}_{5}$ & $\mathrm{H}_{5}$ & $\mathbf{T}_{5}$ & & $\mathbf{H}_{5}$ & & $\mathbf{T}_{5}$ & & $\mathrm{H}_{5}$ & \\
\hline${ }^{\circ} \mathbf{C}$ & kg/kg & ${ }^{\circ} \mathbf{C}$ & $\%$ & ${ }^{\circ} \mathbf{C}$ & $\begin{array}{r}\mathrm{kg} / \mathrm{kg} \\
\mathrm{xP} 000\end{array}$ & ${ }^{\circ} \mathbf{C}$ & $\Delta \%$ & $\begin{array}{l}\mathbf{k g} / \mathbf{k g} \\
(\mathrm{x} 1000\end{array}$ & $\Delta \%$ & ${ }^{\circ} \mathbf{C}$ & $\Delta \%$ & $\left.\begin{array}{c}\mathrm{kg} / \mathrm{kg} \\
(\mathrm{x} 1000\end{array}\right)$ & $\Delta \%$ \\
\hline 24 & 0.014 & 16 & 37 & 16.39 & 7.44 & 16.42 & 0.18 & 7.40 & -0.54 & 16.63 & 1.46 & 7.35 & -1.21 \\
\hline 24 & 0.014 & 20 & 21 & 16.77 & 7.62 & 16.80 & 0.18 & 7.57 & -0.66 & 16.99 & 1.31 & 7.49 & $|-1.71|$ \\
\hline 27 & 0.010 & 16 & 37 & 20.54 & 3.60 & 20.51 & -0.15 & 3.58 & -0.56 & 20.27 & -1.31 & 3.68 & 2.22 \\
\hline 27 & 0.010 & 20 & 21 & 20.95 & 3.70 & 20.94 & -0.05 & 3.69 & -0.27 & 20.64 & -1.48 & 3.86 & 4.32 \\
\hline
\end{tabular}

Table 2.1 Comparison of Kathabar and effectiveness factor model to finite step integration model for conditioner chamber (from [6]) 
In a first modeling approach, two subsystems were created by identical sets of mass and energy balances, since the equations for the conditioner with sump and cooler are of the same form as those for the regenerator with sump and heater. However, the equations were solved in a different way because of different control strategies for the conditioner and regenerator which results in different sets of knowns and unknowns. The sumps were treated as ideal mixers with no volume. The conditioner subsystem was numerically stable. The regenerator part did not converge due to the necessity of iterative determining three unknown temperatures at the interchanger. Therefore the stable conditioner subroutine was used for both subsystems involving a new modeling strategy. Since the conditioner outlet air temperature is a known variable (set point), the corresponding regenerator outlet air temperature had to be assumed before running the regenerator part. Thus, one interchanger temperature and one concentration had to be iterated in addition to the exhaust air temperature. This strategy converged but was extremely slow, resulting in an excessive use of computation time.

Finally, a slightly different control strategy was applied and the idea of modeling subsystems was given up. This final modeling approach, described in the following sections, partitions the equations into physically coherent groups. Results of the LD component simulation are presented in Chapter 4. 


\subsection{Control Strategy}

Figure 2.2 shows the LD unit with denotations taken from the Experimental Test Plan for the SMVA [4]. Known variables are component inputs like weather data and hot and cold water source temperatures, equipment parameters (e.g., pump flow rates) and the constant conditioned air temperature set point. The variable load resulting from variable outside air conditions is met by modulating the flow of cold water through the cooler. The hot water flow rate on the regenerator side is constant.

The mass of the desiccant in the sumps is assumed to be entirely in the regenerator sump. The conditioner sump is treated as T-piece with no volume. The regenerator sump is assumed to be fully mixed, since the flow rates are high. However, the LD component is controlled by the level (i.e., the amount of water) in the sump. The conditioner adds water to the system which must be removed by the regenerator. If the regenerator cannot keep up with the conditioner, the water level will rise and eventually the controls will turn the conditioner off until the regenerator lowers the sump level to a preset value. In this case, auxiliary conventional cooling has to be supplied to meet the load. On the other hand, if there is no load (i.e., the conditioner is off), the water level will drop and the regenerator will be turned off at a specified lower margin. 


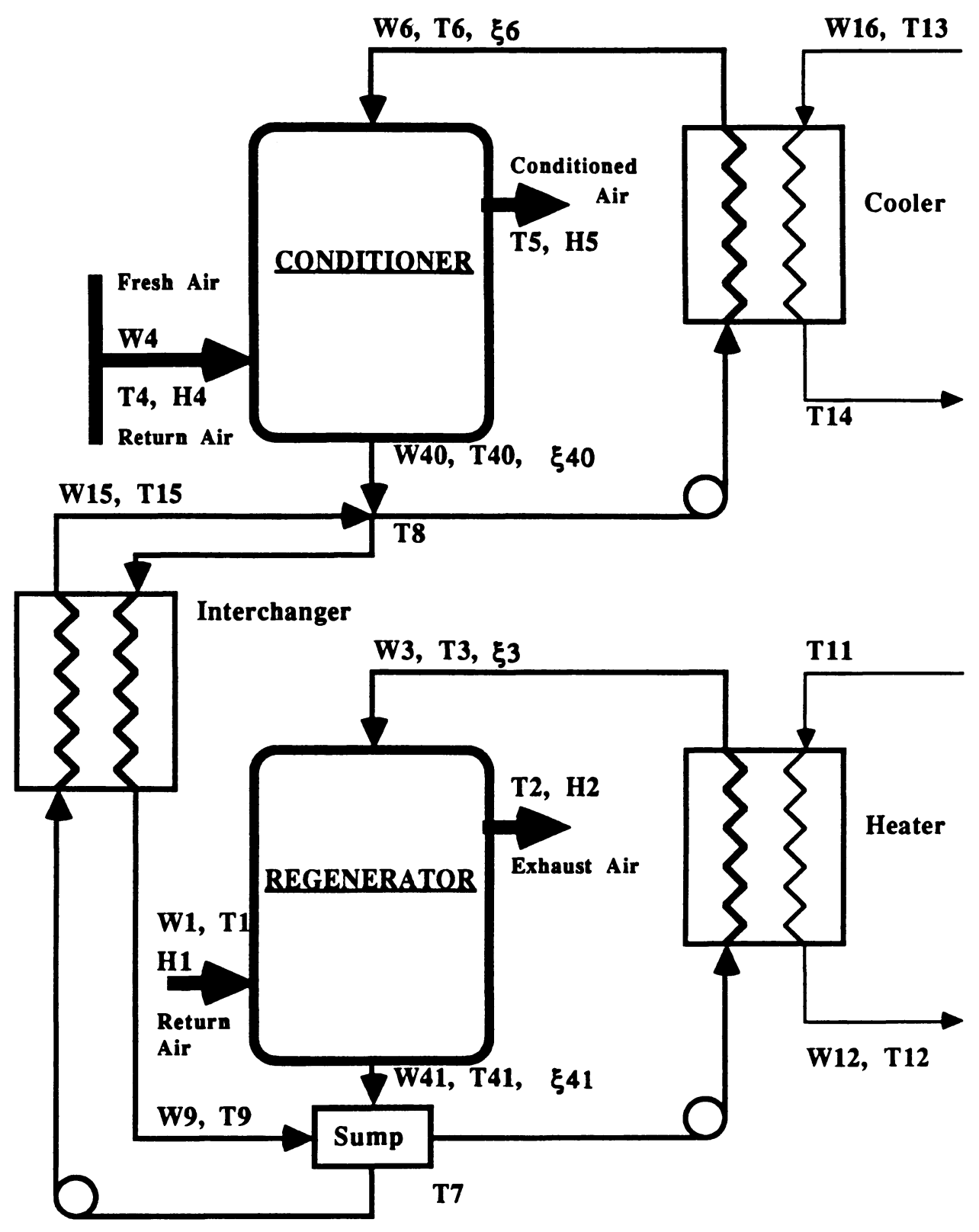

Figure 2.2 Schematic of the liquid desiccant component with sump (including the locations of system variables) 


\subsection{Equations}

A package of physical property subroutines for air-water mixtures and LiCl-water solutions was written by Buschulte [1]. It allows the calculation of enthalpy, concentration, or temperature as function of the two other variables. In the following equations, all presented energy balances neglect the kinetic and the potential energy as they are insignificant compared to internal energy values.

For the conditioner, the water mass balance is

$$
w_{4} H_{4}+w_{6}\left(1-\xi_{6}\right)=w_{4} H_{5}+w_{40}\left(1-\xi_{40}\right)
$$

and the mass balance for the salt reads

$$
w_{6} \xi_{6}=w_{40} \xi_{40}
$$

A mass balance for dry air can be omitted, since the mass flow rate at the outlet is always equal to that at the inlet. The energy balance for the conditioner is

$w_{6} i_{6}\left(T_{6}, \xi_{6}\right)+w_{4} i_{4}\left(T_{4}, H_{4}\right)=W_{40} i_{40}\left(T_{40}, \xi_{40}\right)+W_{4} i_{5}\left(T_{5}, H_{5}\right) \cdot$

Mass and heat transfer in the conditioner are described by the KATHABAR model:

$$
H_{5}=H\left(T_{5}, \xi_{6}\right)
$$




$$
T_{5}-T_{6}=K_{C} *\left[i_{4}\left(T_{4}, H_{4}\right)-i_{5}\left(T_{5}, H_{5}\right)\right] .
$$

The conditioner sump is described by two mass balances and an energy balance:

$$
\begin{gathered}
w_{15}+w_{40}=w_{6}+w_{9} \\
w_{15} \xi_{3}+w_{40} \xi_{40}=\left(w_{6}+w_{9}\right) \xi_{6} \\
w_{15} i_{15}\left(T_{15}, \xi_{3}\right)+w_{40} i_{40}\left(T_{40}, \xi_{40}\right)=\left(w_{6}+w_{9}\right) i_{8}\left(T_{8}, \xi_{6}\right)
\end{gathered}
$$

The heat transfer in the solution cooler is

with

$$
\begin{aligned}
& U A_{c}{ }^{*} \Delta T_{\ell m, c}=W_{16}{ }^{*} C_{p, w}{ }^{*}\left(T_{14}-T_{13}\right) \\
& \Delta T_{\ell m, c}=\frac{\left(T_{8}-T_{14}\right)-\left(T_{6}-T_{13}\right)}{\ln \frac{T_{8}-T_{14}}{T_{6}-T_{13}}},
\end{aligned}
$$

and the energy equality reads

$$
w_{16}\left[i_{13}\left(T_{13}\right)-i_{14}\left(T_{14}\right)\right]=W_{6}\left[i_{6}\left(T_{6}, \xi_{6}\right)-i_{8}\left(T_{8}, \xi_{6}\right)\right] .
$$

The interchanger and the solution heater are characterized by analogous equations, which are for the interchanger 


$$
U A_{i}{ }^{*} T_{\ell m, i}=W_{15}{ }^{*} C_{p, s}{ }^{*}\left(T_{7}-T_{15}\right)
$$

with

$$
\Delta T_{\ell m, i}=\frac{\left(T_{7}-T_{9}\right)-\left(T_{15}-T_{8}\right)}{\ln \frac{T_{7}-T_{9}}{T_{15}-T_{8}}}
$$

and

$W_{9} i_{9}\left(T_{9}, \xi_{6}\right)+W_{15} i_{15}\left(T_{15}, \xi_{3}\right)=W_{9} i_{8}\left(T_{8}, \xi_{6}\right)+W_{15} i_{7}\left(T_{7}, \xi_{3}\right)$,

and for the desiccant heater

$$
U A_{h}{ }^{*} \Delta T_{\ell m, h}=W_{12}{ }^{*} C_{p, w}{ }^{*}\left(T_{11}-T_{12}\right)
$$

where

$$
\Delta T_{\ell m, h}=\frac{\left(T_{11}-T_{3}\right)-\left(T_{12}-T_{7}\right)}{\ln \frac{T_{11}-T_{3}}{T_{12}-T_{7}}}
$$

and

$$
w_{12}\left[i_{11}\left(T_{11}\right)-i_{12}\left(T_{12}\right)\right]=w_{3}\left[i_{3}\left(T_{3}, \xi_{3}\right)-i_{7}\left(T_{7}, \xi_{3}\right)\right] .
$$

The regenerator equations (2.17) through (2.21) are analogous to the equations (2.3) through (2.7) describing the conditioner chamber:

$$
\begin{aligned}
w_{1} H_{1}+w_{3}\left(1-\xi_{3}\right) & =w_{1} H_{2}+w_{41}\left(1-\xi_{41}\right) \\
w_{3} \xi_{3} & =w_{41} \xi_{41}
\end{aligned}
$$




$$
\begin{gathered}
W_{3} i_{3}\left(T_{3}, \xi_{3}\right)+W_{1} i_{1}\left(T_{1}, H_{1}\right)=W_{41} i_{41}\left(T_{41}, \xi_{41}\right)+W_{1} i_{2}\left(T_{2}, H_{2}\right) \\
H_{2}=H\left(T_{2}, \xi_{3}\right) \\
T_{2}-T_{3}=K_{R} *\left[i_{1}\left(T_{1}, H_{1}\right)-i_{2}\left(T_{2}, H_{2}\right)\right] .
\end{gathered}
$$

The control strategy for the liquid desiccant component is governed by the condition for the regenerator sump. Water mass and temperature in the mass and energy balances of the sump vary with time. These balances result in two ordinary coupled differential equations. Since the salt mass in the system and the flow rates through the solution pumps are constant, a single mass balance for the regenerator sump is sufficient. The sump is considered to be fully mixed and adiabatic. The differential equation for the mass of solution in the sump is

$$
\frac{d m}{d t}=w_{\text {in }}-w_{\text {out }}
$$

with

$$
w_{\text {in }}=w_{9}+w_{41}
$$

and

$$
w_{\text {out }}=w_{3}+w_{15} \text {. }
$$

The energy balance reads 


$$
\begin{aligned}
& \frac{d\left(m i_{7}\right)}{d t}=i_{i n}-i_{7} \\
& i_{\text {in }}=\frac{i_{9} W_{9}+i_{41} W_{41}}{W_{9}+W_{41}} .
\end{aligned}
$$

A11 component states are held constant during a simulation timestep. Therefore, the mass flow rates into and out of the sump are constant, and equation (2.22) yields the solution

$$
m(t+\Delta t)=m(t)+\left(W_{\text {in }}-W_{\text {out }}\right) \Delta t
$$

The energy balance $(2.23)$ can be rewritten using equation (2.22) as

$$
m \frac{d i_{7}}{d t}+i_{7}\left(w_{\text {in }}-w_{\text {out }}\right)=w_{\text {in }} i_{\text {in }}-w_{\text {out }} i_{7}
$$

Eliminating $W_{\text {out }}{ }^{i} 7$ and rearranging yields

$$
m \frac{d i_{7}}{d t}=w_{\text {in }}\left(i_{i n}-i_{7}\right)
$$

Substituting $m$ with equation (2.24) and separation of variables leads to

$$
\frac{\mathrm{di}_{7}}{i_{\text {in }}-i_{7}}=\frac{w_{\text {in }}}{m(t)+\left(w_{\text {in }}-w_{\text {out }}\right) \Delta t} d t .
$$

Integration of equation (2.27) finally gives the solution: 
$i_{7}(t+\Delta t)=i_{7}(t)+\left[i_{i n}-i_{7}(t)\right]\left\{1-\exp \left[\frac{-w_{i n} \Delta t}{\left(w_{i n}-w_{\text {out }}\right) \Delta t+m(t)}\right]\right\}$.

Only equations (2.24) and (2.28) explicitly involve time as a variable. They are solved separately at the beginning of each simulation timestep followed by solution of the remaining 19 algebraic equations.

\subsection{Solving the Equations}

Westerberg, Hutchison, Motard, and Winter [7] presented an approach to find solving procedures for sets of linear and nonlinear algebraic equations. The algorithms involved may be either programmed or solved by heuristic methods depending on the size of the system of equations and the user's experience. In general, there is no unique way and order of solving a set of algebraic equations. In order to achieve an optimal solution procedure with programmed algorithms, the computer code has to be very comprehensive. For smaller sets of equations it is often faster to apply heuristic methods. Intelligent decisions at points with several different options to proceed, lead to solutions close to or at the optimum solving procedure.

At first, an incidence matrix is set up as shown in Figure 2.3. The incidence matrix shows which unknown variable appears in which equation. There is no information about the mathematical nature of equations and variables other than the restriction of allowing only algebraic equations. If physically possible, the algorithm of 


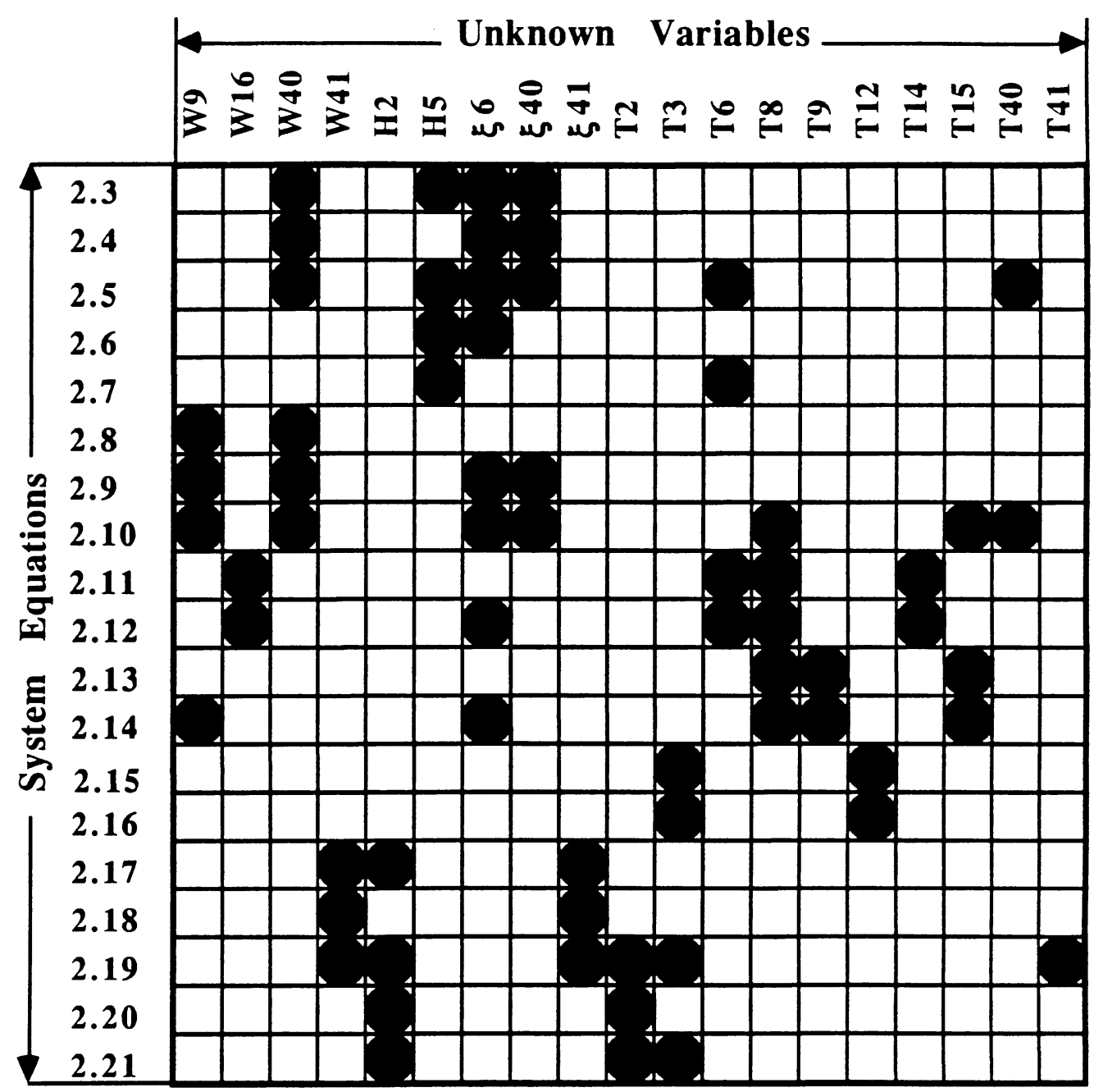

Figure 2.3 Incidence matrix for the liquid desiccant component equations 
Sargent and Westerberg [8] then rearranges the incidence matrix into smaller blocks which can be solved independently, if done in the correct sequence. This procedure is called partitioning and precedence ordering. The partitioned incidence matrix is shown in Figure 2.4 including the sump and decision variables. Decision variables are knowns and set to a fixed value at the beginning of either the timestep or the whole simulation. The sump variables $T_{7}$ and $\xi_{3}$ are obtained from equations (2.24) and (2.28) at the beginning of each timestep and thus can be treated as known variables, too. The entire matrix is of great help for programming, since it shows where a certain variable influences the system of equations. The known variables do not affect the solving procedure. Only the partitioned system of 19 unknowns in 19 equations on the left side of the matrix has to be considered.

A perfect lower triangular matrix would allow solution of the equations by simple forward substitution. Otherwise some of the variables have to be determined iteratively. The $7 \times 7$ block in the upper left hand corner is totally independent of the other equations and unknowns. Within this block, three $2 \times 2$ and one $1 \times 1$ blocks can be solved independently if the solution sequence from top to bottom, the precedence order, is followed. Guessing $T_{12}$, for instance, allows calculating $T_{3}$ with equation (2.16) and recalculating $T_{12}$ using equation (2.15). An iterative method has to be applied until the relative error between the old and new value of $\mathrm{T}_{12}$ is less than or equal to a specified tolerance. Now $T_{3}$ and $T_{12}$ are knowns, so that 


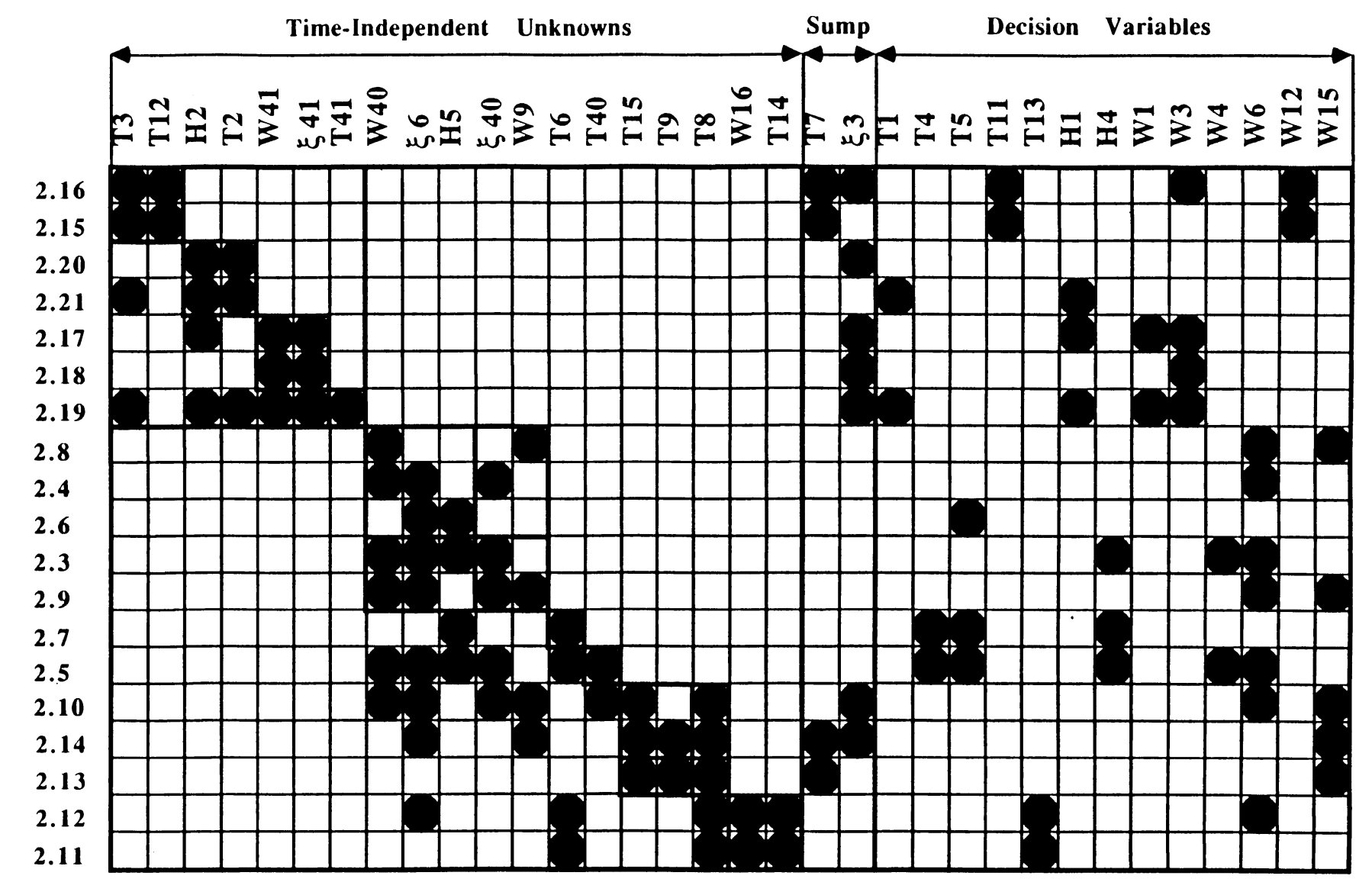

Figure 2.4 Partitioned incidence matrix including sump and decision variables for the liquid desiccant component equations 
the appearance of $\mathrm{T}_{3}$ in equation (2.21) is irrelevant. Thus, the following two $2 \times 2$ blocks can be solved in a similar way until the values for the first 6 unknowns are known. $T_{41}$ is then uniquely determined by equation (2.19). Guessing $\xi_{40}$ and $W_{9}$ solves the following set of 5 equations turning 5 unknowns into knowns for the remaining equations which are treated analogously. Wherever possible, those variables were chosen to be initially guessed whose values promised to stay within close bounds.

Partitioning and precedence ordering reduced the problem of solving a single $19 \times 19$ system to the task of solving 9 systems of order 5 and smaller. The first seven equations describe completely the regenerator and desiccant heater behavior. With known sump variables (for the timestep), the desorber cycle is independent of the rest of the LD component which is reflected in the matrix by the fact that the corresponding $7 \times 7$ block can be solved at any point of the solving procedure. The remaining equations are related to each other and cannot be solved independently in any given order because the absorber cycle including the interchanger is the only other independent part of the LD component besides the regenerator cycle. However, partitioning into smaller units is still possible if the precedence order is followed. The partitions reflect physical devices, e.g., equations (2.11) and (2.12) describe the solution cooler in a separate partition.

It turned out that a simple iteration method with successive substitution and Wegstein acceleration is sufficiently fast. The 
number of iteration steps is on the order of 10 . The Wegstein acceleration step is a modified secant method [7].

\subsection{TRNSYS Component Model}

The computer code for the TRNSYS component "LD Component" is structured according to the partitions described in the preceding section. These subroutines are called by the routine "Solvesystem" depending on control flags that indicate which parts of the system are operating at the present timestep. The control flags are determined by the routine "Tank" which also contains the regenerator sump equations. "Tank" and "Solvesystem" are called by the program "Maincontrol" which essentially sets initial values and is called directly by the user-written TRNSYS subroutine "TYPE42" which makes the program compatible with TRNSYS by defining TRNSYS inputs, parameters, and outputs. TRNSYS inputs may vary with time depending on the supplying component or data file. The parameters are constant for the entire simulation. Equipment specifications or other constant variables that might be changed for another simulation are usually set to parameters. An additional component "TYPE43" provides more output storage space, because TRNSYS allows only 20 outputs per component. Appendix A contains the listing of the computer code for the routines "TYPE42" and "TYPE43". Component inputs, parameters, and outputs are listed in a comment section at the beginning of the program. 


\section{CHAPTER 3: Experimental Test Data Analysis}

One task in this research program was to validate the component model with experimental data taken at the SMVA. A Tennessee Valley Authority (TVA) printout of monitoring data for August 19 through August 23, 1985 was received. An example sheet is presented in Appendix B.

\subsection{Data Analysis and Results}

Inspection of the data reveals three obvious problems:

1. The data channels which were supposed to record absolute humidity in units of grains/pounds were reading improperly; they appear to be off by a factor of 7 . As an example, the data for the conditioner inlet conditions of hour 2 on August 21, 1985 were: Temperature $66.0^{\circ} \mathrm{F}$, rel. humidity $99.9 \%$, absolute humidity 13.6 gr/lb. Assuming the temperature is correct, this value for the absolute humidity corresponds to a relative humidity of about $14 \%$. A 7 times higher absolute humidity, however, corresponds to $99.9 \%$ relative humidity at the given temperature, which is in accordance with the data. This behavior is observed throughout the entire period for which data were received.

2. The temperatures $T_{11}$ and $T_{12}$ which are supposed to be the water temperatures into and out of the heater, respectively (see Figure 2.1), were apparently interchanged. Throughout the received data set, the inlet temperature is lower than the outlet temperature. 
3. The Experimental Test Plan [4] indicates a control strategy for the conditioner such that a constant conditioned air temperature $T_{5}$ should be maintained by modulating the flow of chilled water, $W_{16}$. As described in the previous chapter, the component was modeled to simulate this control. However, the experimental data show $T_{5}$ to vary over a range of up to $11.1^{\circ} \mathrm{F}$ per day and $W_{16}$ to be constant.

In addition to these observations energy balances were performed on the cooler, heater (with $T_{11}$ and $T_{12}$ interchanged) and conditioner using the experimental data. An energy balance cannot be made on the regenerator because of missing outlet air humidity data. The results are presented in Tables 3.1 through 3.3 for data taken on August 19, 1985. Only 3 hours are shown, since the pattern of the results is essentially the same for the whole day. In Tables 3.1 and 3.2 , the calculated average heat flux on the desiccant side of the heat exchangers, $\dot{Q}_{S}$, and on the water side, $\dot{Q}_{W}$, are shown. Table 3.3 shows the energy balance for the conditioner with the average product of the specific enthalpy differences and mass flow rates of the air flow, $\Delta \dot{I}_{a}$, and the desiccant stream, $\Delta \dot{I}_{s}$, respectively.

The differences are obvious and cannot be explained by energy losses from the heat exchanger jackets or the conditioner chamber.

Finally, the experimental data for the conditioner have been compared with the predicted performance using the KATHABAR model. The comparisons show that the model consistently predicts a $10-39 \%$ lower outlet air humidity, $\mathrm{H}_{5}$, than measured. Furthermore, the ratio $K_{C}$ of the enthalpy difference of the inlet and outlet air to the dif- 
Table 3.1. Energy Balance on the Cooler

$\begin{array}{lll}\text { Hour } & Q_{S}[k W] & Q_{w}[k W] \\ 1 & 102.3 & 44.1 \\ 2 & 103.6 & 44.7 \\ 3 & 102.5 & 44.3\end{array}$

Table 3.2. Energy Balance on the Heater

$\begin{array}{ccc}\text { Hour } & \dot{Q}_{s}[k W] & \dot{Q}_{W}[k W] \\ 1 & 118.8 & 39.7 \\ 2 & 119.0 & 40.4 \\ 3 & 120.3 & 40.8\end{array}$

Table 3.3. Energy Balance on the Conditioner

Hour

1

2

3
$\Delta \dot{I}_{a}[k W]$

$\Delta \mathrm{I}_{\mathrm{s}}[\mathrm{kW}]$

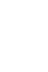


Table 3.4. Check of KATHABAR Predictions (Selected Hours of 8/19/85)

$\begin{array}{lllll}\begin{array}{c}\mathrm{H}_{5, \mathrm{~m}} \\ {[\mathrm{~kg} / \mathrm{kg}]}\end{array} & \begin{array}{c}\mathrm{H}_{5, \mathrm{~d}} \\ {[\mathrm{~kg} / \mathrm{kg}]}\end{array} & \begin{array}{c}\mathrm{K}_{\mathrm{C}, \mathrm{m}} \\ {[\mathrm{kgK} / \mathrm{kJ}]}\end{array} & \begin{array}{c}\mathrm{K}_{\mathrm{C}, \mathrm{d}} \\ {[\mathrm{kgK} / \mathrm{kJ}]}\end{array} & \begin{array}{c}\mathrm{W}_{4, \mathrm{~d}} \\ {[\mathrm{~kg} / \mathrm{s}]}\end{array} \\ 0.00533 & 0.00750 & 0.04013 & 0.06223 & 6.34 \\ 0.00519 & 0.00740 & 0.04013 & 0.06539 & 6.33 \\ 0.00505 & 0.00712 & 0.04013 & 0.06004 & 6.21 \\ 0.00483 & 0.00680 & 0.04013 & 0.06057 & 6.15 \\ 0.00457 & 0.00670 & 0.04013 & 0.06007 & 6.21 \\ 0.00568 & 0.00770 & 0.04013 & 0.03353 & 6.20 \\ 0.00565 & 0.00760 & 0.04013 & 0.03130 & 6.19\end{array}$

ference in temperatures of the inlet streams is not constant at a fixed air flow rate of $6.3 \mathrm{~kg} / \mathrm{s}$ as indicated by the KATHABAR model, but varies from $75 \%$ to $187 \%$ of the value given in the test plan. Some examples are given in Table 3.4.

A correlation of the measured values of $K_{C}$ with the air flow rate, $W_{4}$, cannot be found. Since the measured outlet humidity does not oscillate between higher and lower values compared to the prediction as $K_{C}$ does, it is assumed that the inconsistency is due to data errors in the cooling water flow rate or temperatures. 


\subsection{Conclusions}

Assuming that the heating water temperatures were not read incorrectly but just interchanged, and that the humidity values were converted by a wrong, but constant factor, these data might be useful. However, the obviously different control strategy indicated by the data and especially the large energy imbalances on cooler, heater, and conditioner make it impossible to use these data. Although it is assumed that incorrectly measured water mass flow rates through the heat exchangers are the cause for the energy imbalances, the temperatures could be off as well.

Validation of the component as a model of the SMVA LD component by means of the existing experimental test data is not possible.

The TRNSYS LD component models a wide variety of differently sized systems, as long as the cycle and the control strategy essentially remain the same. It allows general predictions and recommendations which include the system installed at the SMVA. 


\section{CHAPTER 4: Liquid Desiccant Component Simulation}

A standard liquid desiccant component was defined as basis for the description of the component behavior and the comparison of different operation modes. The following section characterizes this base case.

\subsection{Definition of a Standard Liquid Desiccant Component}

Table 4.1 contains all independent component variables with their names, symbols, their chosen standard values, and the source for this choice. It also indicates whether the variables are TRNSYS parameters (P) or TRNSYS inputs (I). As described in Chapter 2, TRNSYS parameters stay constant for an entire simulation run, whereas inputs may or may not vary according to the supplying component or data file.

Temperature and humidity of a 'Typical Meteorological Year' (TMY) [9] in Cape Hatteras, NC for the month of July were taken as conditioner input. For the standard simulation, the ambient pressure and regenerator inlet states were assumed to be constant, although the model allows these factors to vary with time. The conditioner outlet temperature is set to a fixed $19.3^{\circ} \mathrm{C}$ as 1 ong as the inlet air temperature is higher. The base case values for the equipment variables were taken from Meckler [4] and from Buschulte [1].

In order to find a timestep which produces accurate results without the expense of extreme computation, monthly simulation runs were done for a 1, 5 and 15 minute timestep. The upper part of Table 
Table 4.1 LD Component Base Case Variables

\begin{tabular}{|c|c|c|c|c|}
\hline Variable Name & Symbol & $\mathrm{P} / \mathrm{I}$ & Standard Value & Source \\
\hline Timestep & $\Delta t$ & - & $5 \mathrm{~min}$. & examination \\
\hline$U^{1}{ }^{1}$ Cooler & $U A_{c}$ & $P$ & $22.667 \mathrm{~kW} / \mathrm{K}$ & {$[1]$} \\
\hline UA Heater & $U A_{h}$ & $P$ & $11.231 \mathrm{~kW} / \mathrm{K}$ & [1] \\
\hline UA Interchanger & $U A_{j}$ & $P$ & $1.58 \mathrm{~kW} / \mathrm{K}$ & {$[1]$} \\
\hline Sp. Heat of Water & $c_{p, w}$ & $P$ & $4.194 \mathrm{~kJ} / \mathrm{kgK}$ & - \\
\hline $\begin{array}{l}\text { KATHABAR Constant } \\
\text { Conditioner }\end{array}$ & $\mathrm{K}_{\mathrm{C}}$ & $P$ & $0.04013 \mathrm{kgK} / \mathrm{kJ}$ & {$[4]$} \\
\hline $\begin{array}{l}\text { KATHABAR Constant } \\
\text { Regenerator }\end{array}$ & $K_{R}$ & $P$ & $0.01911 \mathrm{kgK} / \mathrm{kJ}$ & [4] \\
\hline $\begin{array}{l}\text { Initial Water Mass } \\
\text { in Sump }\end{array}$ & $m_{w}$ & $P$ & $3333.33 \mathrm{~kg}$ & $\begin{array}{l}\text { examination/ } \\
\text { estimation }\end{array}$ \\
\hline Initial Salt Mass & $\mathrm{m}_{\mathrm{LiCl}}$ & $P$ & $1374.76 \mathrm{~kg}$ & conc. $29 \%$ \\
\hline Initial Sump Temp. & $\mathrm{T}_{7,0}$ & $P$ & $39.2^{\circ} \mathrm{C}$ & [1] \\
\hline Lower Margin for & $\mathrm{m}_{1}$ & $P$ & $4698.1 \mathrm{~kg}$ & hysteresis \\
\hline Regenerator Control & & & & $\begin{array}{l}\text { nonlinearity } \\
\text { symmetrical }\end{array}$ \\
\hline $\begin{array}{l}\text { Upper Margin } \\
\text { Regenerator Control }\end{array}$ & $\mathrm{m}_{\mathrm{u}}$ & $P$ & $4718.1 \mathrm{~kg}$ & $\begin{array}{l}\text { with respect } \\
\text { to initial } \\
\text { sump mass }\end{array}$ \\
\hline $\begin{array}{l}\text { Solution Flow into } \\
\text { Regenerator }\end{array}$ & $w_{3}$ & $P$ & $8.3 \mathrm{~kg} / \mathrm{s}$ & {$[4],[1]$} \\
\hline $\begin{array}{l}\text { Solution Flow into } \\
\text { Conditioner }\end{array}$ & $w_{6}$ & $P$ & $8.18 \mathrm{~kg} / \mathrm{s}$ & {$[4],[1]$} \\
\hline $\begin{array}{l}\text { Solution Flow } \\
\text { Reg. } \rightarrow \text { Cond. }\end{array}$ & $w_{15}$ & $P$ & $0.55 \mathrm{~kg} / \mathrm{s}$ & {$[4],[1]$} \\
\hline $\begin{array}{l}\text { Max. Error for } \\
\text { Internal Iteration }\end{array}$ & $\varepsilon$ & $P$ & $0.001 \%$ & $\begin{array}{l}\text { examination } \\
\text { (EB off }<.1 \%)\end{array}$ \\
\hline $\begin{array}{l}\text { Max. Add. Sump Mass } \\
\text { Conditioner Control }\end{array}$ & $\Delta \mathrm{m}_{\mathrm{u}}$ & $P$ & $300 \mathrm{~kg}$ & estimation \\
\hline
\end{tabular}

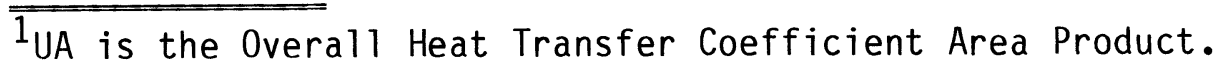




\begin{tabular}{|c|c|c|c|c|}
\hline Variable Name & Symbol & $P / I$ & Standard Value & Source \\
\hline $\begin{array}{l}\text { Min. Add. Sump Mass } \\
\text { Conditioner Control }\end{array}$ & $\Delta m_{1}$ & $P$ & $15 \mathrm{~kg}$ & $\begin{array}{l}\text { lower } \\
\text { margin for } \\
\text { hysteresis }\end{array}$ \\
\hline $\begin{array}{l}\text { Air Temperature at } \\
\text { Regenerator Inlet }\end{array}$ & $\mathrm{T}_{1}$ & I & $36.1^{\circ} \mathrm{C}$ & {$[1]$} \\
\hline $\begin{array}{l}\text { Air Temperature at } \\
\text { Conditioner Inlet }\end{array}$ & $\mathrm{T}_{4}$ & I & $\begin{array}{l}\text { variable } \\
\text { with time }\end{array}$ & weather data \\
\hline $\begin{array}{l}\text { Air Temperature at } \\
\text { Conditioner Outlet }\end{array}$ & $T_{5}$ & I & $19.3^{\circ} \mathrm{C}$ & set point \\
\hline $\begin{array}{l}\text { Hot Water } \\
\text { Temperature }\end{array}$ & $\mathrm{T}_{11}$ & $\mathrm{I}$ & $60.0^{\circ}$ & {$[4],[1]$} \\
\hline $\begin{array}{l}\text { Cold Water } \\
\text { Temperature }\end{array}$ & $\mathrm{T}_{13}$ & I & $12.8^{\circ}$ & {$[4],[1]$} \\
\hline $\begin{array}{l}\text { Humidity at } \\
\text { Regenerator Inlet }\end{array}$ & $\mathrm{H}_{1}$ & $\mathrm{I}$ & $0.0093 \mathrm{~kg} / \mathrm{kg}$ & {$[1]$} \\
\hline Humidity at & $\mathrm{H}_{4}$ & $\mathrm{I}$ & variable & weather data \\
\hline Conditioner Inlet & & & with time & \\
\hline $\begin{array}{l}\text { Air Flow through } \\
\text { Regenerator }\end{array}$ & $w_{1}$ & $\mathrm{I}$ & $2.8 \mathrm{~kg} / \mathrm{s}$ & {$[4],[1]$} \\
\hline $\begin{array}{l}\text { Air Flow through } \\
\text { Conditioner }\end{array}$ & $w_{4}$ & I & $6.7 \mathrm{~kg} / \mathrm{s}$ & {$[4],[1]$} \\
\hline Hot Water Flow & $w_{12}$ & I & $4.3 \mathrm{~kg} / \mathrm{s}$ & {$[4],[1]$} \\
\hline Ambient Pressure & $P_{a m b}$ & $\mathrm{I}$ & $101.3 \mathrm{kPa}$ & $\begin{array}{l}1 \text { atm taken } \\
\text { as estimate }\end{array}$ \\
\hline
\end{tabular}


4.2 shows integrated monthly energy rates in $100 \mathrm{GJ}$. LOAD is the integrated product of the air mass flow rate and specific enthalpy difference between ambient air state and set point for the simulation time period:

$$
\text { LOAD }=w_{4} \int\left(i_{4}-i_{\text {set }}\right) d t
$$

The delivered cooling energy, DEL, is calculated in a similar way using the actual air states at the conditioner inlet and outlet:

$$
D E L=w_{4} \int\left(i_{4}-i_{5}\right) d t
$$

AUX is the difference between load and delivered energy:

$$
A U X=L O A D-D E L \text {. }
$$

$L O A D, D E L$, and $A U X$ are zero for $T_{4}$ being less than or equal to the set temperature. The numbers in brackets are the percent differences of the longer timesteps compared to the 1 minute timestep.

The load is essentially the same for all three cases. The delivered cooling energy, however, is different, since the conditioner is off for a longer overall period when the timestep is larger. As stated in Chapter 2, the conditioner can be off either when there is no load or when the regenerator cannot remove as much water as the conditioner adds to the system. The controls turn the regenerator 
Table 4.2. Calculated Energies (100 GJ) and Daily Operation

Fractions for Different Timesteps

\begin{tabular}{|c|c|c|c|c|c|}
\hline Minutes & 1 & 5 & $(\Delta \%)$ & 15 & $(\Delta \%)$ \\
\hline $\begin{array}{l}\text { LOAD } \\
\text { DEL } \\
\text { AUX }\end{array}$ & $\begin{array}{l}5.594 \\
4.322 \\
1.272\end{array}$ & $\begin{array}{l}5.595 \\
4.303 \\
1.292\end{array}$ & $\begin{array}{l}(.0179) \\
(.4396) \\
(1.572)\end{array}$ & $\begin{array}{l}5.594 \\
4.138 \\
1.455\end{array}$ & $\begin{array}{l}(.0000) \\
(4.257) \\
(14.47)\end{array}$ \\
\hline $\begin{array}{ll}\text { Cond. On } & \text { On } \\
\text { Reg. } & \text { On }\end{array}$ & $\begin{array}{l}.7878 \\
.9830\end{array}$ & $\begin{array}{l}.7835 \\
.9796\end{array}$ & $\begin{array}{l}(.5458) \\
(.3459)\end{array}$ & $\begin{array}{l}.7516 \\
.9408\end{array}$ & $\begin{array}{l}(4.595) \\
(4.293)\end{array}$ \\
\hline
\end{tabular}

off when the sump level is down to its lower margin, which can occur after a period with no load or when there is a large drop in the outdoor humidity so that the water mass in the system drops. The bottom part of Table 4.2 shows the average fraction of the time in which the conditioner and the regenerator cycle, respectively, are on. The results for a timestep of 5 minutes are sufficiently close to those for 1 minute, whereas the 15 minute timestep yields results which are off by several percent.

It was investigated whether a larger sump allows a large simulation timestep without a penalty in accuracy. Figure 4.1 shows the calculated monthly values of DEL for 3 sump sizes each with 3 timesteps. Again, it is observed that the 15 minute timestep is too 1 ong for the base case conditions, since its values for DEL are several percent different from the values for the 1 minute timestep. The values for 1 and 5 minutes are close together. DEL slightly de- 


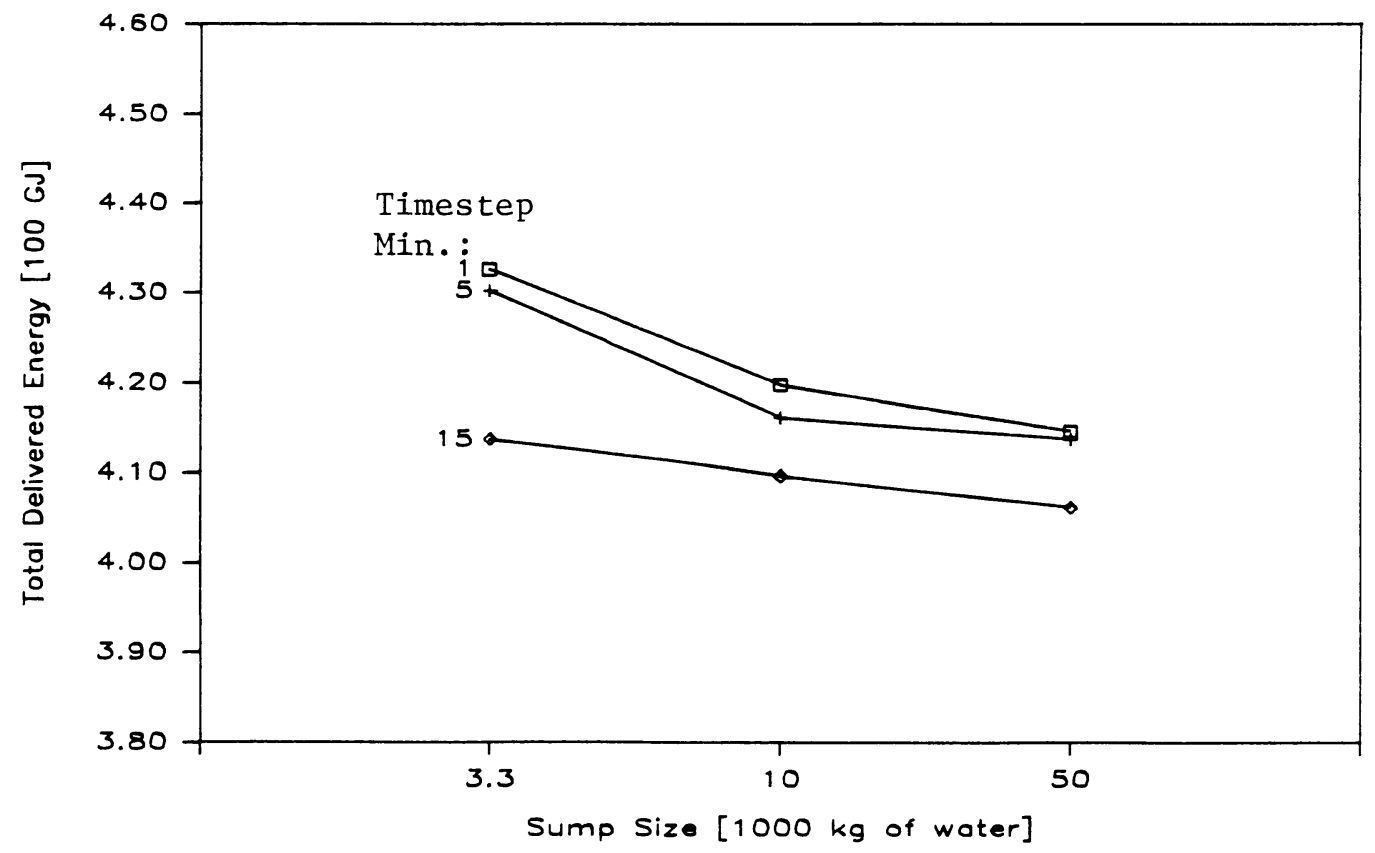

Figure 4.1 Cooling energy delivered by the LD component as function of sump size and timestep for monthly simulation (July, Cape Hatteras, NC)

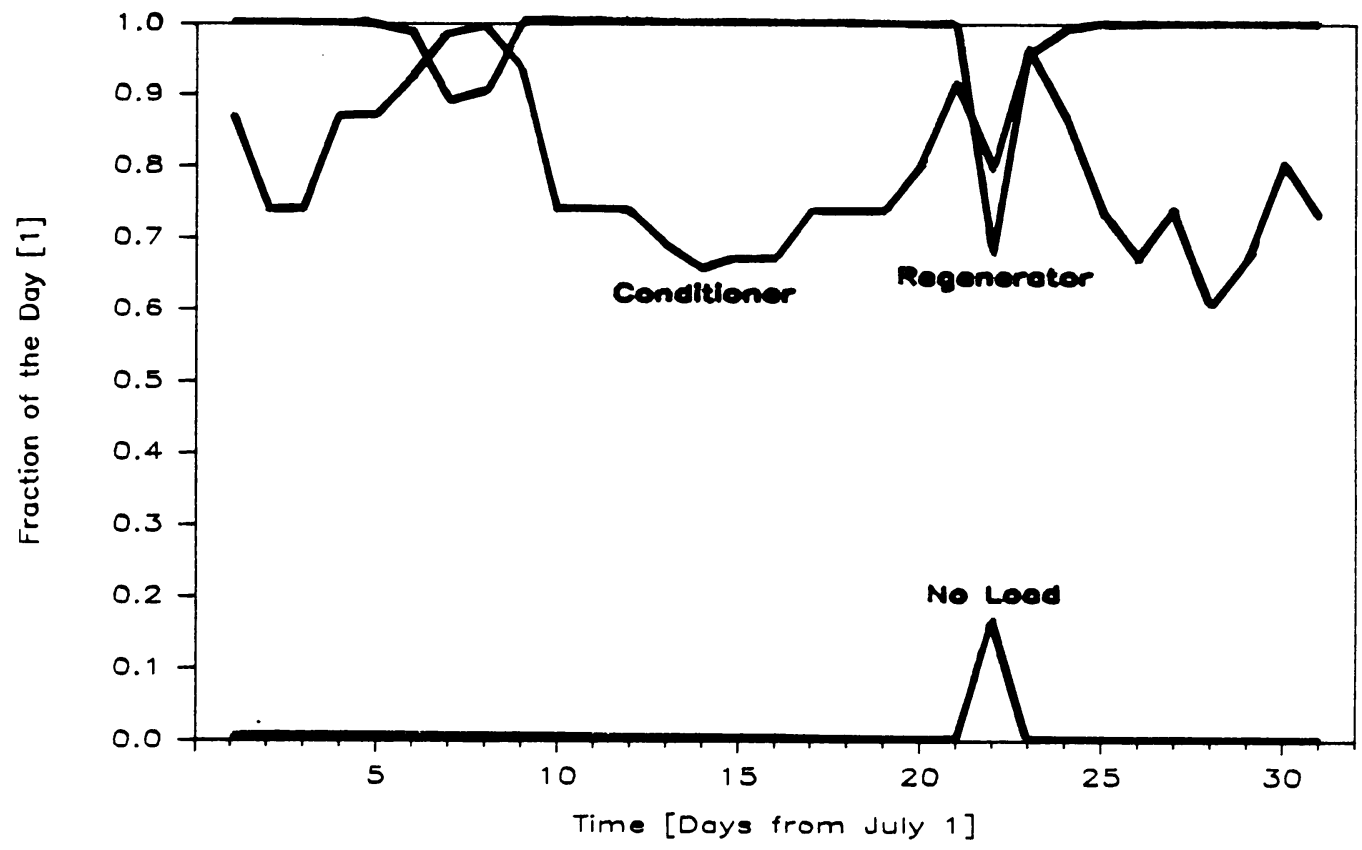

Figure 4.2 Daily operating time fractions of conditioner and regenerator and times with no load for monthly base case simulation 
creases with increasing sump size, because the average temperature is higher due to increased energy storage in the (adiabatic) sump. The average desiccant temperature entering the conditioner is higher and therefore less cooling energy is delivered to the air stream. A relation between sump size and timestep for a specified accuracy cannot be observed. A timestep of 5 minutes and a water mass of $3333 \mathrm{~kg}$ were chosen and used throughout all the following simulations. The water mass is an arbitrary but reasonable choice, given the estimated size of the SMVA sumps. The salt mass was adjusted to a sump concentration of $29 \%$ (One of the 3 concentrations considered in the Experimental Test Plan is $28.5 \%[4])$. The upper sump level limit for the conditioner is subject to further investigation in Section 4.3.4.

\subsection{Standard Simulation Results}

In order to examine the component performance, a standard simulation was carried out. The TRNSYS output gave daily summaries of the fraction of the day in which the conditioner and regenerator were operational. These fractions are plotted in Figure 4.2. In Figure 4.2 a value of 1.0 indicates that the cycle was on all day, whereas, for instance, 0.75 means that the cycle was on only in $75 \%$ of the 288 timesteps of the day, a daily average of 18 hours.

The conditioner is off frequently for the air flow rates used in the base case simulation. There is only one day (July 22) when there is no load for a fraction of this day. More often the conditioner is off because the upper limit of the sump level is reached. The level 
is set to $300 \mathrm{~kg}$ of water in addition to the initial state. The conditioner can remove this amount of water from the air stream within 2 to 3 hours. Since this value is relatively large, it cannot be the reason for the conditioner to be off that often. It is more likely that the low regenerator air flow (compared to the conditioner) causes this behavior. This question will be investigated in the following section.

For the standard system, the regenerator is rarely off. Figure 4.3 shows the humidity ratios of conditioner and regenerator outlet as well as the inlet humidity ratio for the conditioner, as given in the weather data file. The conditioned air humidity is for almost always well within the comfort range of $0.0042 \mathrm{~kg} / \mathrm{kg}$ to $0.012 \mathrm{~kg} / \mathrm{kg}$ as defined by the American Society of Heating, Refrigerating and AirConditioning Engineers (ASHRAE) [10]. The regenerator outlet humidity is almost constant when the regenerator is on because the base case simulation uses a constant regenerator inlet humidity. Although this is a simplification, its effect on the overall performance is small, as is shown in the following section.

The variation of the air temperatures with time are shown in Figure 4.4, along with the regenerator sump temperature. The conditioner outlet temperature shows the constant set point for all times when the ambient temperature is higher than the set temperature. The regenerator outlet air temperature is nearly constant, since the inlet temperature and the hot water source temperature are assumed to be constant. The (fully mixed) sump shows a temperature variation of 


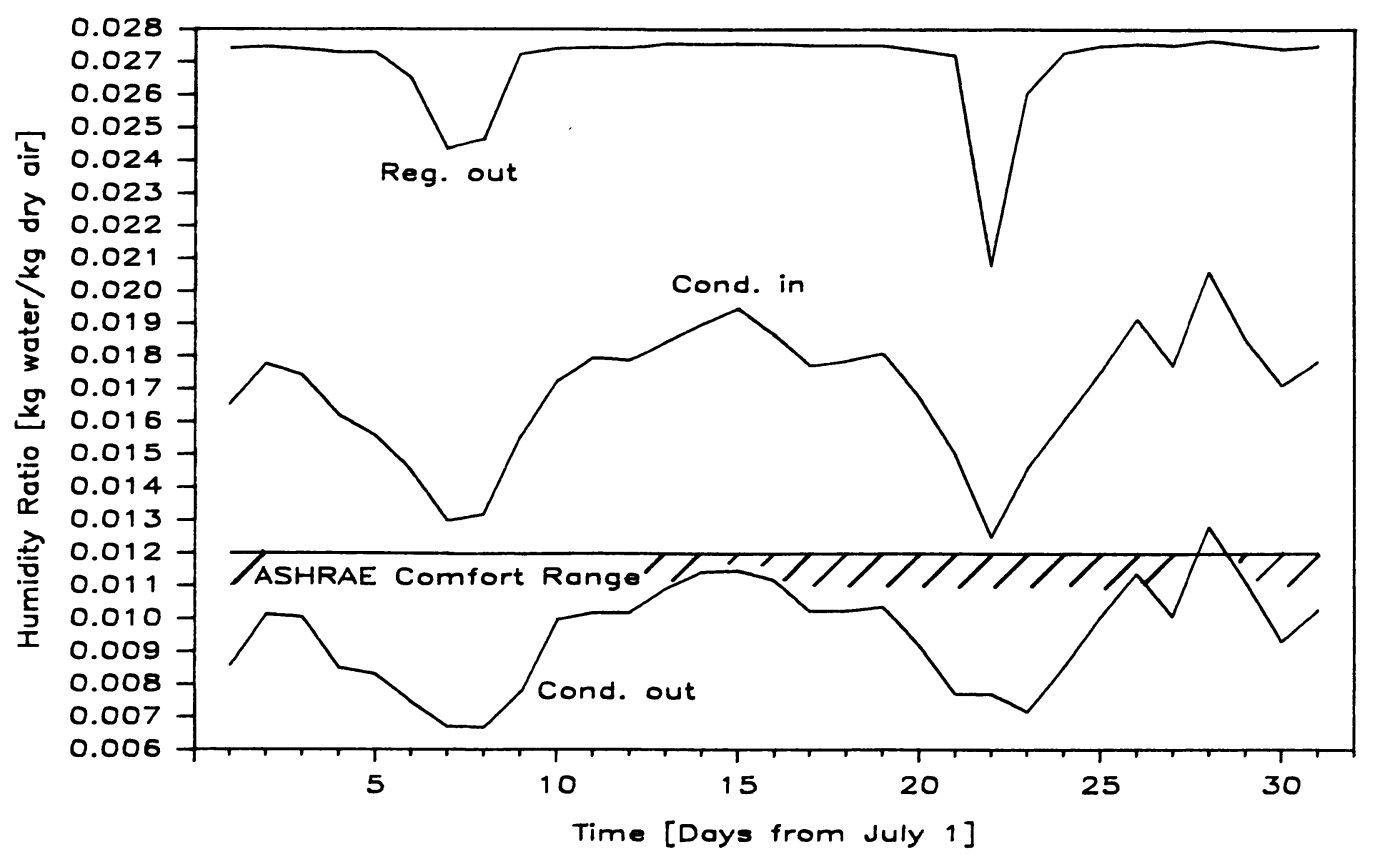

Figure 4.3 Conditioner inlet and outlet and regenerator outlet humidity for monthly base case simulation

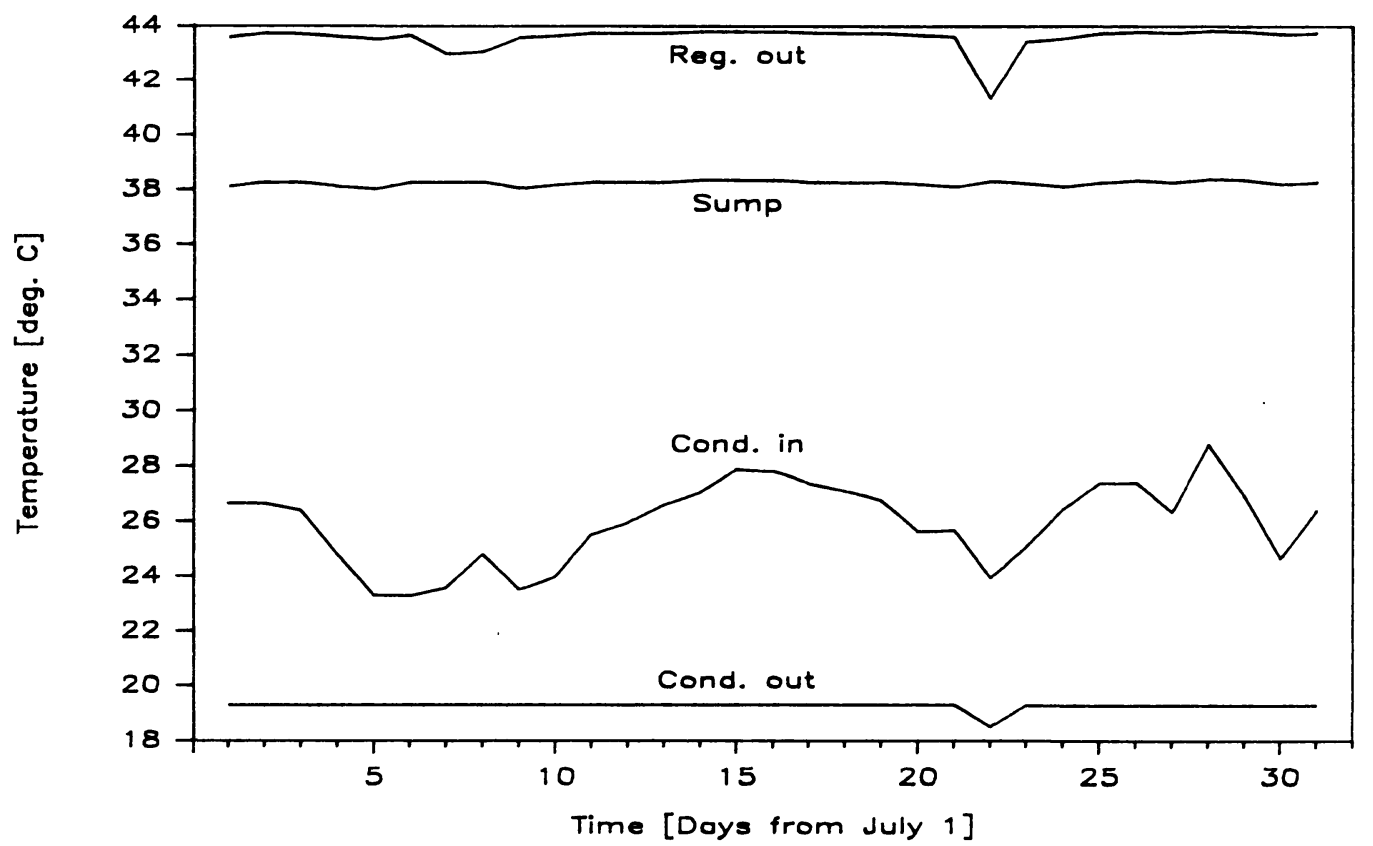

Figure 4.4 Conditioner inlet and outlet, regenerator outlet, and sump temperature for monthly base case simulation 
less than $0.5^{\circ} \mathrm{C}$ due to its mass and the assumption of being adiabatic.

Figures 4.5 and 4.6 show characteristic integrated energy rates. As long as the conditioner is on, the load (LOAD) and the cooling energy, DEL, delivered by the LD component, are equal. Otherwise auxiliary cooling AUX has to be supplied by a conventional chiller to account for the difference in $L O A D$ and DEL. This energy, along with the heat transfer in cooler, $Q_{C}$, and heater, $Q_{h}$, plus parasitic energy for pumps and fans is the energy input into the system. The cost of this energy input should be minimized.

According to the simulation results, it can be stated that the base case defined in the previous section is not an optimal configuration because auxiliary conventional cooling must be supplied. However, for the purpose of describing the LD component behavior it is not necessary to simulate an optimal system. The applied control strategy can be observed even better in the non-optimal case (see Figure 4.2)

\subsection{LD Component Behavior}

The standard LD component described in the preceding section is a matter of definition. Variables considered to be constant may be different or even transient. Therefore a variation of single variables was carried out leaving the rest of the model unchanged (i.e., in its standard state) to investigate their role in the overall LD system performance. The influence of these variations on the energy 


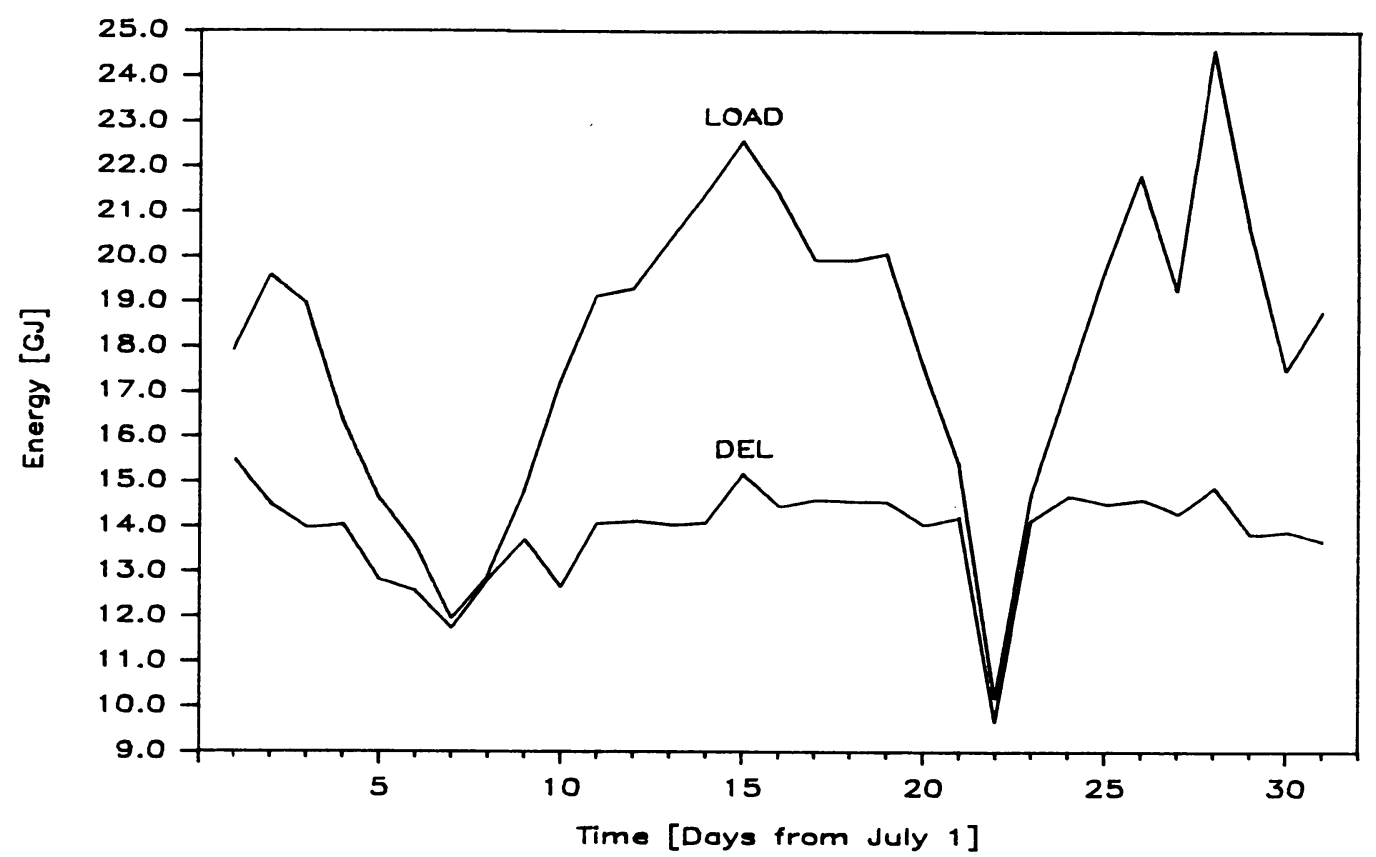

Figure 4.5 Cooling load and delivered cooling energy for monthly base case simulation

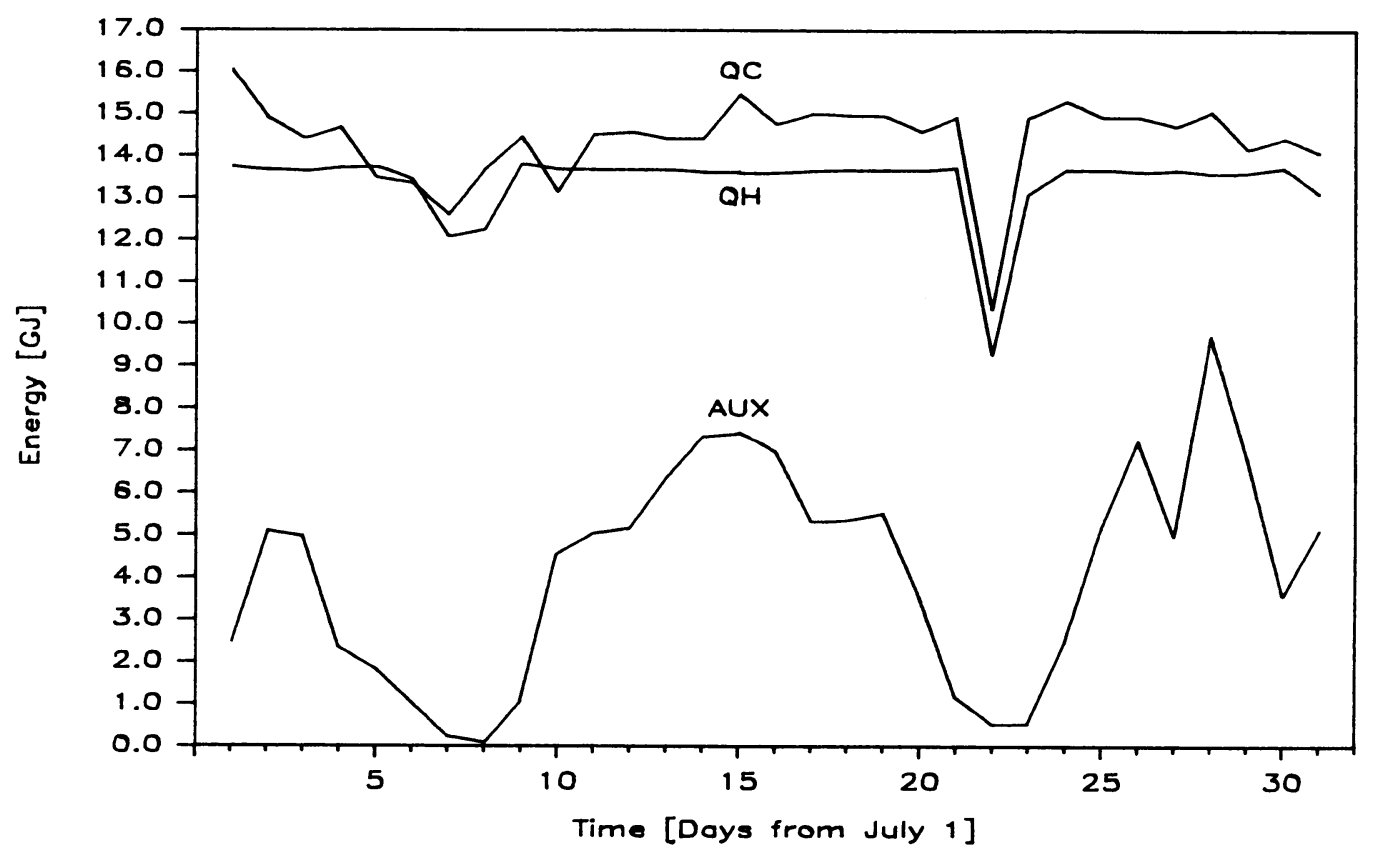

Figure 4.6 Desiccant cooling and heating energy and required auxiliary cooling energy for monthly base case simulation 
input through solution heater, cooler, and auxiliary conventional cooling to meet the load was investigated.

The results not only show the component's sensitivity to the variation of certain variables, but also give indications of ways to optimize the SMVA system.

\subsubsection{Variations in Conditioner Air Flow Rate and Set Point}

An increasing air mass flow rate, $W_{4}$, through the conditioner is equivalent to an increasing load, which results in a higher energy input. Figure 4.7 shows the energy demands for the base case with $W_{4}$ being the independent variable.

Up to an air mass flow rate of $3.4 \mathrm{~kg} / \mathrm{s}$, no auxiliary conventional cooling, AUX, is required. Cooling and heating energy for the heat exchangers in the LD component, $Q_{c}$ and $Q_{h}$, respectively, are increasing. For high flow rates, the demand for AUX is growing at a constant rate, while $Q_{C}$ and $Q_{h}$ stay at constant values. The solution heater is at its maximum possible performance. Although the cooler has to handle an increased load, it eventually cools at a constant integrated energy rate, since the conditioner cycle including the cooler is turned off for a longer overall time (proportional to AUX).

With an increased set temperature for the conditioned air, all energy inputs are decreasing, as shown in Figure 4.8 for a set temperature range of $18^{\circ} \mathrm{C}$ to $21^{\circ} \mathrm{C}$. This is due to the declining load. 


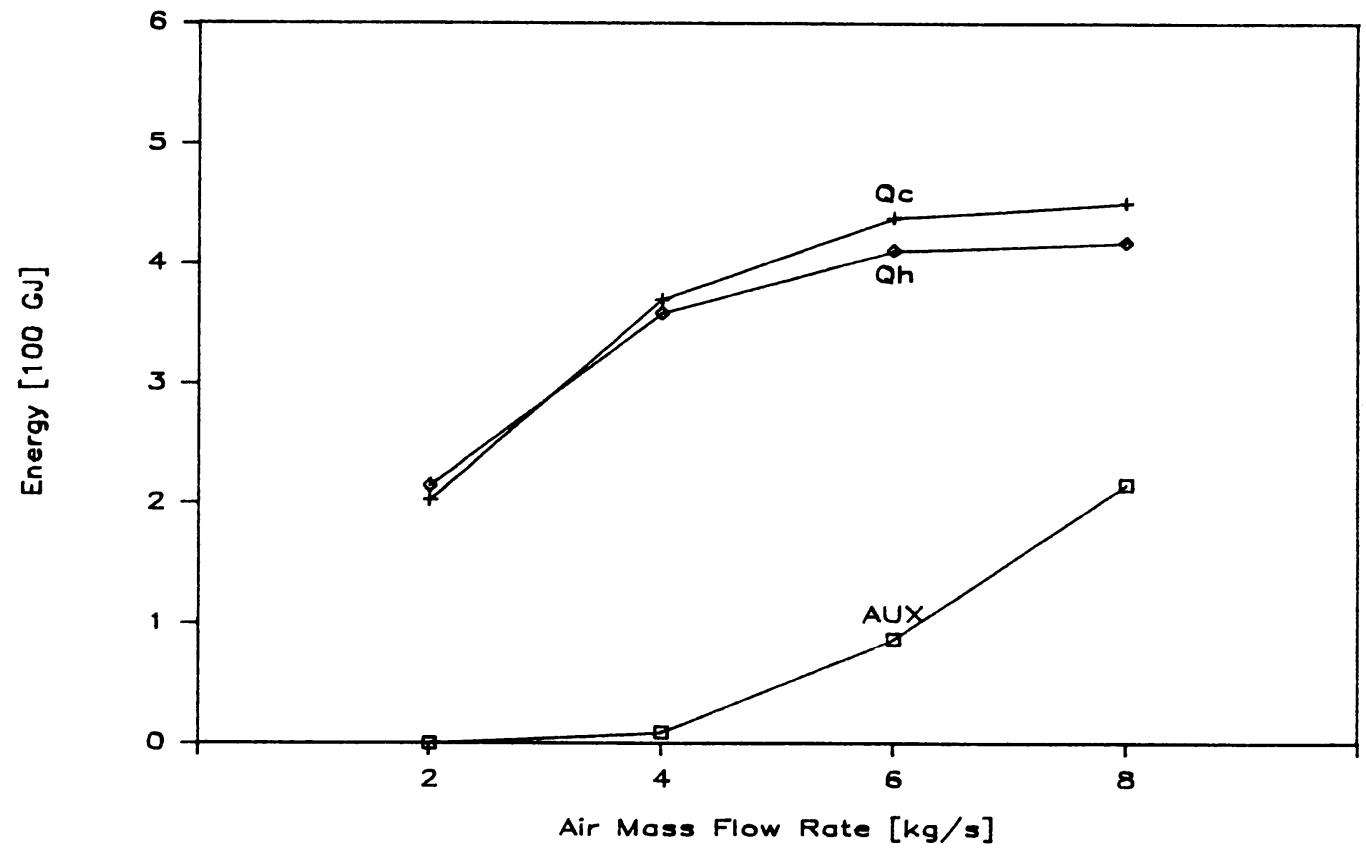

Figure 4.7 Cooling and heating input and required auxiliary cooling energy as function of the conditioner air mass flow rate (monthly simulation)

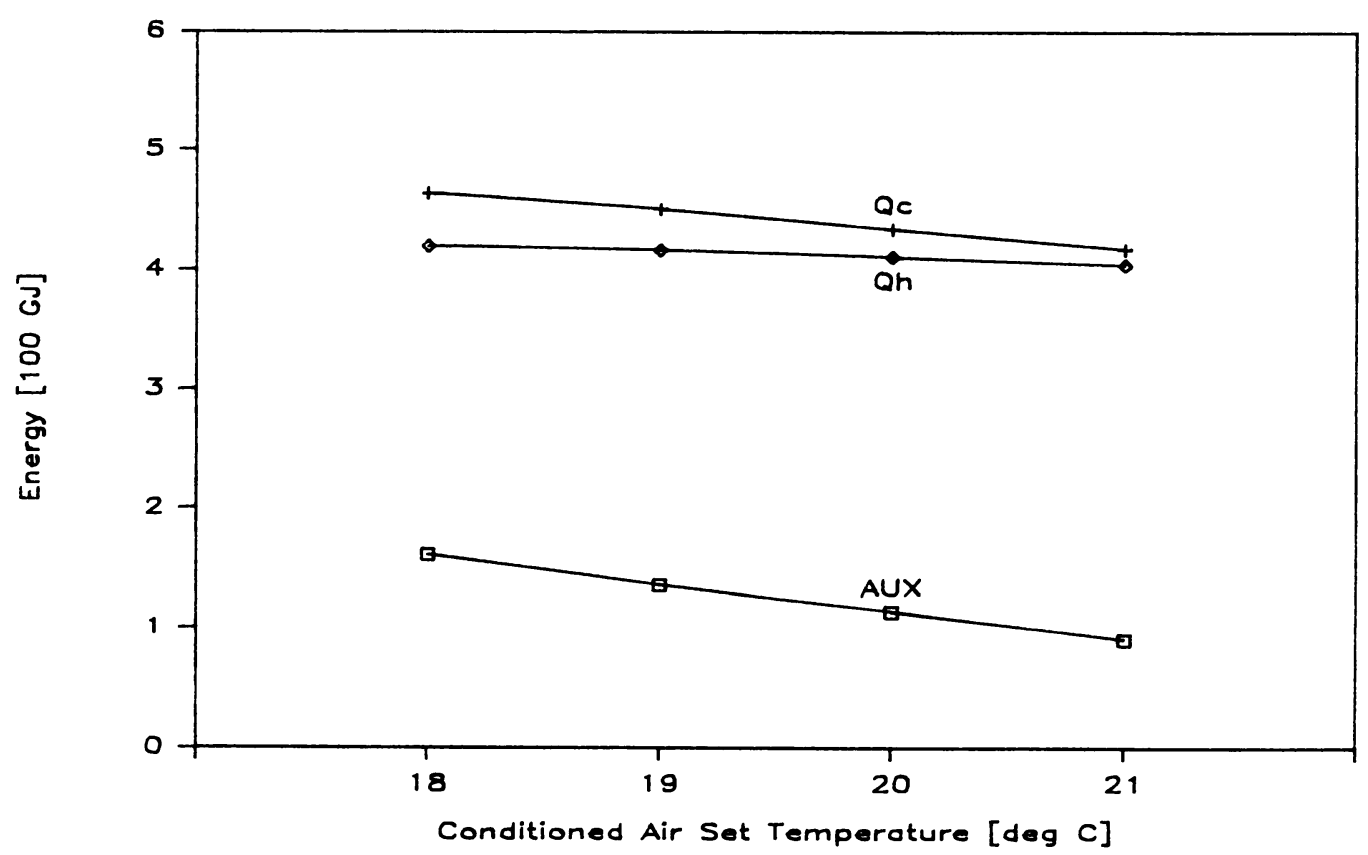

Figure 4.8 Cooling and heating input and required auxiliary cooling energy as function of the conditioned air set temperature (monthly simulation) 


\subsubsection{Variations in Regenerator Air Fl ow Rate and Inlet Conditions}

An increasing air mass flow rate through the regenerator results in improved regeneration for a constant load. Therefore, the conditioner can operate longer meaning that the required conventional cooling, AUX, is decreasing, which is illustrated in Figure 4.9. The increased conditioner operation results in an increased demand for solution cooling, $Q_{c}$. More heating energy, $Q_{h}$, is needed for the improved regeneration. The absolute rates at which the energy demands are changing decline with a growing regenerator air mass flow rate. This behavior can be explained by looking at the temperatures in the regenerator part of the system. Due to the increased air mass flow rate, the temperature difference between air outlet and inlet, $T_{2}{ }^{-T_{1}}$, is decreasing, resulting in a smaller temperature difference between solution inlet and outlet, $T_{3}{ }^{-T} 41$. Therefore, the temperature rise of the solution in the heat exchanger is smaller and less heating energy is required. This effect counteracts the improved regeneration and can be observed clearly in Figure 4.9. At high flow rates, the heating energy demand is even decreasing. The same behavior is observed when the regenerator inlet air temperature is raised (Figure 4.10): $Q_{h}$ is diminishing at a constant rate. At the same time, AUX is constantly decreasing, while $Q_{C}$ increases. This is because the hotter inlet air can absorb more water from the solution and thus improve the regeneration process, resulting in a longer conditioner operating time. A higher humidity ratio at the air inlet has an opposite effect on the regeneration. As shown in Figure 4.11, the 


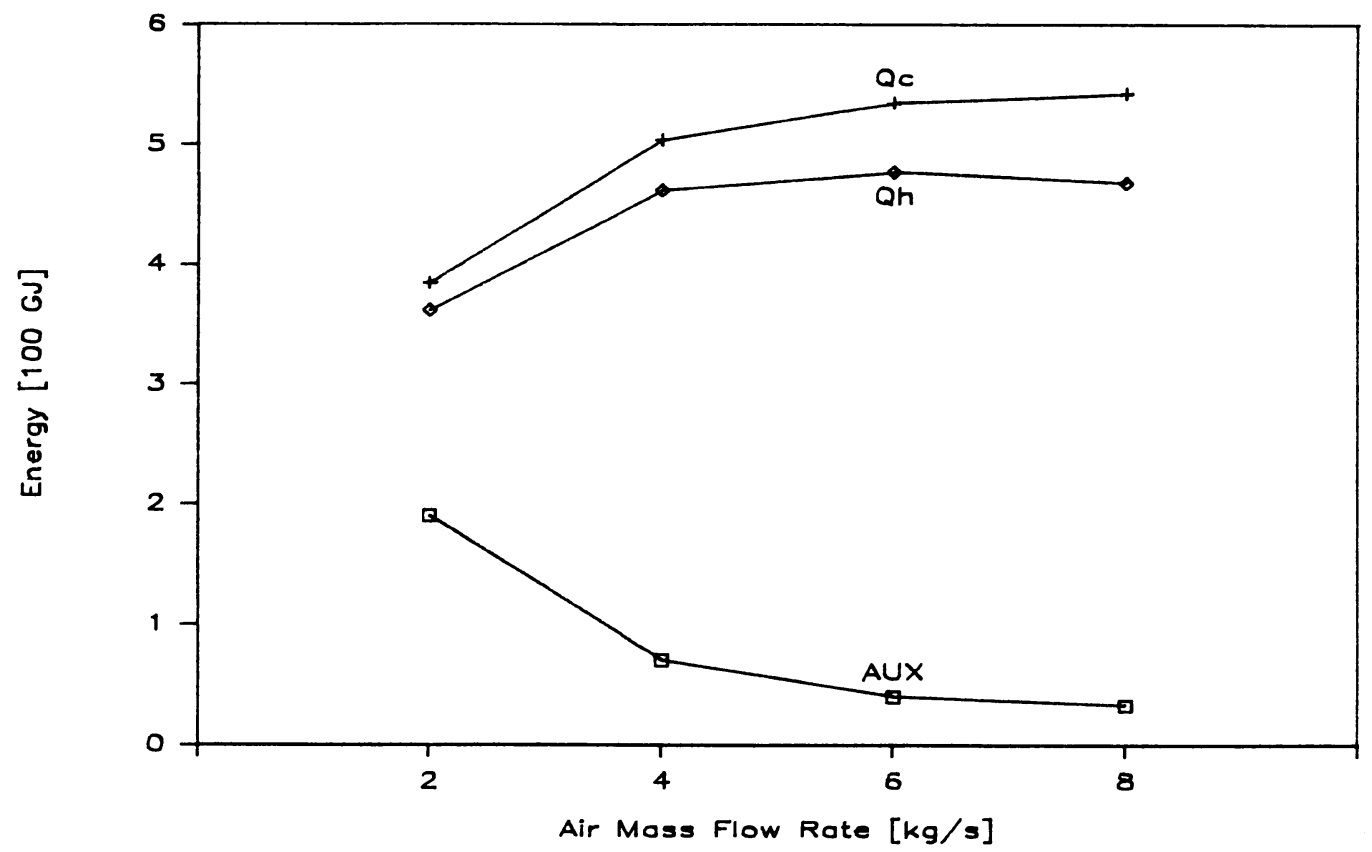

Figure 4.9 Cooling and heating input and required auxiliary cooling energy as function of the regenerator air mass flow rate (monthly simulation)

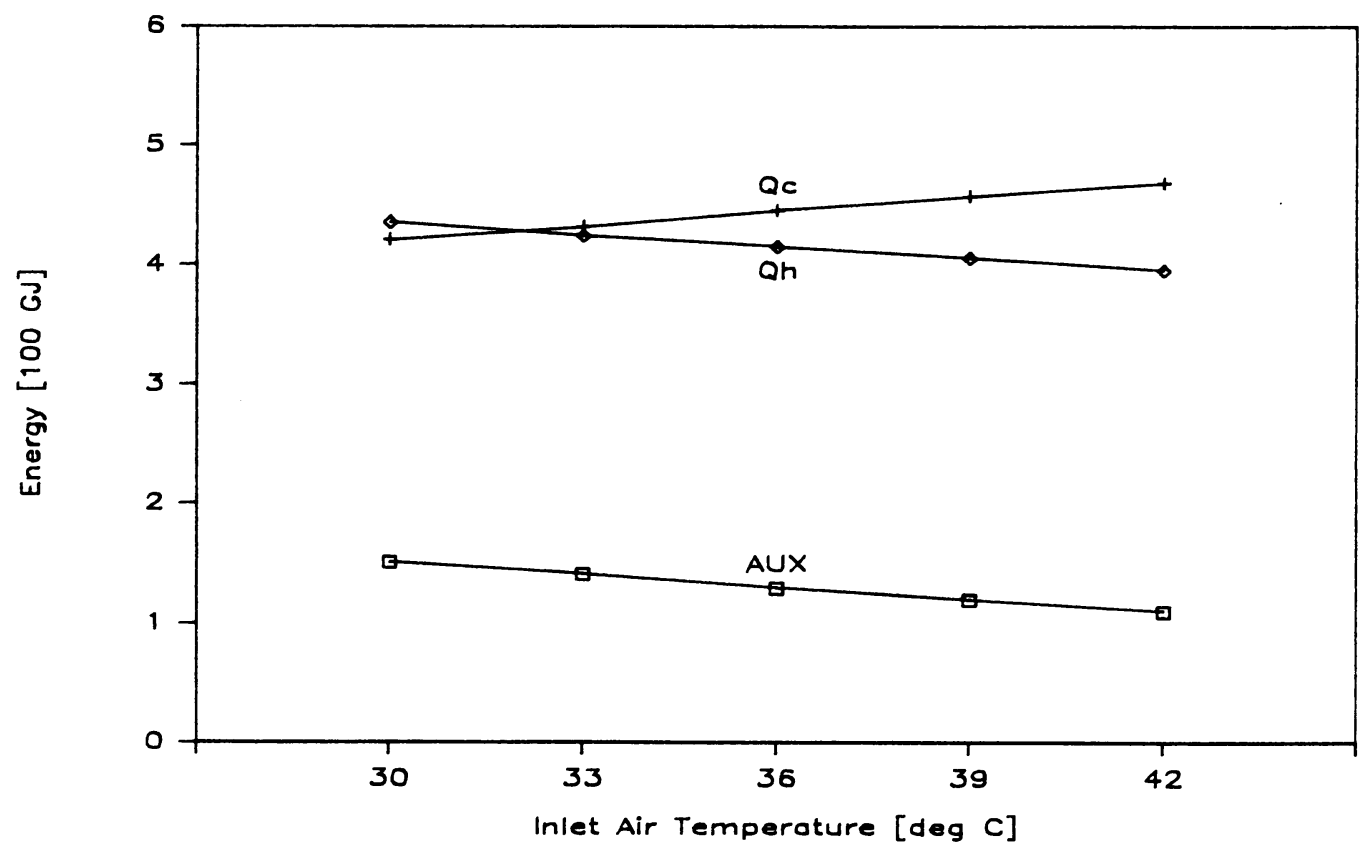

Figure 4.10 Cooling and heating input and required auxiliary cooling energy as function of the regenerator air inlet temperature (monthly simulation) 


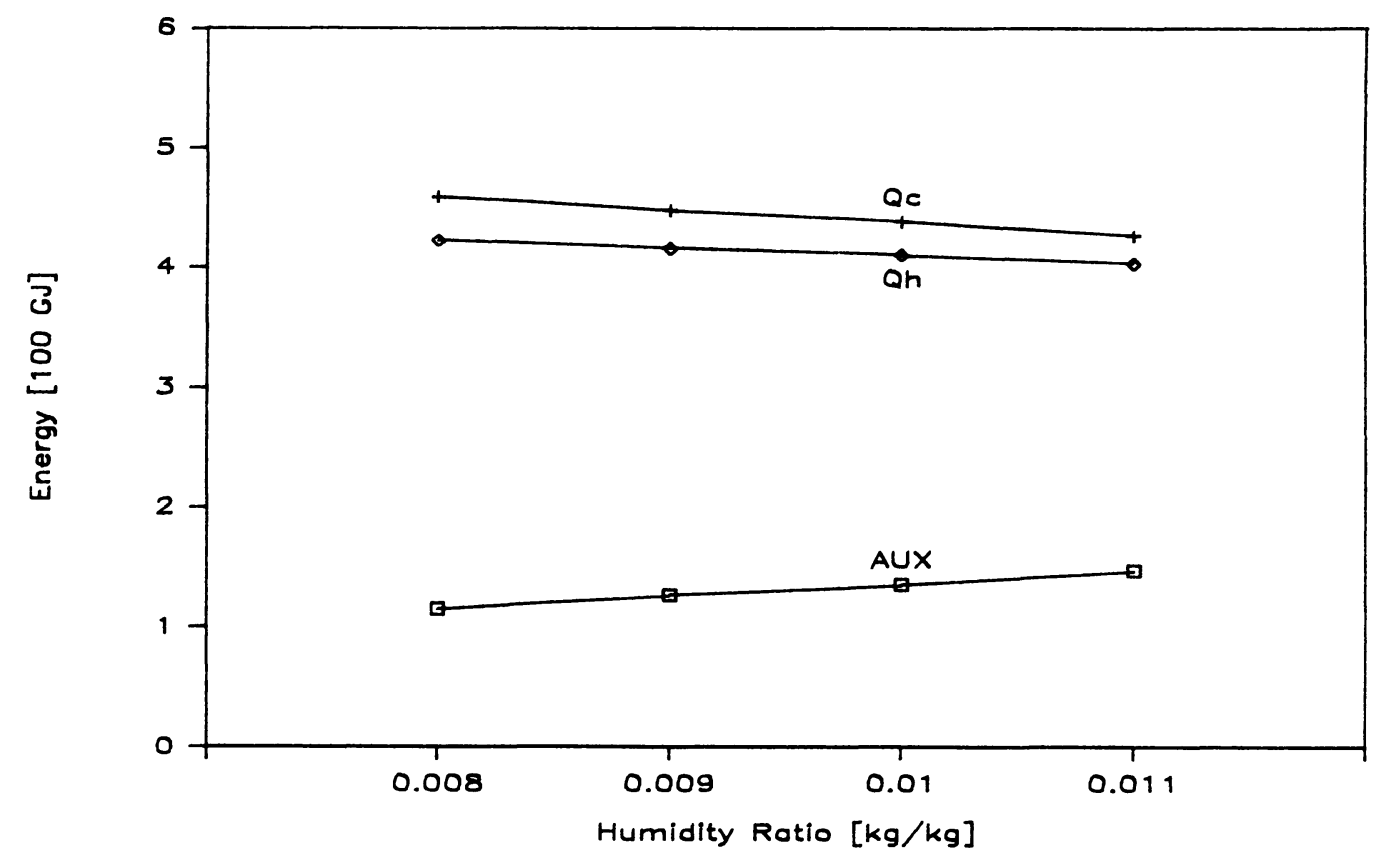

Figure 4.11 Cooling and heating input and required auxiliary cooling energy as function of the regenerator air inlet humidity (monthly simulation)

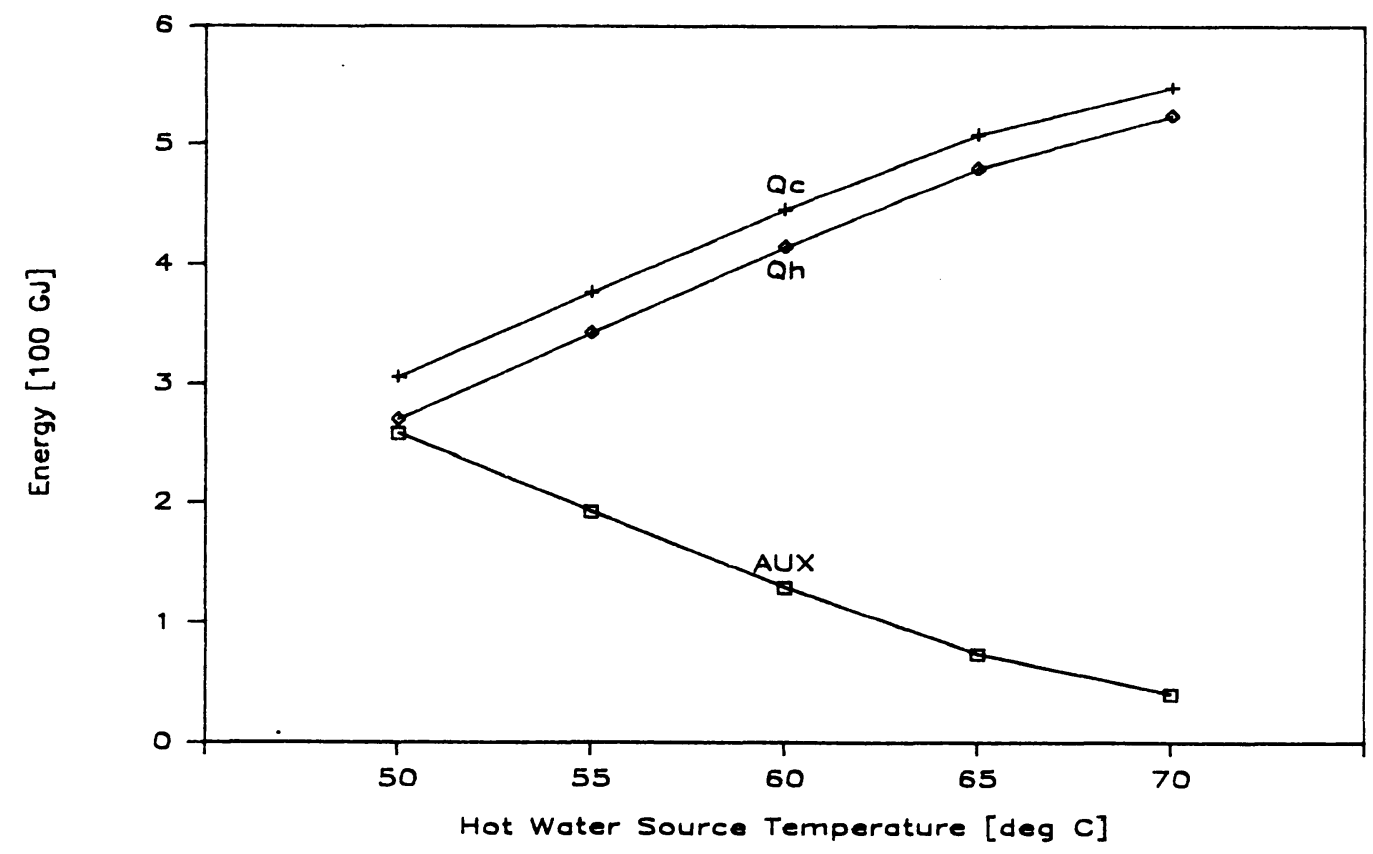

Figure 4.12 Cooling and heating input and required auxiliary cooling energy as function of the hot water source temperature (monthly simulation) 
conditioner is operating less which is indicated by $Q_{C}$ decreasing and AUX increasing. The heating energy is slightly decreasing due to the deteriorated regeneration process.

\subsubsection{Variations in the Hot Water Source Temperature and Flow Rate}

Figures 4.12 and 4.13 show the effects of the hot water supply temperature and mass flow rate on the required energy inputs. It is clear that regeneration is improved with a higher heating energy supply. Again, the conditioner operating time increases and more cooling energy for the conditioner cycle is needed. The demand for conventional cooling is decreasing.

\subsubsection{Variations in the Upper Sump Level for the Conditioner Control}

Another way of improving the regeneration process is to allow a higher maximum sump level at which the controls turn the conditioner off. This strategy can work only if the regenerator is able to remove the additional mass at times with low loads or no loads at all. The typical pattern for the energy input needs at improved regeneration can be observed in Figure 4.14 , here due to a higher sump level for the conditioner control.

\subsubsection{Conclusions}

To be able to compare different possible operation modes of a hybrid liquid desiccant system, it is desirable to have no need for auxiliary conventional cooling. This can be achieved by lowering the 


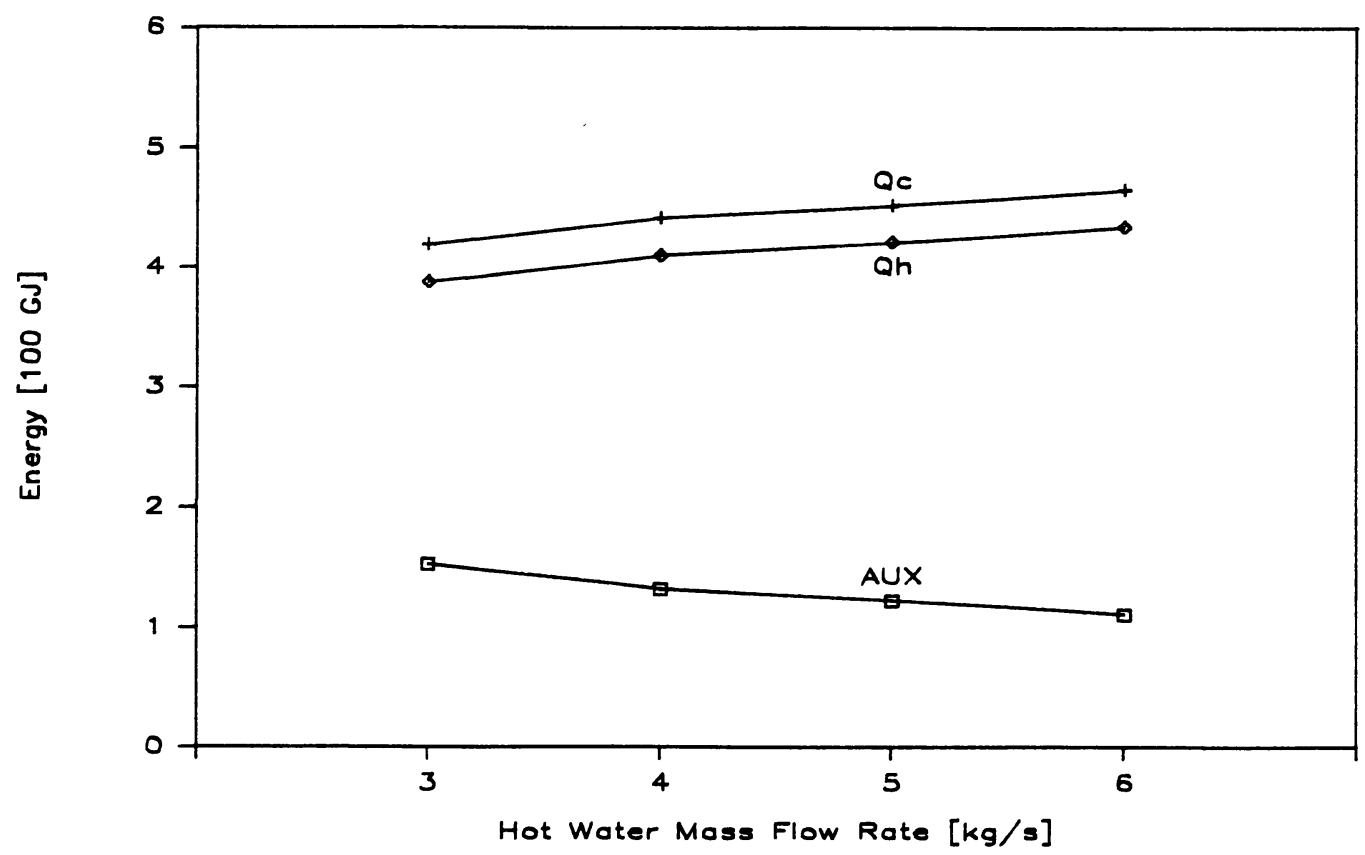

Figure 4.13 Cooling and heating input and required auxiliary cooling energy as function of the hot water source flow rate (monthly simulation)

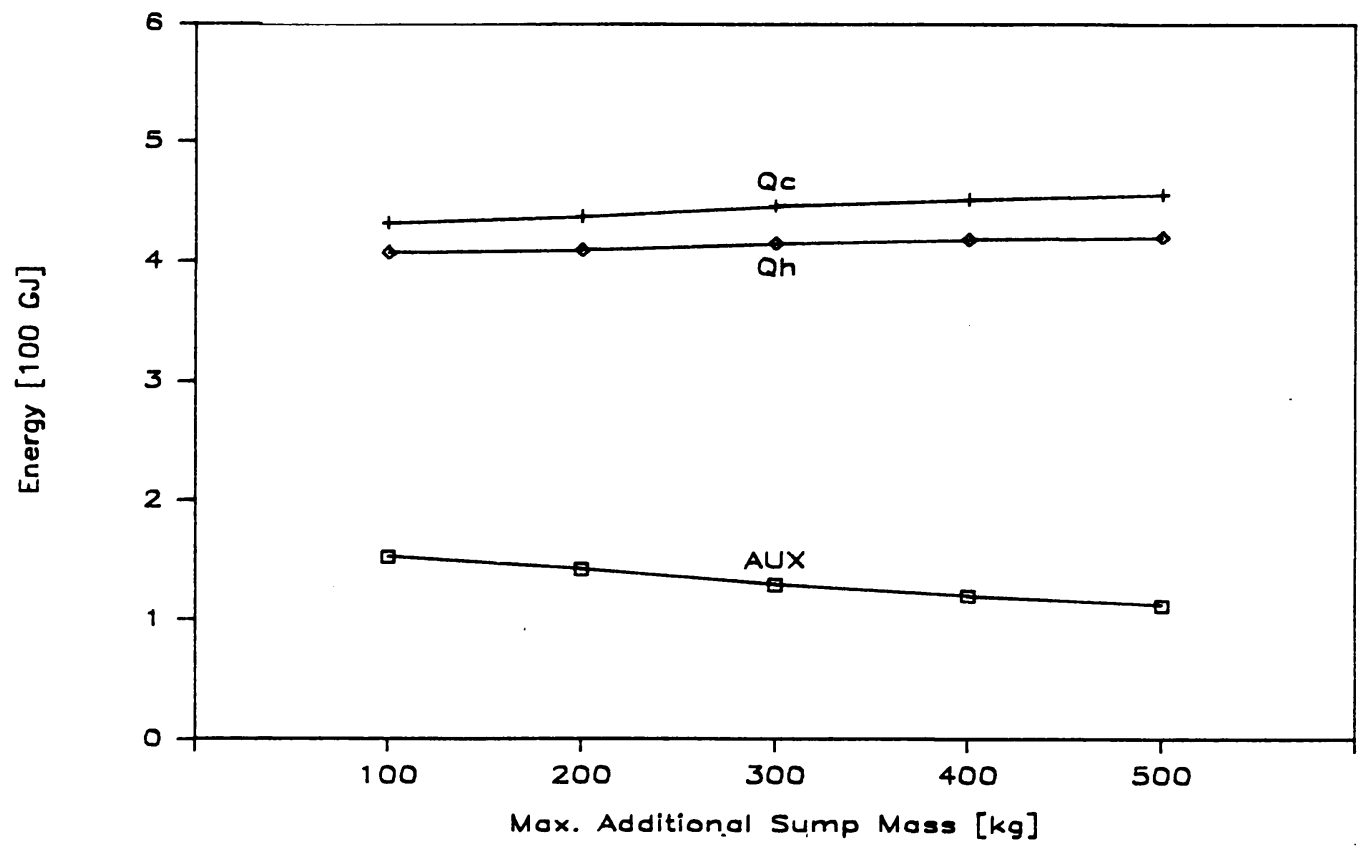

Figure 4.14 Cooling and heating input and required auxiliary cooling energy as function of the upper sump level for the conditioner control (monthly simulation) 
conditioner air mass flow rate to $3.4 \mathrm{~kg} / \mathrm{s}$. The simulations conducted for hybrid systems (Chapter 5) use this flow rate. Also, the upper sump level margin for the conditioner control was set to an additional $500 \mathrm{~kg}$ of water.

The hot water source temperature is of particular interest. The higher this temperature is, the better is the regeneration. However, the more expensive cooling energy demand in the conditioner cycle is increasing due to a higher overall solution temperature. Therefore, it is questionable if a higher regeneration temperature results in a more efficient liquid desiccant process. An examination of different regeneration temperatures was conducted and is described in Chapter 5. 


\section{CHAPTER 5: System Simulation and Results}

A hybrid liquid desiccant cooling system is the combination of conventional and liquid desiccant air conditioning equipment. There is a variety of machinery available at the SMVA which allows different ways to supply the hybrid LD system with the heating, cooling, and electrical energy inputs it requires.

System simulations were conducted with records of actual meteorological data for Cape Hatteras, NC and Sterling, VA. Both locations have a high demand for air conditioning. Also, they are geographically close to Richmond, VA and thus compare to the weather conditions at the SMVA. The Cape Hatteras load is about 1.7 times higher than the Sterling load and its latent load fraction is greater as well. The period of April through October was assumed to be the cooling season. The seasonal LD component load, the cooling energy delivered by the LD component, and the energy input demands for a regeneration temperature of $60^{\circ} \mathrm{C}$ are given in Figure 5.1 for both locations.

Since both gas and electricity are required, the operational costs in dollars were compared assuming a gas price of $0.03 \$ / \mathrm{kWh}$ and the electricity price to be $0.07 \$ / \mathrm{kWh}$. If excess electricity is produced and resold to the power plant, the resale rate is assumed to be $0.04 \$ / \mathrm{kWh}$. 


$$
\text { IFII }
$$




\subsection{Operation Modes}

Three operation modes of a hybrid LD system have been examined. In addition, a conventional system consisting of a chiller-cooling tower combination has been simulated in order to serve as basis for the comparisons. This configuration is called the 'Conventional Mode'. The three hybrid modes are defined by the following characteristics:

'Chiller Mode': A gas cogenerator provides heat for the desorber cycle and electricity to drive a vapor compression chiller which supplies the cold water for the absorber cycle. A supplementary boiler provides additional heat if needed. Also, additional electricity may be obtained from the power plant. Thus, it is guaranteed that the energy input required by the LD system is provided at any instant of time. As a result, the operational costs resulting from the use of different capacity gas cogenerators can be calculated based on energy flows during a single simulation: the energy demands of the LD component in every simulation timestep are split up into the available energy sources and their corresponding costs for various cogenerator sizes. A zero-capacity cogenerator is equivalent to an energy supply solely by the boiler and the electrical power plant.

'Heat Pump Mode': The chiller is replaced by a heat pump which produces hot water for the desorber and cold water for the absorber cycle. In all other respects the Heat Pump Mode is treated like the Chiller Mode. 
'Solar Mode': The Chille'r Mode is modified such that the heat for the desorber cycle is partially supplied by flat-plate solar collectors via thermal storage. For a zero-capacity gas-cogenerator the energy is supplied entirely by the collector, a boiler, and the power plant.

\subsection{Simulation Results}

The results are given in the form of gas and electricity energy inputs and their related costs. The electricity demand consists of the electric power for chiller, heat pump, and parasitics. Based on information from Buschulte [1] and a mechanical drawing of the SMVA system [11], the parasitics are the electric power consumptions of pumps and fans and are estimated to be as follows:

Building supply and return fans

$59.8 \mathrm{~kW}(\mathrm{C})$

Conditioner and regenerator fans

$4.5 \mathrm{~kW}(\mathrm{C})$

Solution pumps in LD component

$4.5 \mathrm{~kW}$

Pumps for heater and cooler

$4.4 \mathrm{~kW}$

Chiller pumps

$13.4 \mathrm{~kW} \mathrm{(C)}$

Cogenerator pump

$1.5 \mathrm{~kW}$

The power consumption depends on the operational state of the LD system. The regenerator fan and solution pump as well as the heater pump, for instance, are running only when the regenerator is operating. Consequently, these parasitics are zero when the regenerator 
is off. Parasitics marked with a (C) are taken into account for both the hybrid LD system and the conventional mode, where the fan load through the cooling coil is assumed to be equivalent to the conditioner and regenerator fan loads. The building supply and return fans are running independently of the operation mode and thus do not contribute to the comparison of different ways of operation. However, they are included in order to account for a correct consideration of the resale of possible excess electricity produced by the cogenerator. Electricity is considered to be resold only when it exceeds the entire air conditioning system electricity load including a11 parasitics.

For each operation mode, a TRNSYS component (TYPE47) was written to handle the control of the energy supply. This component receives the system energy demands for cooling, heating, and electricity and distributes these loads to the gas and electricity supply according to the available equipment and to the desired control. Except for the Solar Mode, the model assumes that the loads can always be met through the supply of extra heat by a boiler and extra electricity by the power plant. Thus, no storage tank model needs to be included, although storage may be physically existent. Energy supplied to the system from the tank is assumed to be immediately replaced. Appendix A contains the energy supply control component for the Chiller Mode. For all the simulations, the cogenerator was modeled to convert onethird of its gas input into useful heat and one-third into electricity. The last third is lost to the surroundings. The boiler loses 
one-third of its input capacity to the indoor environment as well, while the remaining two-thirds are turned into useful heat.

\subsubsection{Chiller Mode}

In the Chiller Mode, the cold water demand of the LD component is supplied by a chiller. A TRNSYS chiller component, based on the manufacturer's data [12] for the SMVA chiller and written by Buschulte [1], was modified such that the cooling tower fan load was considered in the chiller's electric power consumption. The electric power demand of the cooling tower adds $12.2 \%$ to the chiller power consumption. This total electric chiller consumption and the parasitics are supplied by the gas-cogenerator as far as possible. The cogenerator also provides hot water for the regeneration. Excess heat is dumped and excess electricity is resold to the power plant. The option of no resale opportunity is included in the model. Different cogenerator capacities may be examined during one simulation, since the load is not affected by the cogenerator size because it is always met.

The average operational costs during a cooling season for different cogenerator capacities and regeneration temperatures are shown in Figures 5.2 and 5.3 for the weather conditions of Cape Hatteras and Sterling, respectively. There will be an optimum non-zero cogenerator capacity if the costs to run the cogenerator are less than the amount of money saved by lower boiler usage and less purchased electricity. Therefore, a higher electricity to gas price ratio will 


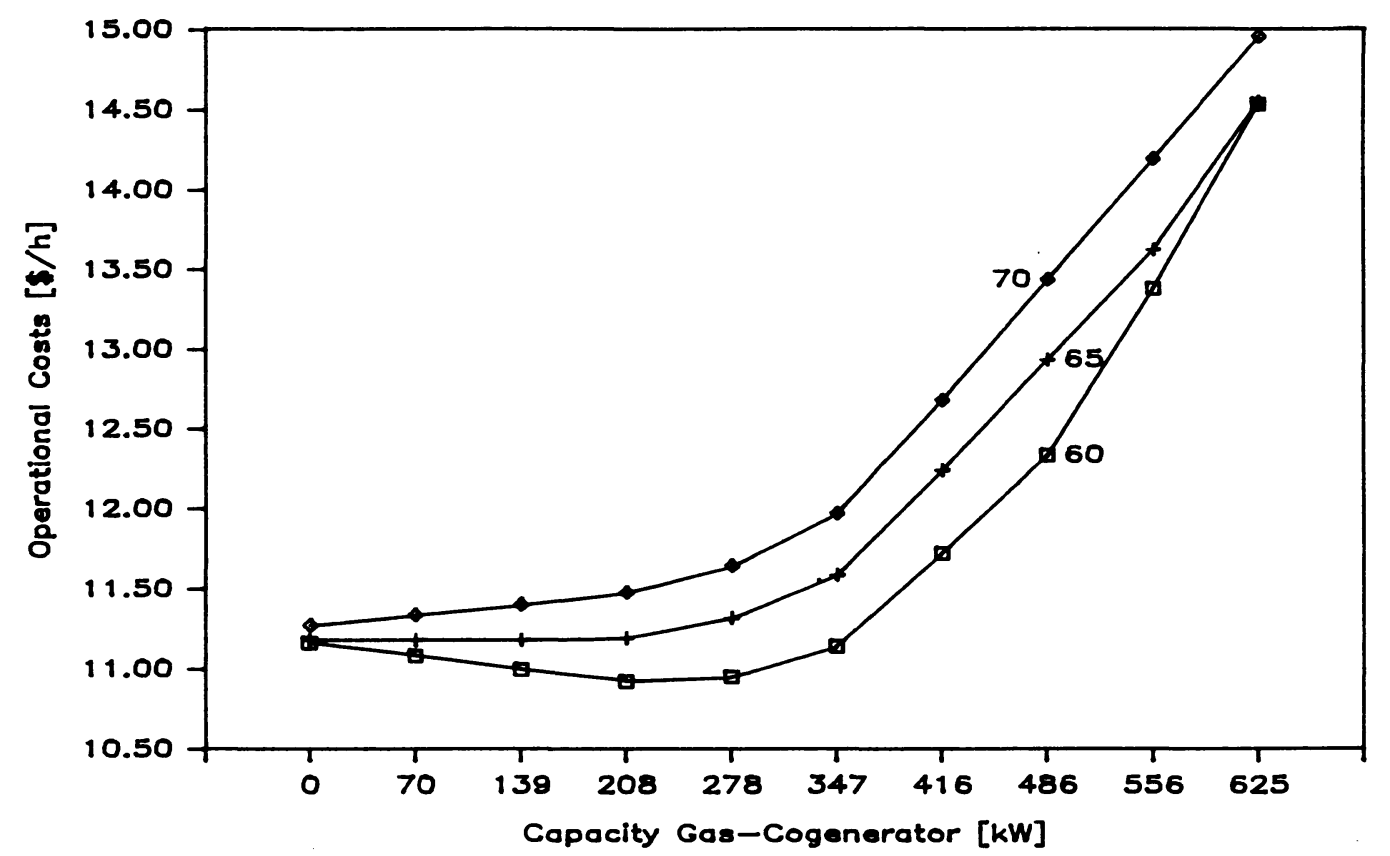

Figure 5.2 Average total operational costs of Chiller Mode as function of cogenerator capacity and regeneration temperature for Cape Hatteras

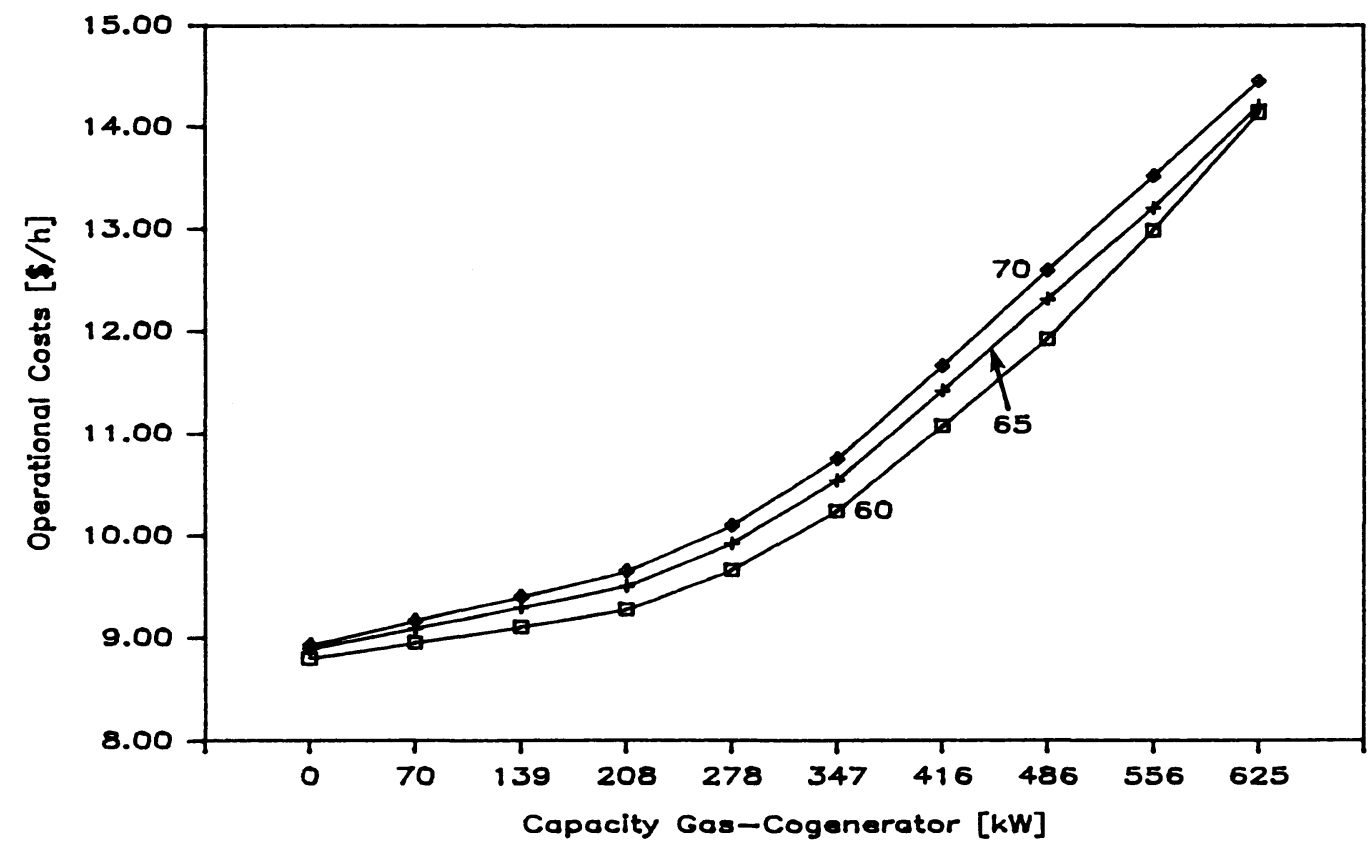

Figure 5.3 Average total operational costs of Chiller Mode as function of cogenerator capacity and regeneration temperature for Sterling 
more likely yield an optimum non-zero capacity. Considering the heat alone, the boiler is more efficient than the cogenerator. For a low electricity demand, it is thus possible that the zero capacity cogenerator is the optimum. For the Cape Hatteras conditions with a 1.7 times higher load than in Sterling, a cost minimum occurs at about $208 \mathrm{~kW}$ capacity for a regeneration temperature of $60^{\circ} \mathrm{C}$. For the conditions of Sterling the minimum is at zero capacity.

In Figure 5.4 the average gas and electric power requirements and their sum for Cape Hatteras are shown for $60^{\circ} \mathrm{C}$ regeneration temperature. The corresponding costs are given in Figure 5.5. The equivalent graphs for the Sterling conditions are shown in Figures 5.6 and 5.7. The minimum in the sum of the operational costs for Cape Hatteras rather than Sterling is due to the higher gas demand which is met by the boiler. A cogenerator of about $320 \mathrm{~kW}$ capacity provides $100 \%$ of the electricity demand at any timestep. A higher capacity consequently leads to higher costs. Therefore, the upper bound for an optimum capacity is at $320 \mathrm{~kW}$. Only a cogenerator with a capacity of $486 \mathrm{~kW}$ or more will supply $100 \%$ of the heat at all times. It can be concluded that a cogenerator is not necessarily advantageous, even if the initial investment is not taken into account.

Figures 5.2 and 5.3 indicate that the total operational costs are increasing with increasing regeneration temperature. $60^{\circ} \mathrm{C}$ is the lowest hot water temperature at which no auxiliary conventional cooling is needed for the given LD component configuration. Higher 


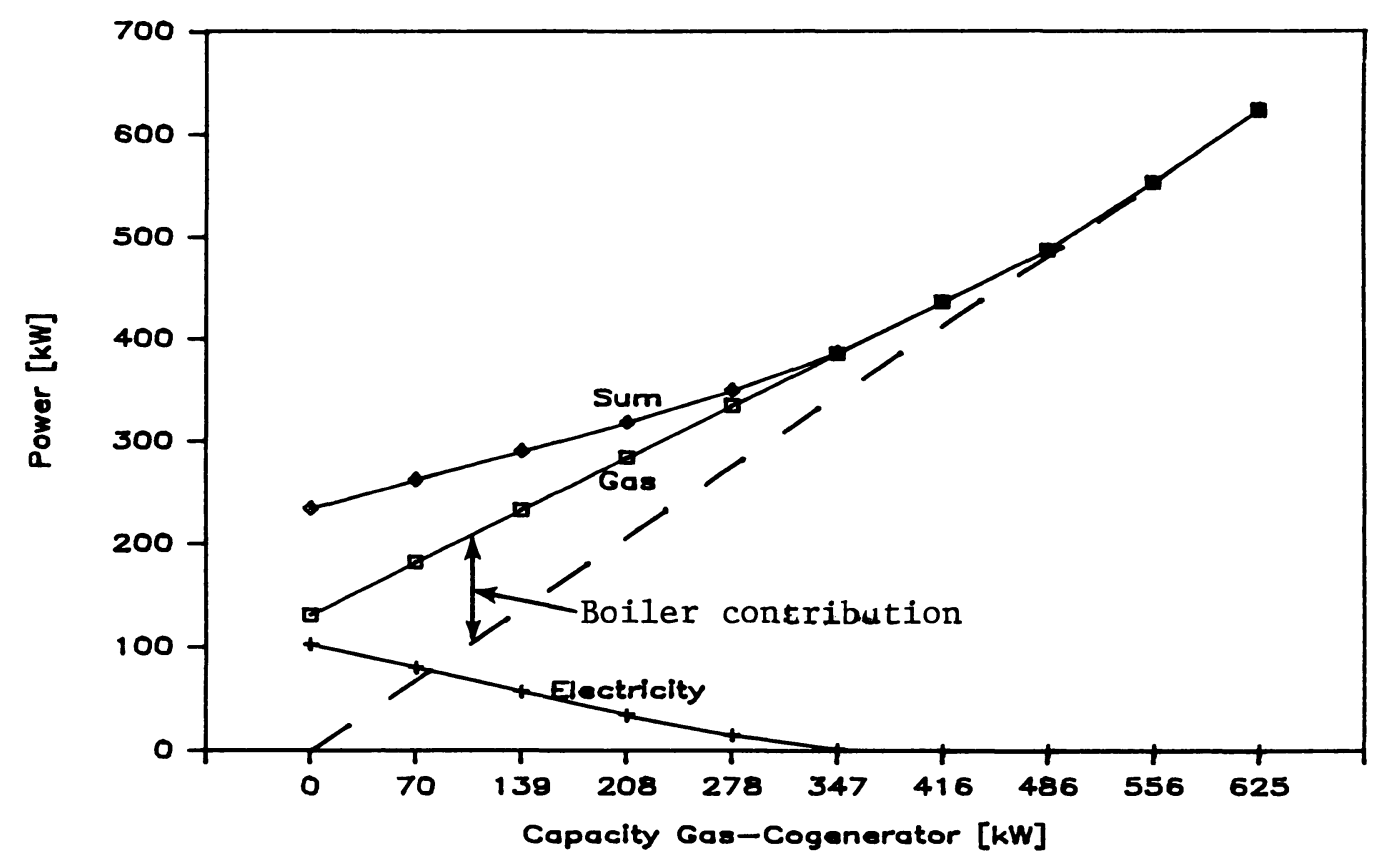

Figure 5.4 Gas, electricity, and total energy consumption of Chiller Mode for Cape Hatteras $\left(60^{\circ} \mathrm{C}\right.$ regeneration temperature)

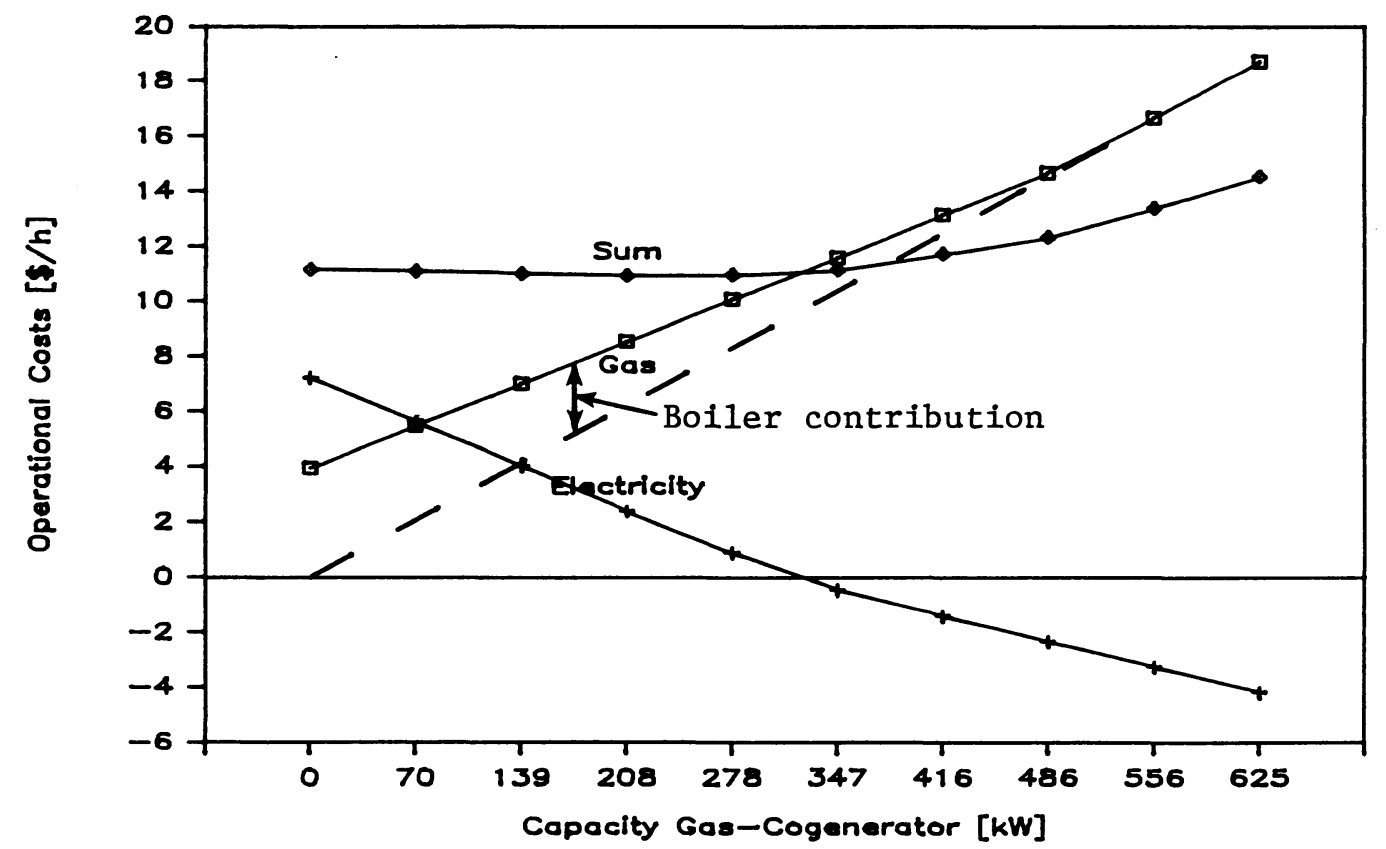

Figure 5.5 Gas, electricity, and total operational costs of Chiller Mode for Cape Hatteras $\left(60^{\circ} \mathrm{C}\right.$ regeneration temperature) 


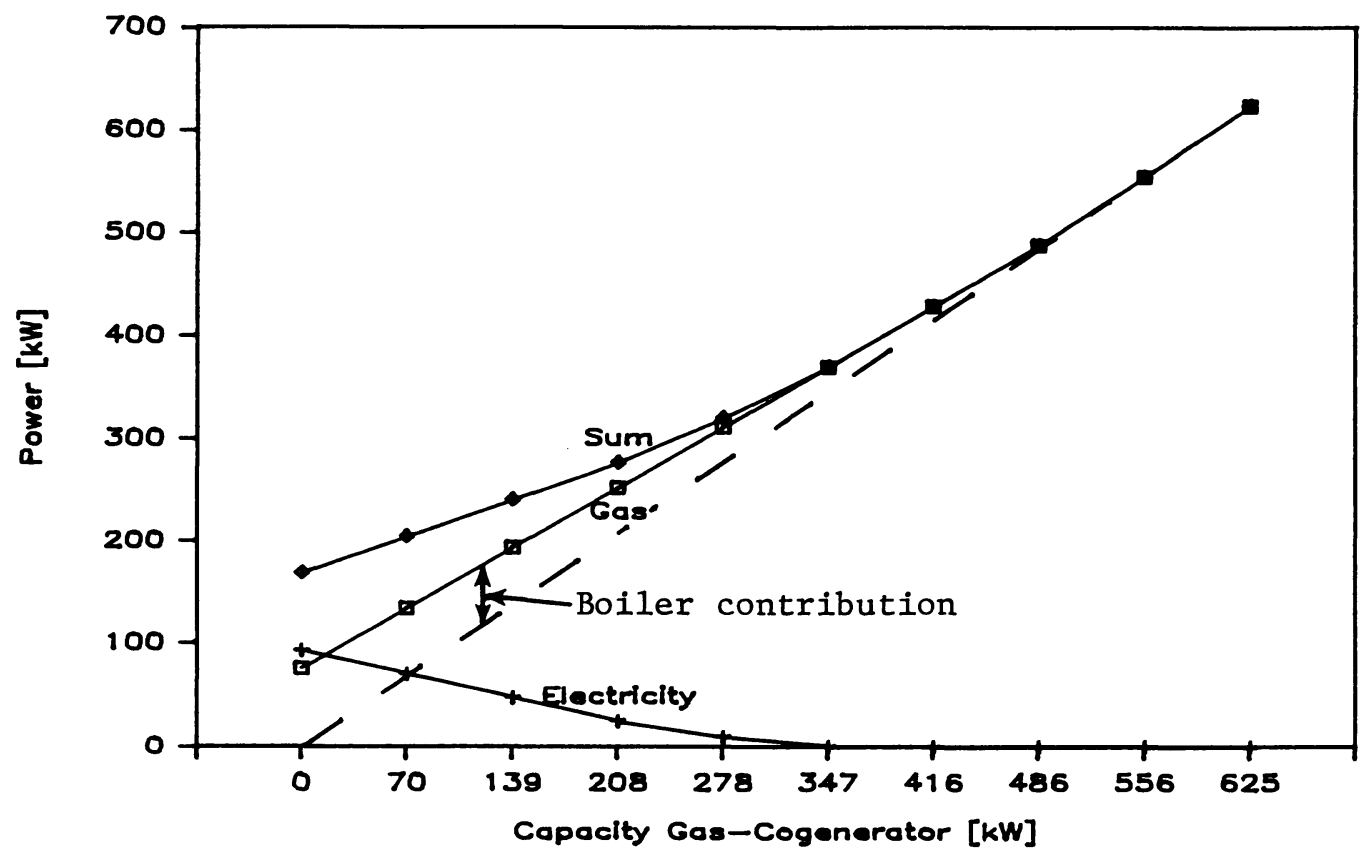

Figure 5.6 Gas, electricity, and total energy consumption of Chiller Mode for Sterling $\left(60^{\circ} \mathrm{C}\right.$ regeneration temperature)

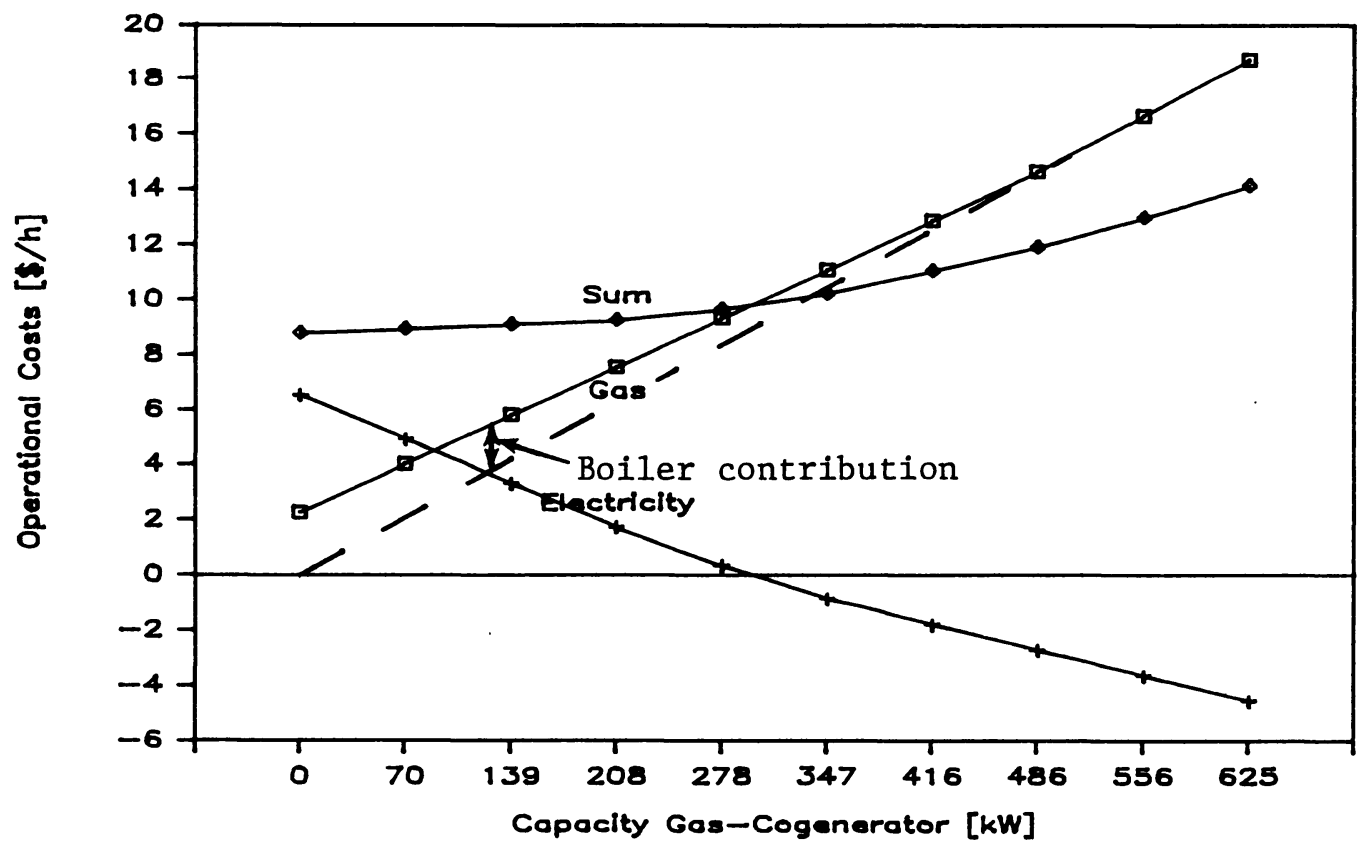

Figure 5.7 Gas, electricity, and total operational costs of Chiller Mode for Sterling $\left(60^{\circ} \mathrm{C}\right.$ regeneration temperature) 
temperatures improve the regeneration. On the other hand, they heat up the solution in the entire system, which results in an increased desiccant cooling demand, as shown in Figure 5.8 for a monthly simulation (July, Cape Hatteras). Figure 5.8 also indicates that increasing the interchanger UA value does not change the situation significantly. The average energy supply to the regenerator is almost independent of the hot water source temperature because the regenerator is turned off for a longer overall time as illustrated in Figure 5.9. The influence of the regeneration temperature can also be observed in Figures 5.2 and 5.3. As long as the cogenerator is below $100 \%$ capacity, the electricity demand grows faster for higher regeneration temperatures, indicated by larger absolute slopes. The curves are diverging. Above $100 \%$ cogenerator capacity the total costs are represented by straight lines. The slope of these lines is dependent on the amount of resold electricity and therefore declining with with increasing regeneration temperature. Consequently, the curves are converging in this range. If no electricity were resold, the slope of all curves beyond the $100 \%$ capacity margin would be equal to the gas price.

\subsubsection{Heat Pump Mode}

The use of a heat pump instead of a chiller is considered in the Heat Pump Mode. The electricity-driven heat pump supplies the regenerator and conditioner cycles with heating and cooling energy, respectively. A TRNSYS model for the heat pump installed at the SMVA 


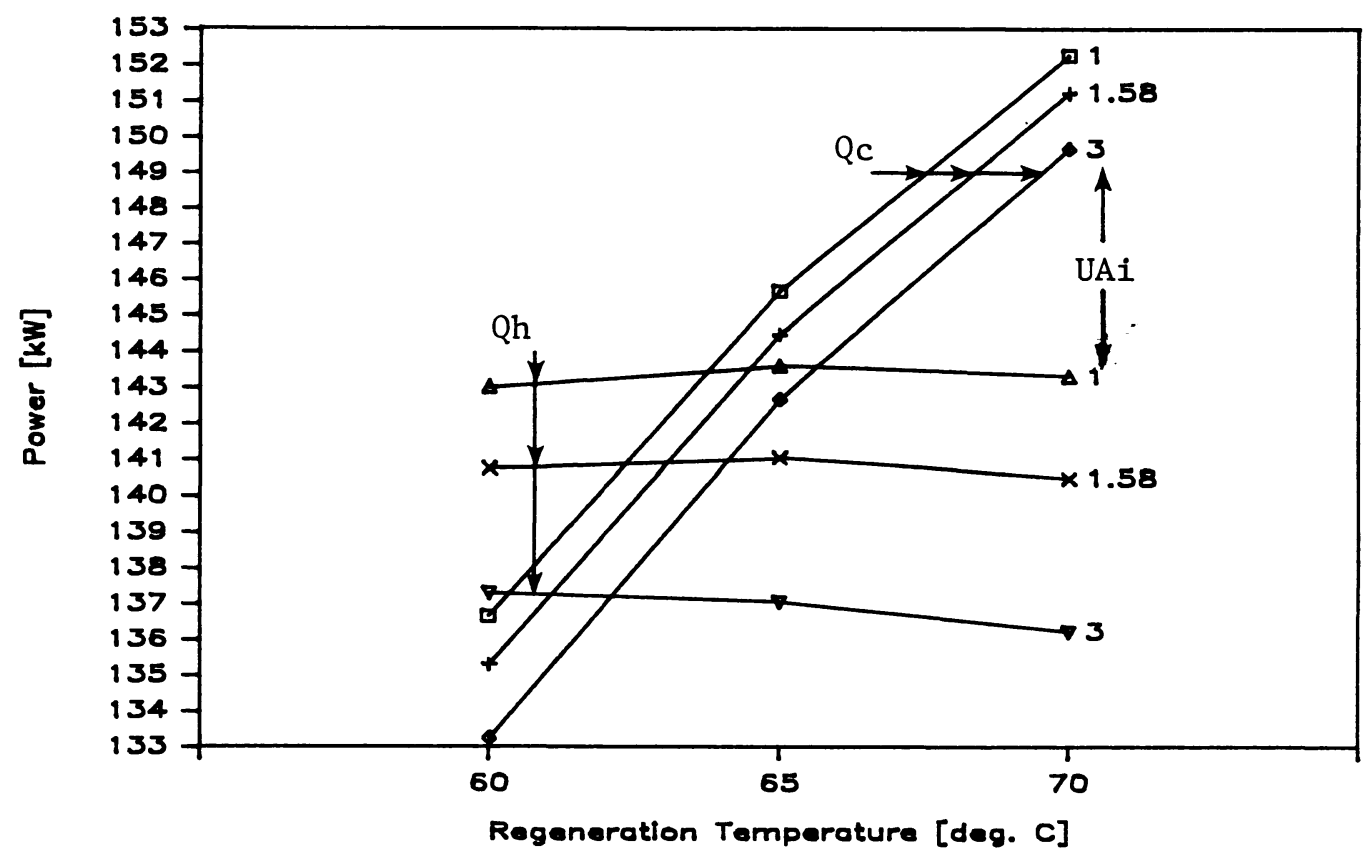

Figure 5.8 Cooling and heating energy input versus regeneration temperature varying interchanger UA-value (monthly simulation)

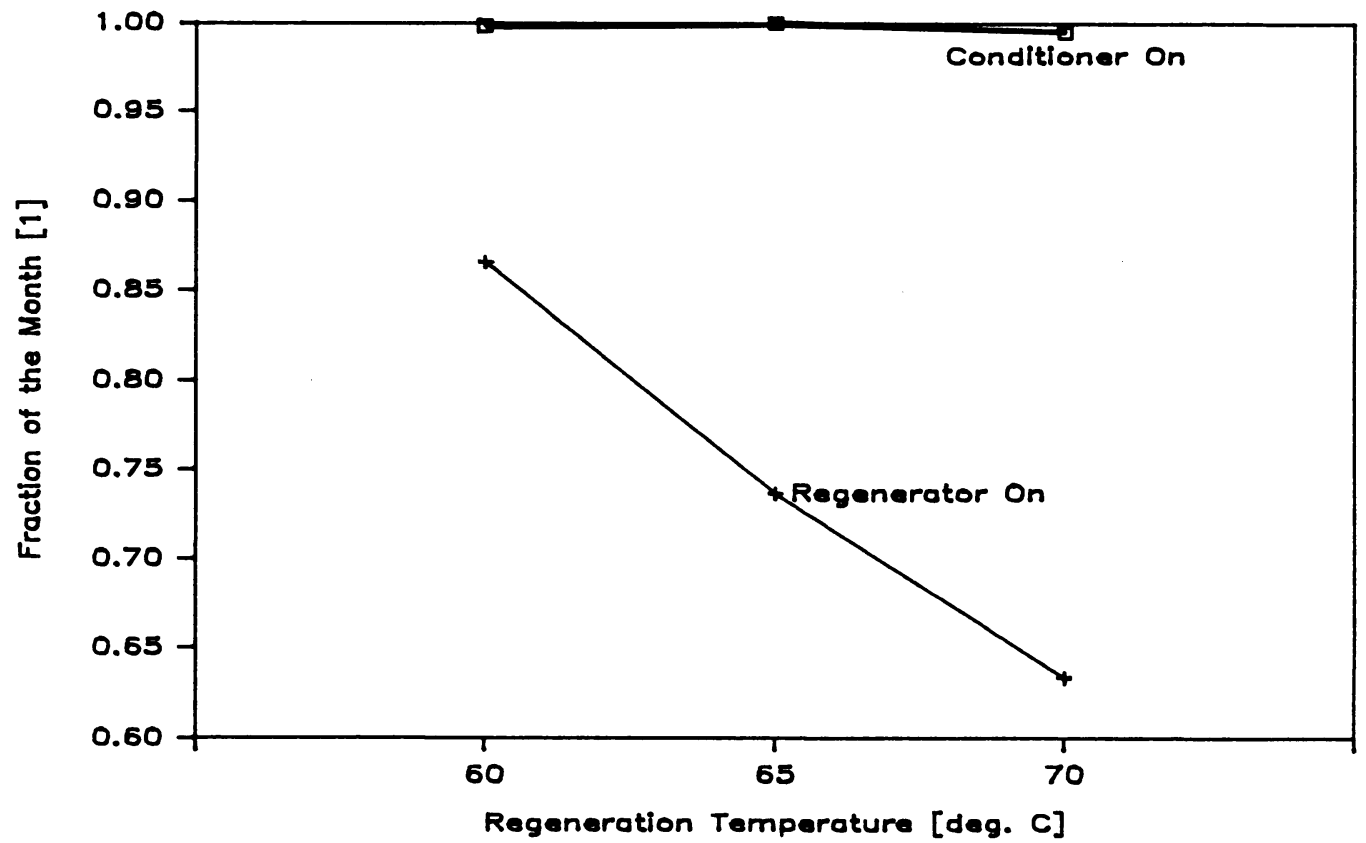

Figure 5.9 Monthly operating time fractions of conditioner and regenerator versus regeneration temperature 
is available. It was also written by Buschulte [1] based on manufacturer's data [13]. The model assumes that the heat pump delivers hot water to the regenerator at the desired set point at any time when there is a demand. A boiler is therefore not necessary. When the heat pump cannot deliver cooling water at the desired temperature, $T_{13}$, or below, the TRNSYS energy supply control component for the Heat Pump Mode uses the chiller equations for the remaining cooling needs. Thus it is guaranteed that the conditions for the Heat Pump Mode are always comparable to those of the Chiller Mode. In all other respects, the Heat Pump and the Chiller Modes are treated identically.

The use of a gas-cogenerator is certainly less promising, since the heat is supplied solely by the heat pump. For the given electricity to gas price ratio $(7: 3)$, a cogenerator would raise the operational costs for all regeneration temperatures and both locations. Figure 5.10 shows the sum of the costs for Cape Hatteras, while the Sterling case is illustrated in Figure 5.11. For Cape Hatteras and $60^{\circ} \mathrm{C}$ regeneration temperature, gas and electricity inputs as well as the total is given in Figure 5.12. The related costs are shown in Figure 5.13. The corresponding information for Sterling is contained in Figures 5.14 and 5.15 .

For a regeneration temperature of $60^{\circ} \mathrm{C}$, a simulation was conducted using an electricity to gas price ratio of 3 by assuming a price for buying electricity to be $0.09 \$ / \mathrm{kWh}$. The operational costs for this case and for both locations are given in Figures 5.16 and 


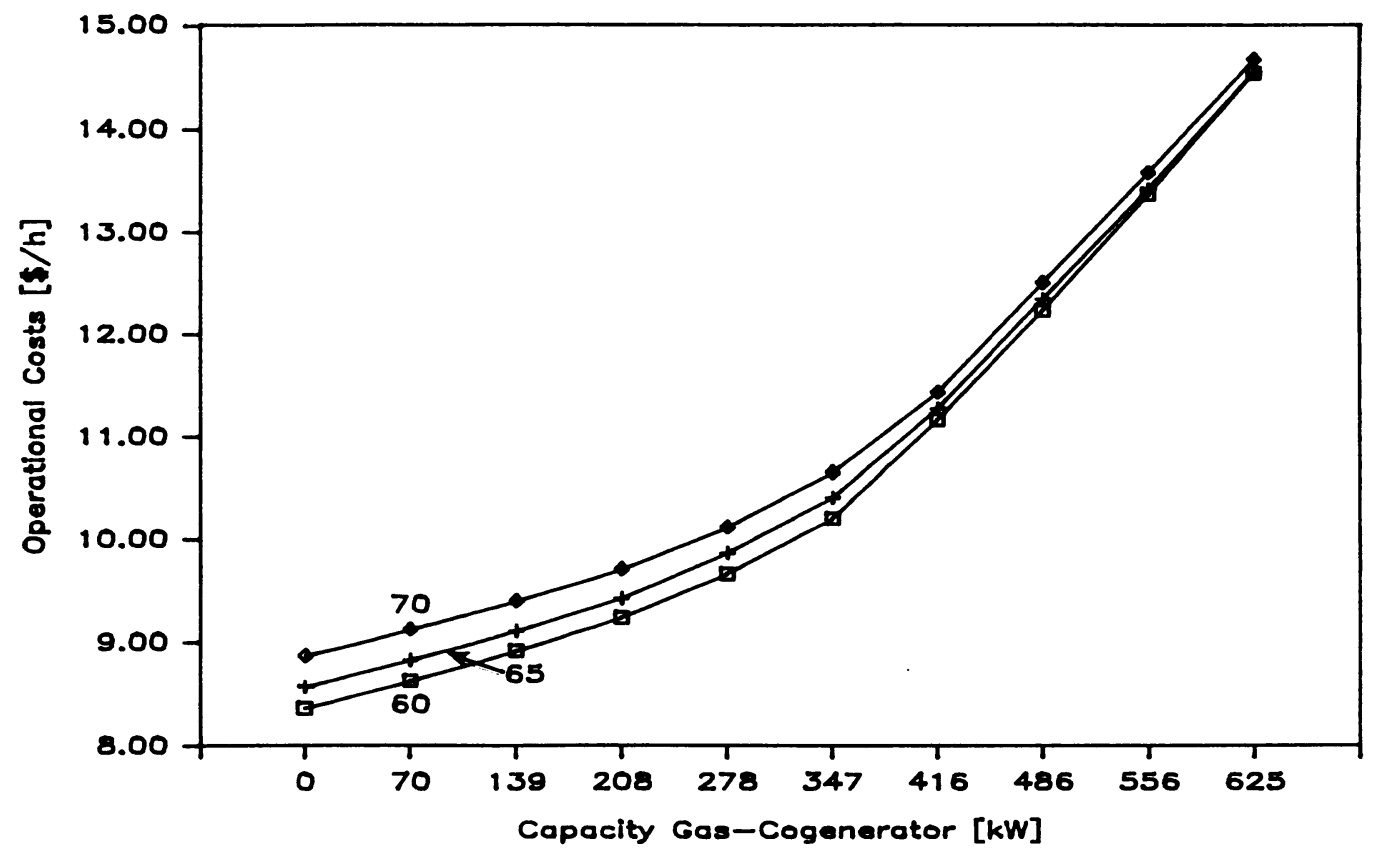

Figure 5.10 Average total operational costs of Heat Pump Mode as function of cogenerator capacity and regeneration temperature for Cape Hatteras

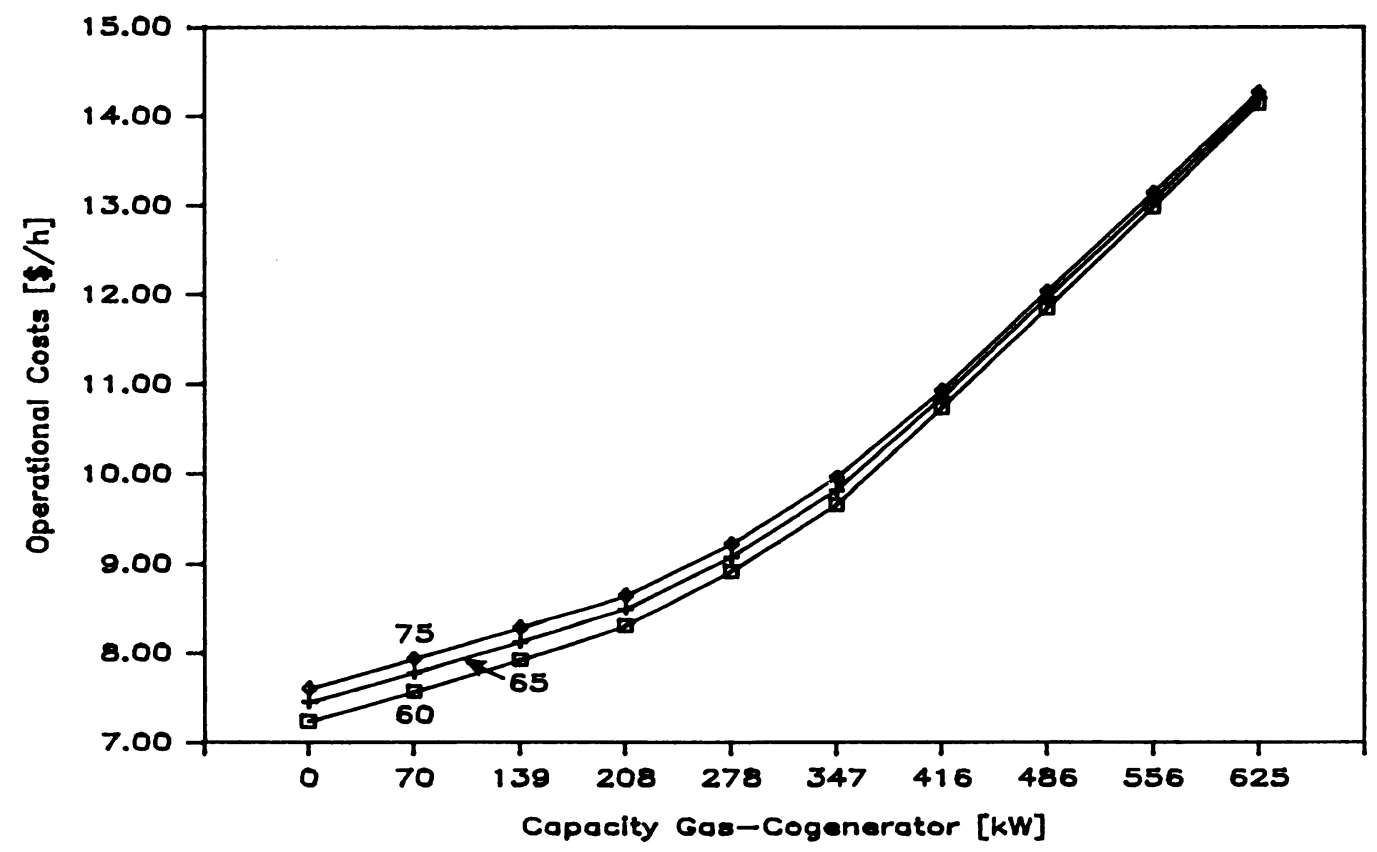

Figure 5.11 Average total operational costs of Heat Pump Mode as function of cogenerator capacity and regeneration temperature for Sterling 


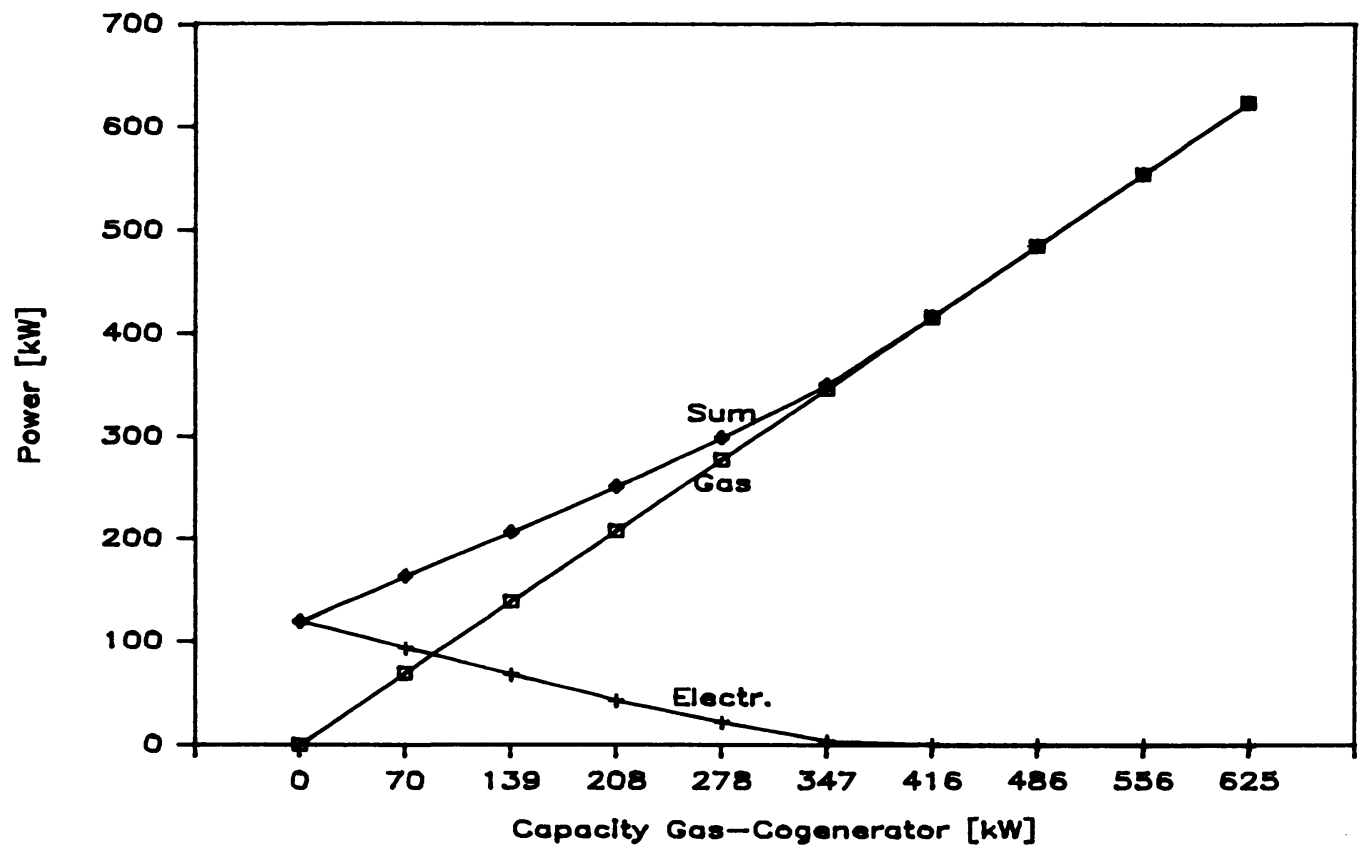

Figure 5.12 Gas, electricity, and total energy consumption of Heat Pump Mode for Cape Hatteras $\left(60^{\circ} \mathrm{C}\right.$ regeneration temperature)

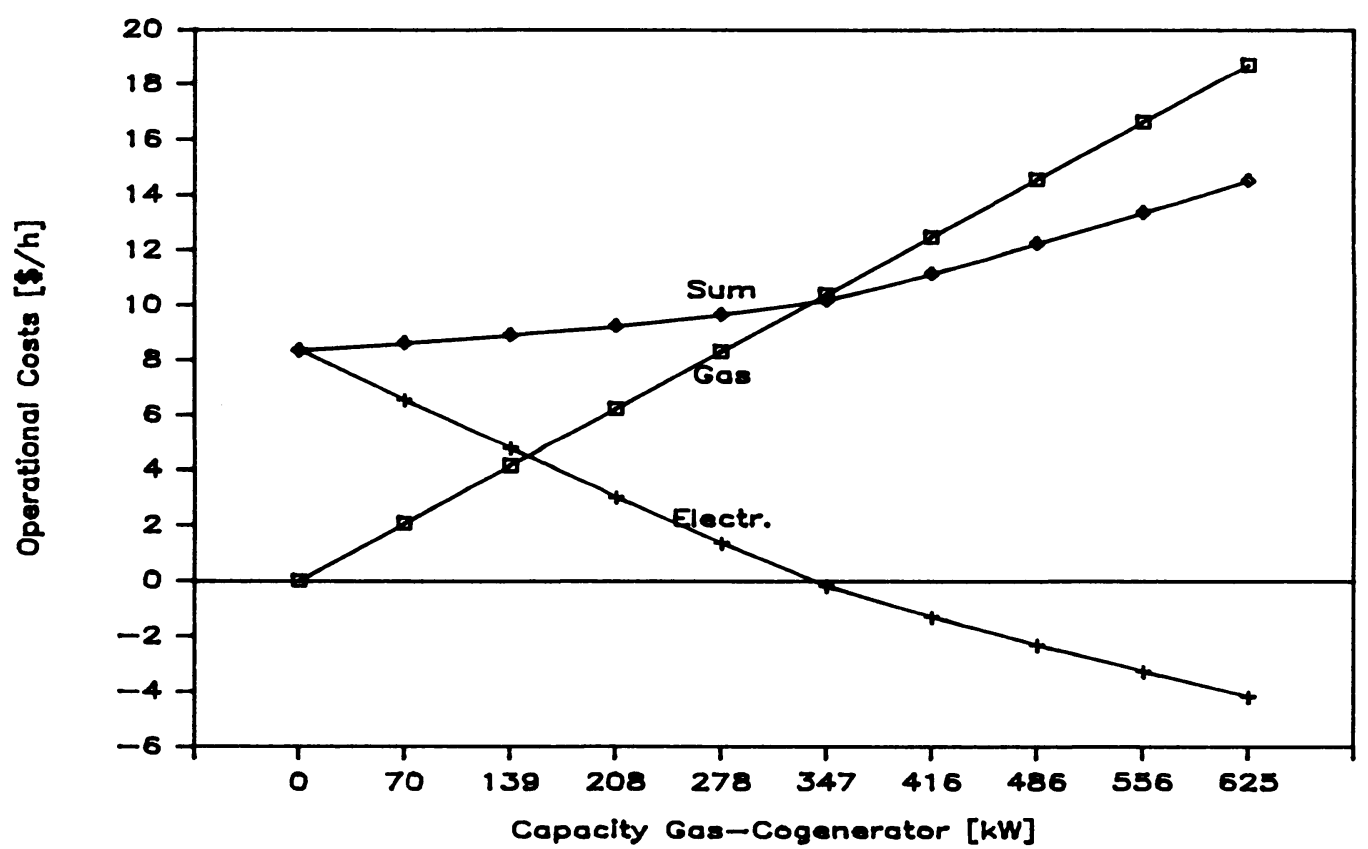

Figure 5.13 Gas, electricity, and total operational costs of Heat Pump Mode for Cape Hatteras $\left(60^{\circ} \mathrm{C}\right.$ regeneration temperature) 


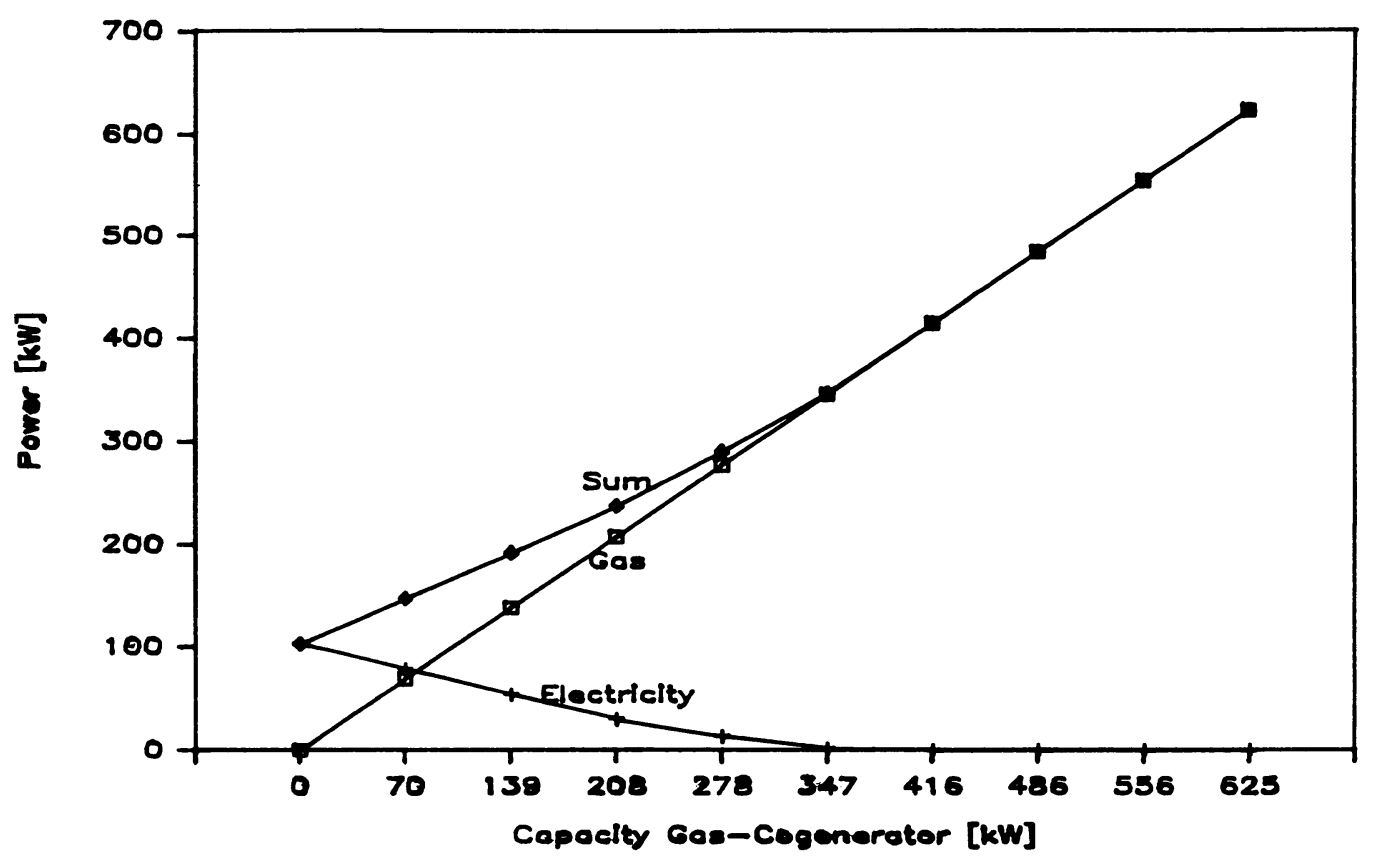

Figure 5.14 Gas, electricity, and total energy consumption of Heat Pump Mode for Sterling $\left(60^{\circ} \mathrm{C}\right.$ regeneration temperature)

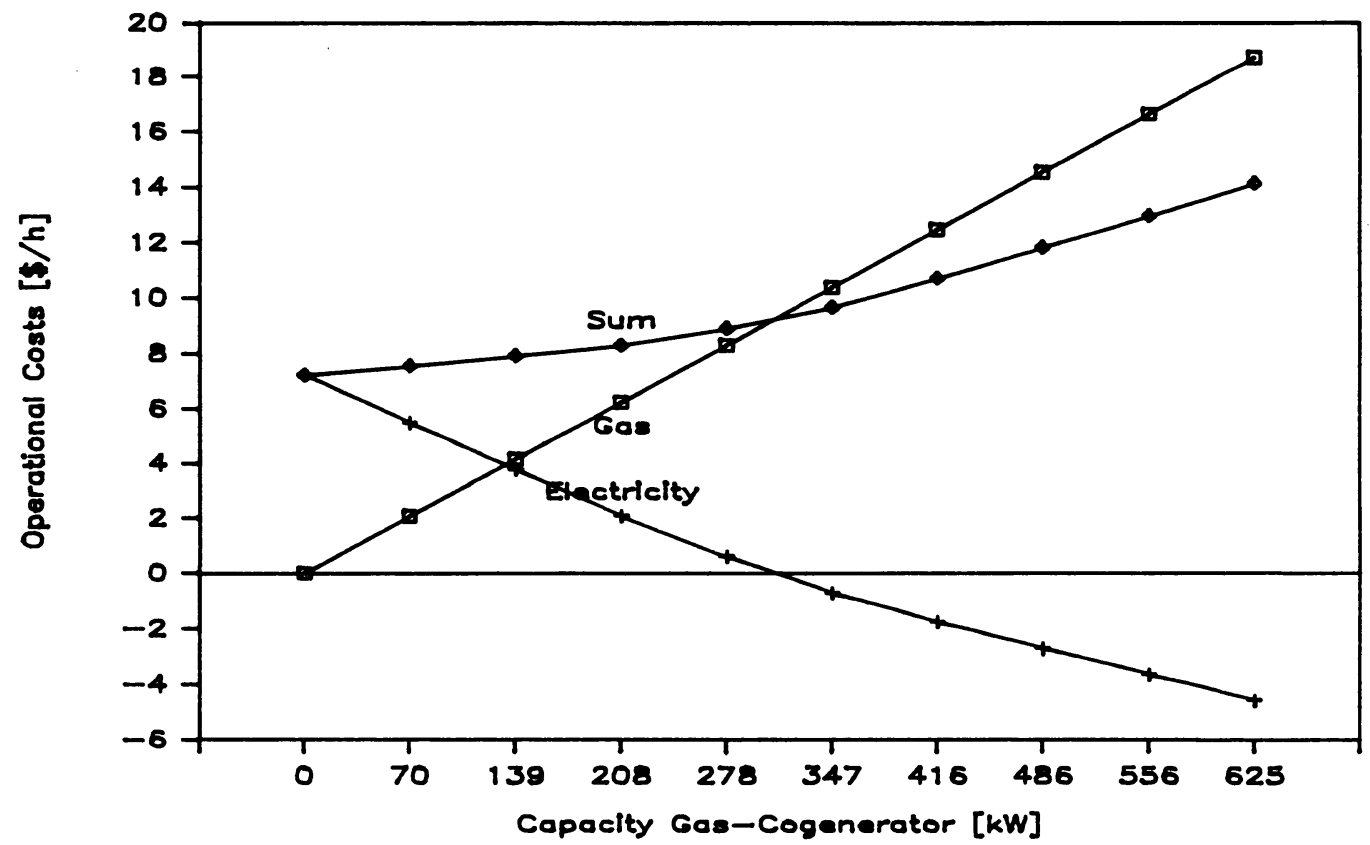

Figure 5.15 Gas, electricity, and total operational costs of Heat Pump Mode for Sterling $\left(60^{\circ} \mathrm{C}\right.$ regeneration temperature) 


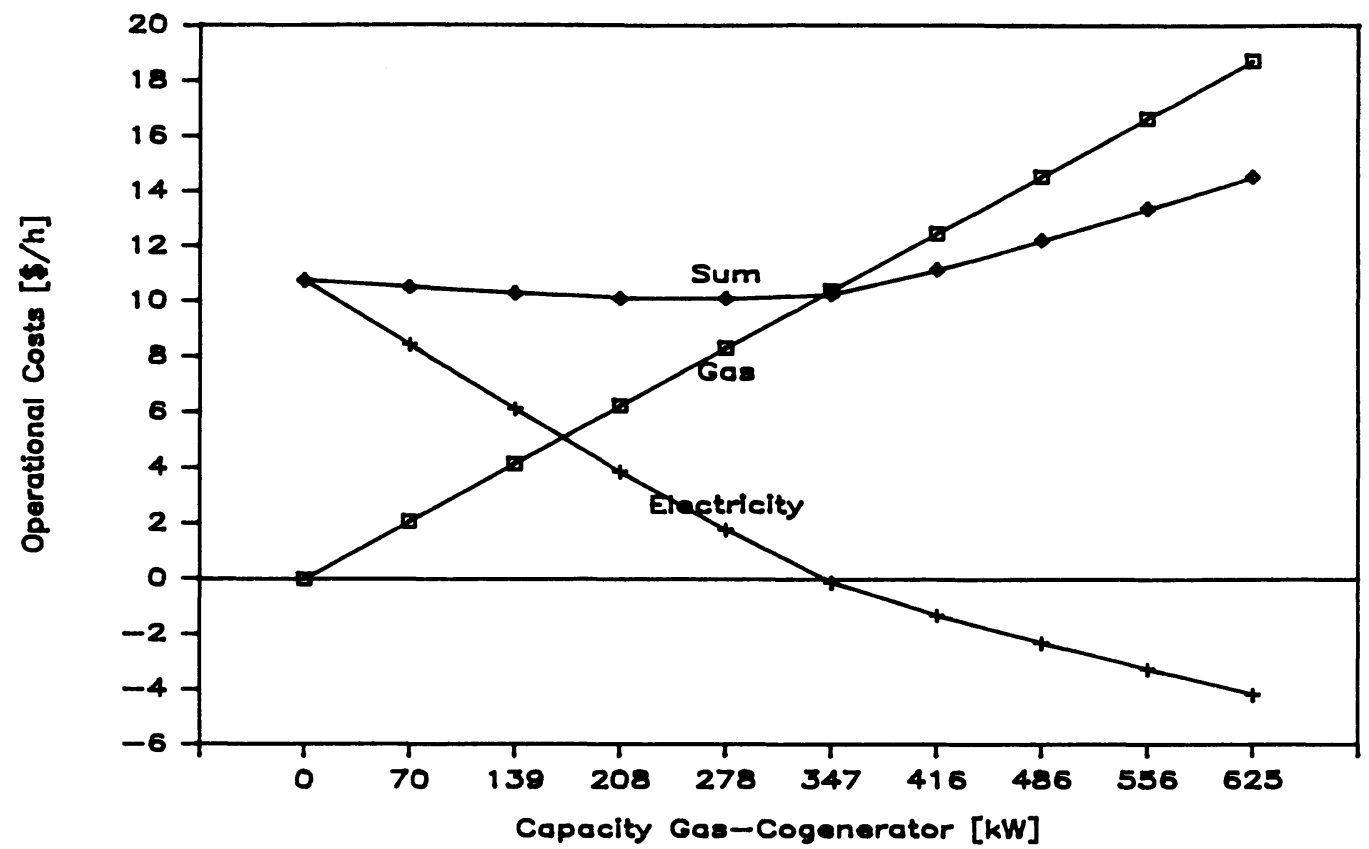

Figure 5.16 Gas, electricity, and total operational costs of Heat Pump Mode for Cape Hatteras (electricity rate 0.09 $\$ /$ kWh $)$

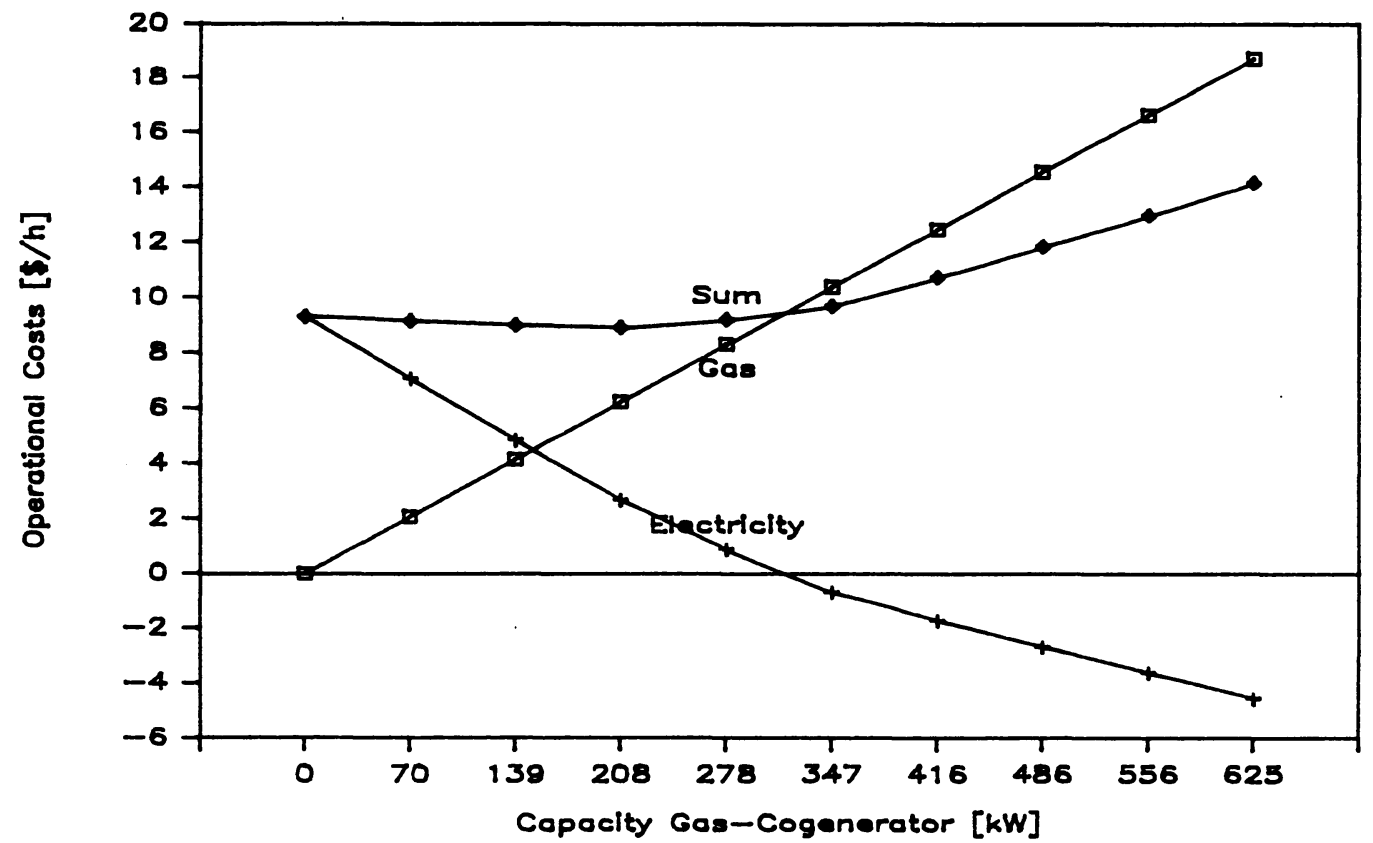

Figure 5.17 Gas, electricity, and total operational costs of Heat Pump Mode for Sterling (electricity rate $0.09 \$ / \mathrm{kWh}$ ) 
5.17. Both cases show a cost minimum for a non-zero cogenerator capacity.

\subsubsection{Solar Mode}

For solar operation, it cannot be assumed that heat is available at any time when there is a demand. A storage tank model has to be included. A tank size of $19 \mathrm{~m}^{3}$ was chosen which represents roughly the size of one of the two storage tanks at the SMVA. The collector flow rate was set to $20 \mathrm{~kg} /\left(\mathrm{h}-\mathrm{m}^{2}\right.$ collector area). Collector areas of $250 \mathrm{~m}^{2}, 500 \mathrm{~m}^{2}$, and $750 \mathrm{~m}^{2}$ were investigated. Typical values were chosen for the other solar system parameters $[14,15]$. They are listed in Table 5.1 and also in the TRNSYS deck for the Solar Mode in Appendix C. The tank is heated by the solar collectors. It delivers heat when its temperature is greater than or equal to the regeneration set temperature, for which values of $60^{\circ} \mathrm{C}, 65^{\circ} \mathrm{C}$, and $70^{\circ} \mathrm{C}$ were investigated. Otherwise a boiler or, if installed, a cogenerator supplies the regeneration heat at the set temperature.

In Figures 5.18 and 5.19 the sum of the operational costs in the Solar Mode are given for Cape Hatteras and Sterling, respectively, for a regeneration temperature of $60^{\circ} \mathrm{C}$ and varying collector areas. If no cogenerator is used, the operational costs decrease with increasing collector area. It should be noted that the initial investment for solar collectors, which is strongly dependent on the collector area, is not reflected in these graphs. The lower the collector area, the higher is the tendency of having a cost minimum at a 


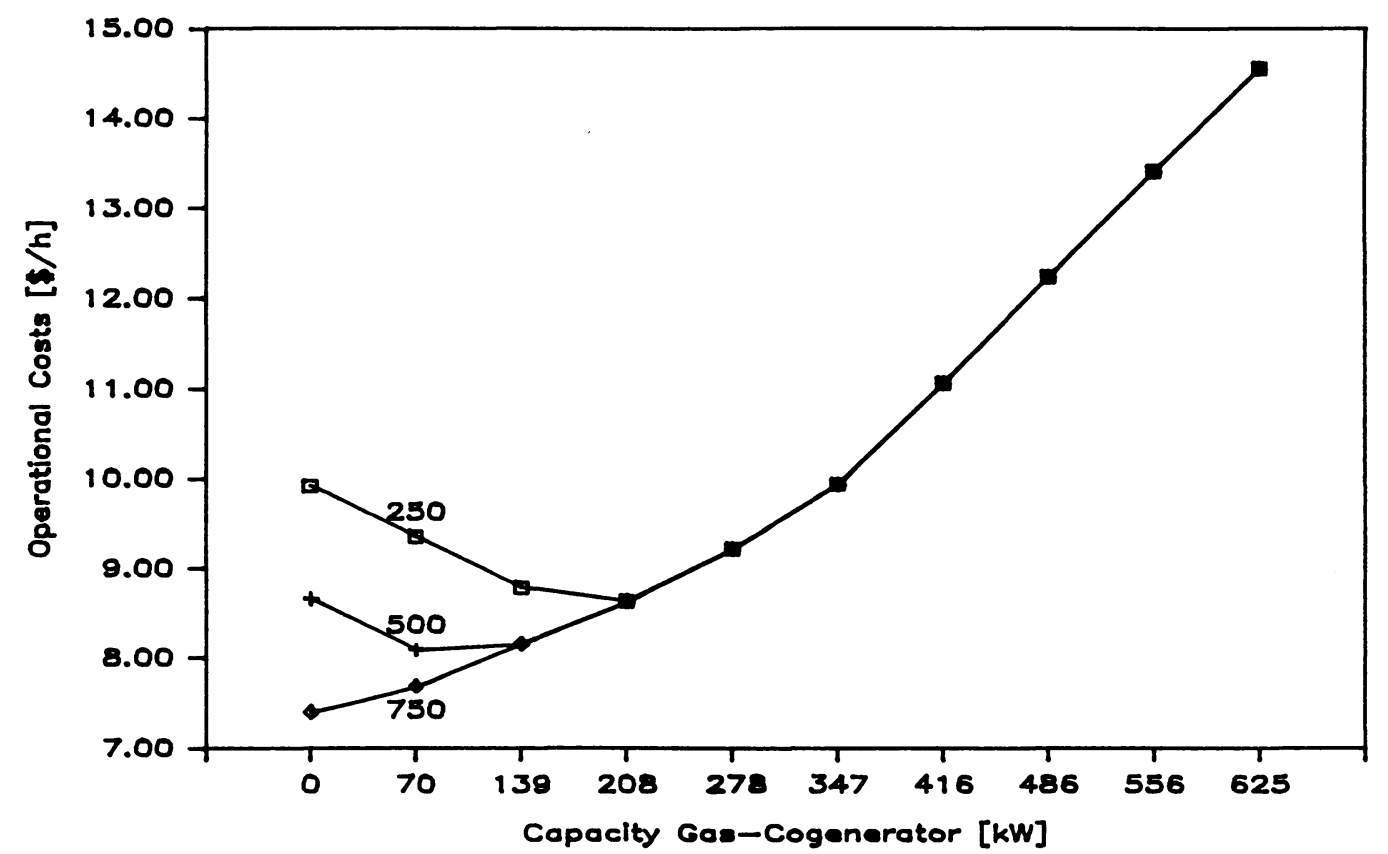

Figure 5.18 Average total operational costs of Solar Mode as function of cogenerator capacity and collector area for Cape Hatteras $\left(60^{\circ} \mathrm{C}\right.$ regeneration temperature)

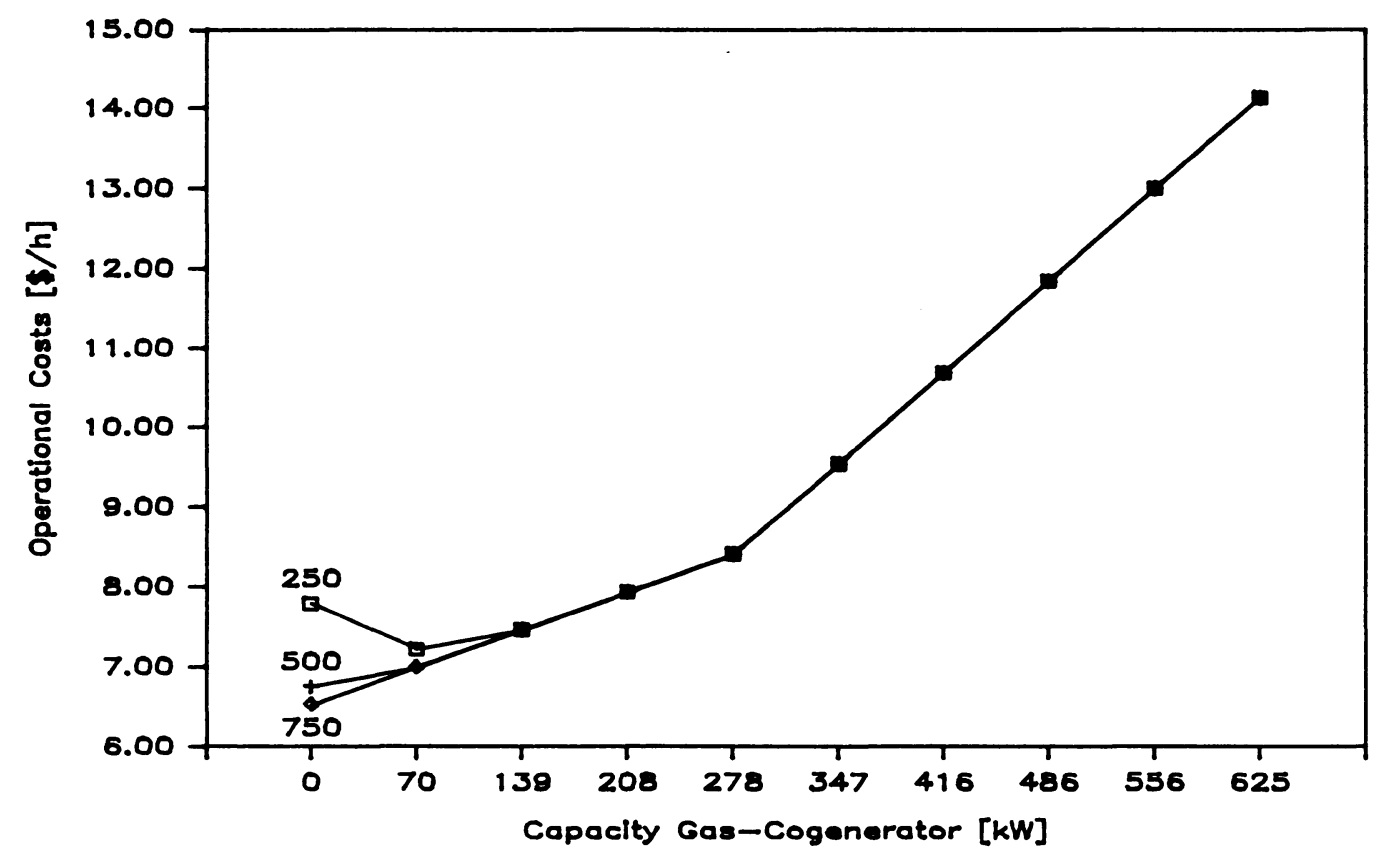

Figure 5.19 Average total operational costs of Solar Mode as function of cogenerator capacity and collector area for Sterling $\left(60^{\circ} \mathrm{C}\right.$ regeneration temperature) 


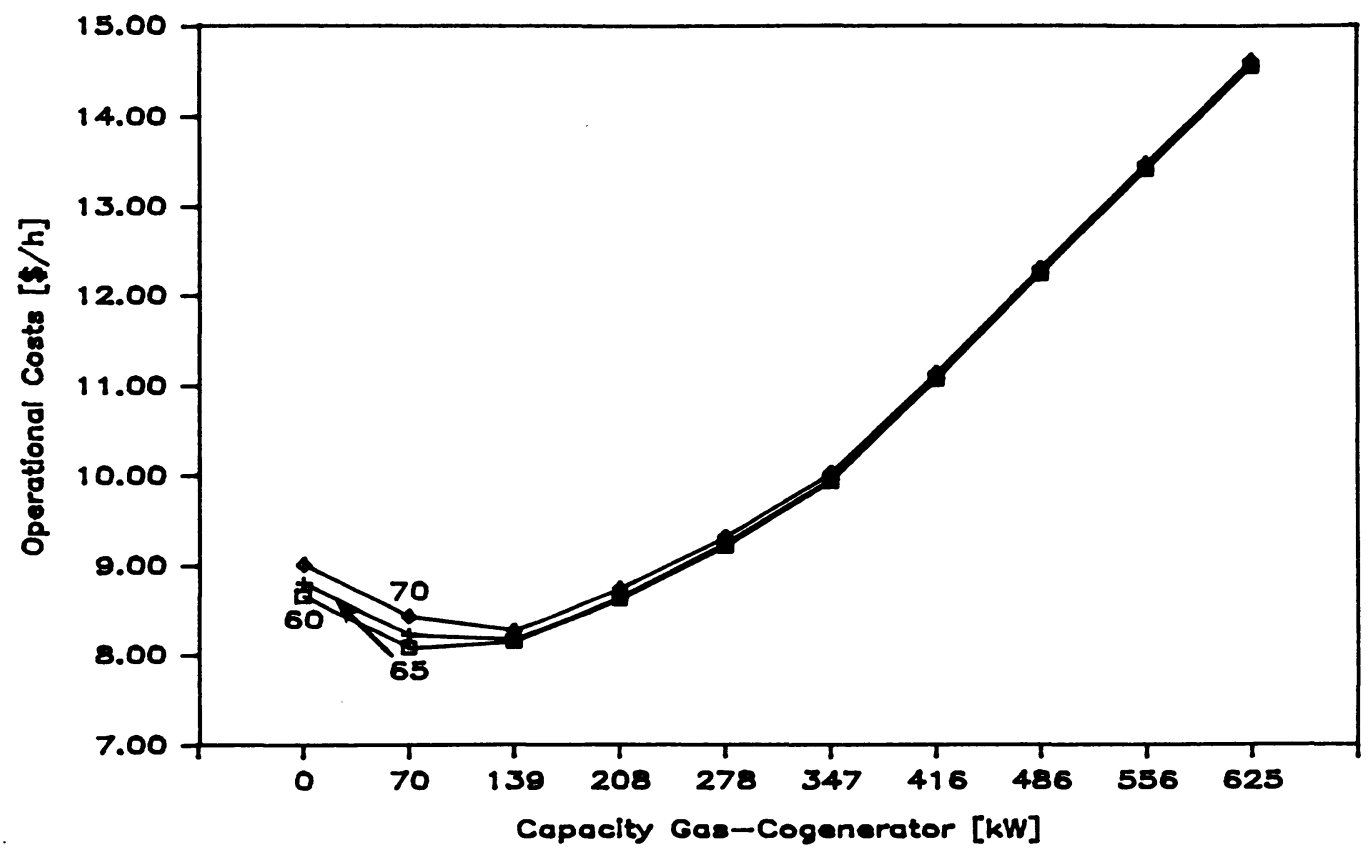

Figure 5.20 Average total operational costs of Solar Mode as function of cogenerator capacity and regeneration temperature for Cape Hatteras $\left(500 \mathrm{~m}^{2}\right.$ collector area)

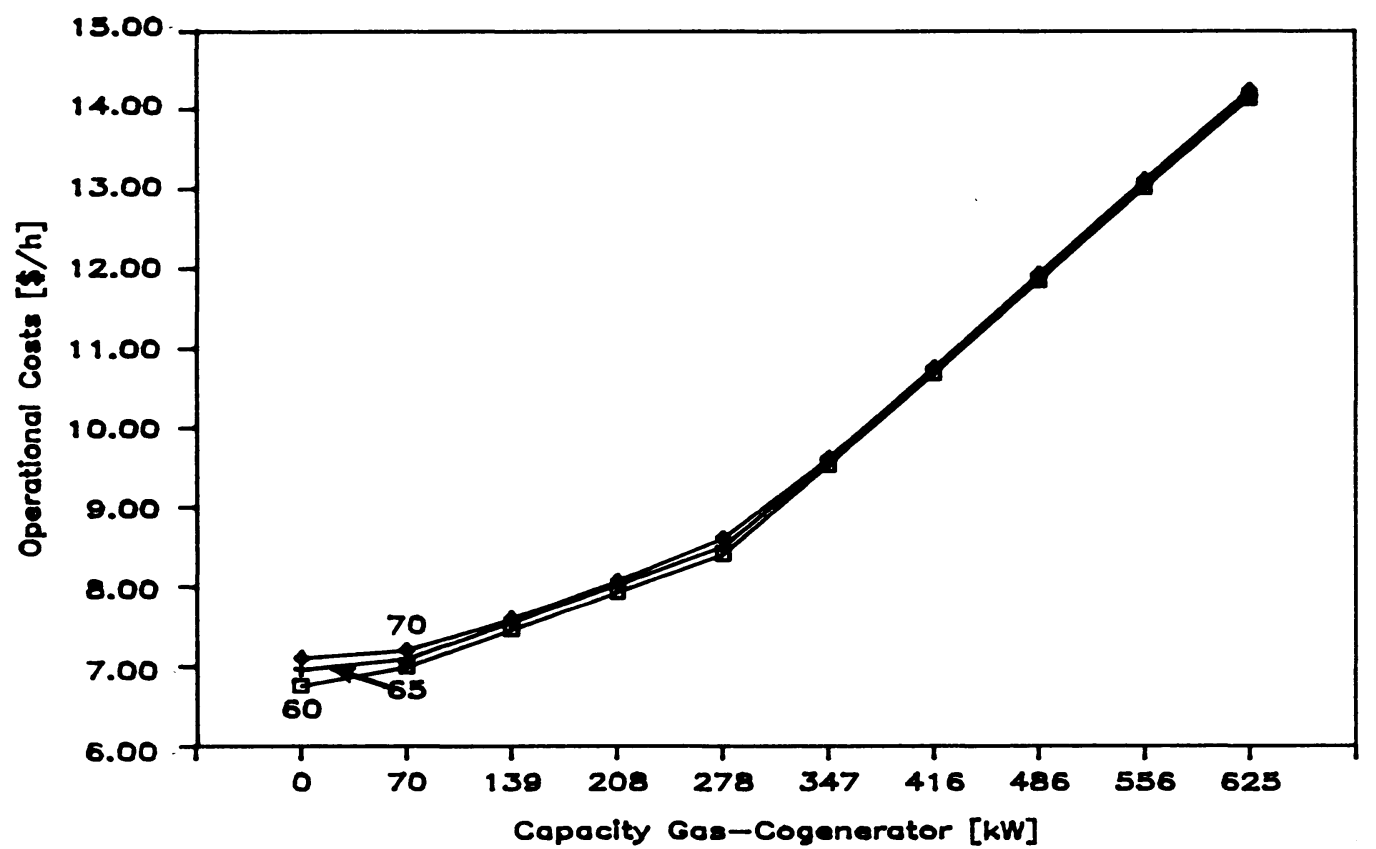

Figure 5.21 Average total operational costs of Solar Mode as function of cogenerator capacity and regeneration temperature for Sterling (500 $\mathrm{m}^{2}$ collector area) 
Table 5.1. Solar System Parameters

Parameter

Total collector area

Ground reflectance

Collector slope

Test flow rate ${ }^{1}$
Symbol Value

A $\quad 250 \mathrm{~m}^{2}, 500 \mathrm{~m}^{2}, 750 \mathrm{~m}^{2}$

$\rho \quad 0.2$

B $\quad 35^{\circ}$

$G_{\text {test }} \quad 20 \mathrm{~kg} / \mathrm{h}-\mathrm{m}^{2}$

$F_{R}(\tau \alpha)_{n} \quad 0.8$

$\mathrm{F}_{\mathrm{R}} \mathrm{U}_{\mathrm{L}} \quad 17 \mathrm{~kJ} / \mathrm{h}-\mathrm{K}-\mathrm{m}^{2}$

Incidence angle modifier coefficient $b_{0} \quad 0.1$

Tank volume

V $19 \mathrm{~m}^{3}$

Tank loss coefficient

$u_{t} \quad 1.7 \mathrm{~kJ} / \mathrm{h}-\mathrm{k}-\mathrm{m}^{2}$

Tank height

h $\quad 2.5 \mathrm{~m}$

Number of nodes in tank

\section{3}

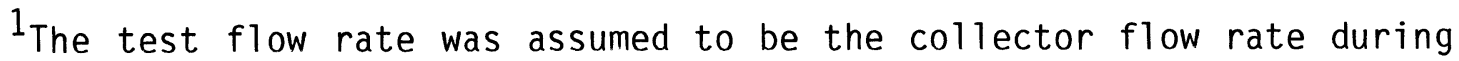
all Solar Mode simulations

non-zero cogenerator capacity. This minimum is located where a boiler contribution to the heat load is no more necessary and the cogenerator is not yet producing excess heat. Large cogenerators that produce enough heat to meet the heating load themselves make collectors unnecessary and are therefore of no interest for the Solar Mode. Figures 5.20 and 5.21 show the total operation costs with the regene- 
ration temperature as a parameter for a collector area of $500 \mathrm{~m}^{2}$. The costs increase with increasing set temperature. This can be explained with the Hottel-Whillier equation for the actual useful energy gain, $Q_{u s e}$, in flat-plate collectors [14]:

$$
Q_{\text {use }}=A F_{R}\left[S-U_{L}\left(T_{\text {inlet }}-T_{\text {amb }}\right)\right] \text {, }
$$

where $S$ is the absorbed solar energy per unit collector area and the second term in the brackets is the loss term. Tinlet is the fluid temperature at the collector inlet and will rise with an increasing tank temperature due to a higher regeneration set temperature. Therefore, the loss term in the Hottel-Whillier equation increases, resulting in a lower solar energy gain.

Energy demands and costs for both locations are shown in Figures 5.22 through 5.25 for a collector area of $500 \mathrm{~m}^{2}$ and $60^{\circ} \mathrm{C}$ regeneration temperature. For Sterling conditions, this area is almost enough to supply the whole regeneration heat, while for Cape Hatteras additional heat is needed. As in the Heat Pump Mode, in can be concluded from the graphs that a higher electricity price will increase the tendency to form an optimum non-zero cogenerator capacity.

\subsubsection{Conventional Mode}

In order to evaluate the performance of the different operation modes, an estimate was made of the seasonal average hourly costs of 


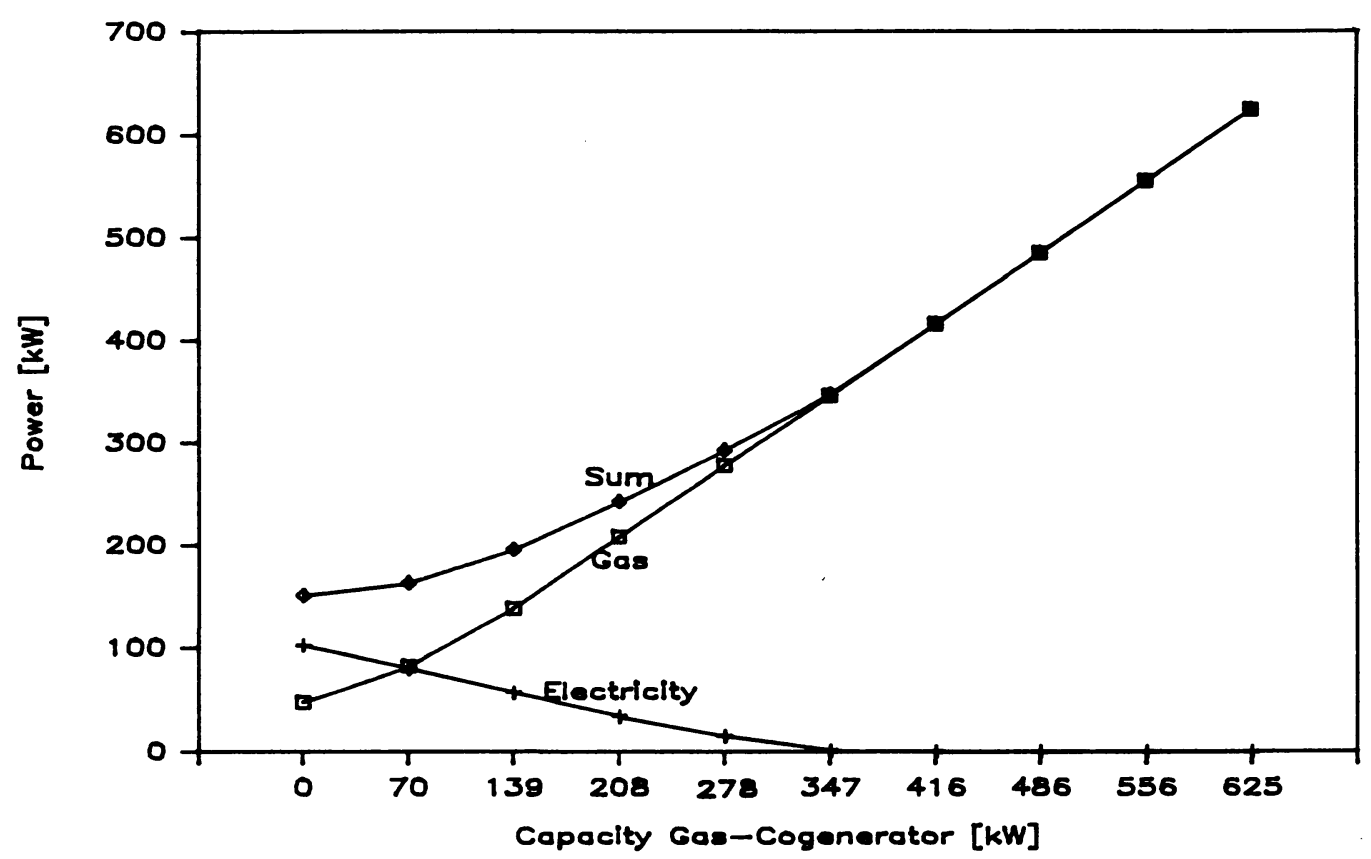

Figure 5.22 Gas, electricity, and total gnergy consumption of Solar Mode for Cape Hatteras (500 $\mathrm{m}^{2}$ collector area)

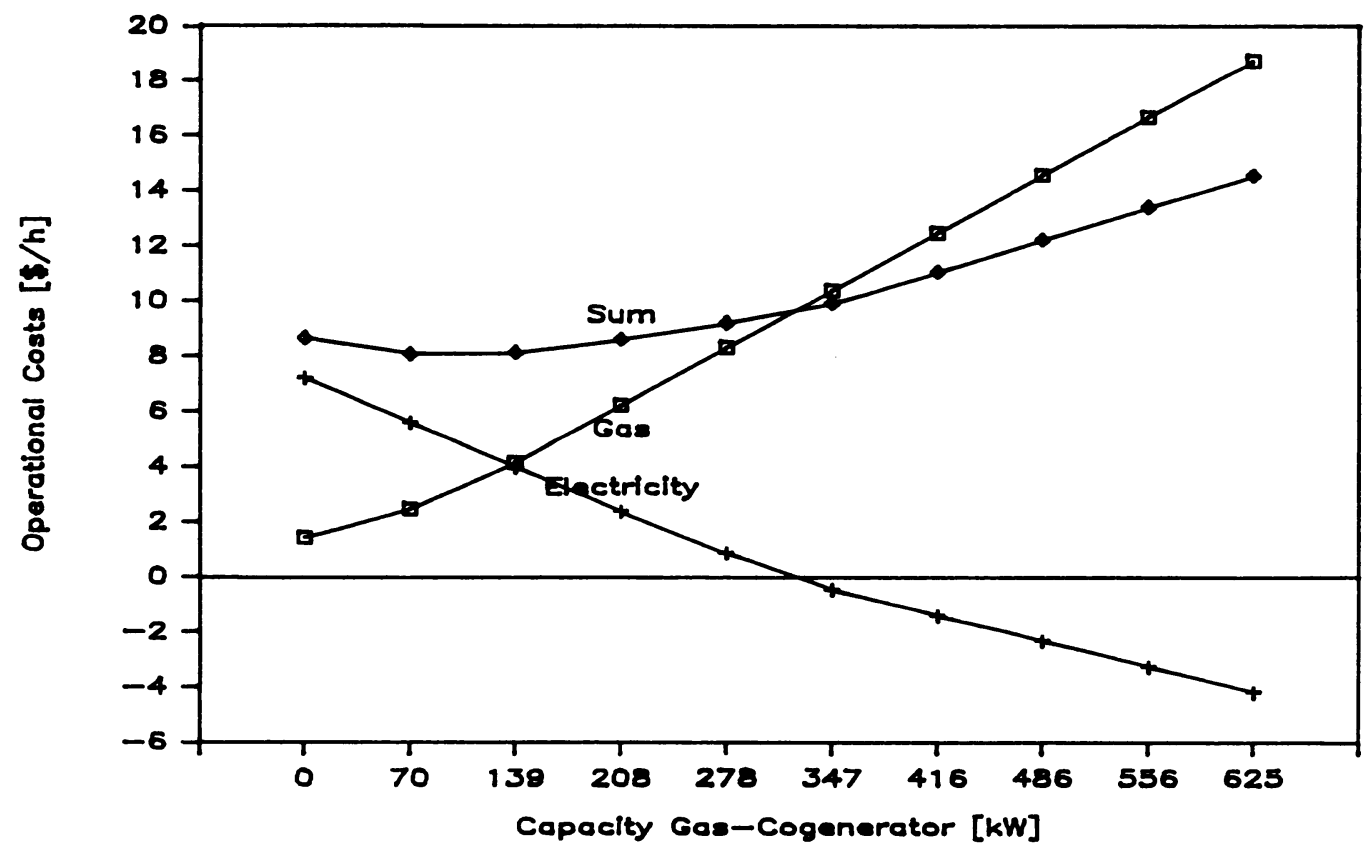

Figure 5.23 Gas, electricity, and total operational costs of Solar Mode for Cape Hatteras (500 $\mathrm{m}^{2}$ collector area) 


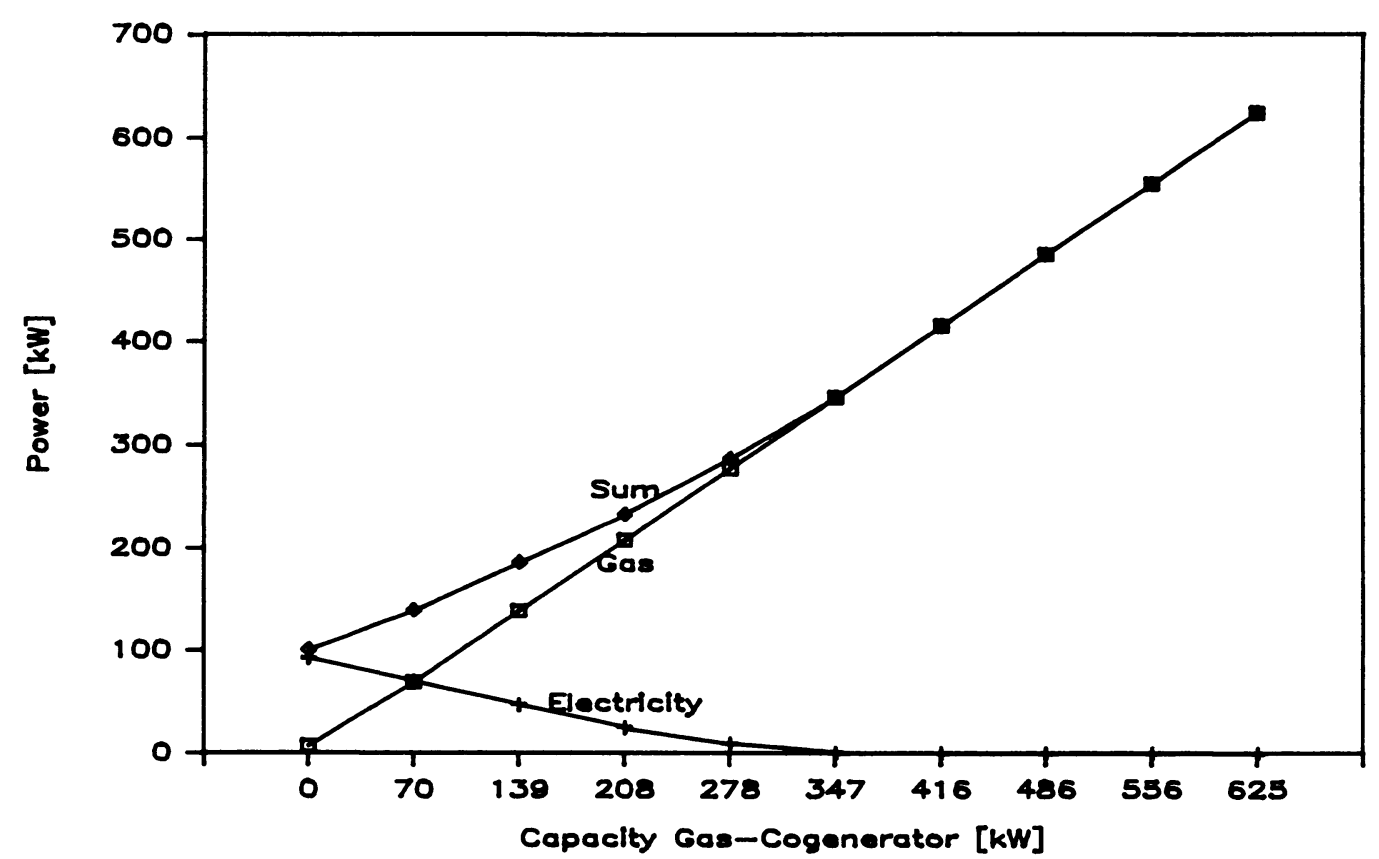

Figure 5.24 Gas, electricity, and tgtal energy consumption of Solar Mode for Sterling (500 $\mathrm{m}^{2}$ collector area)

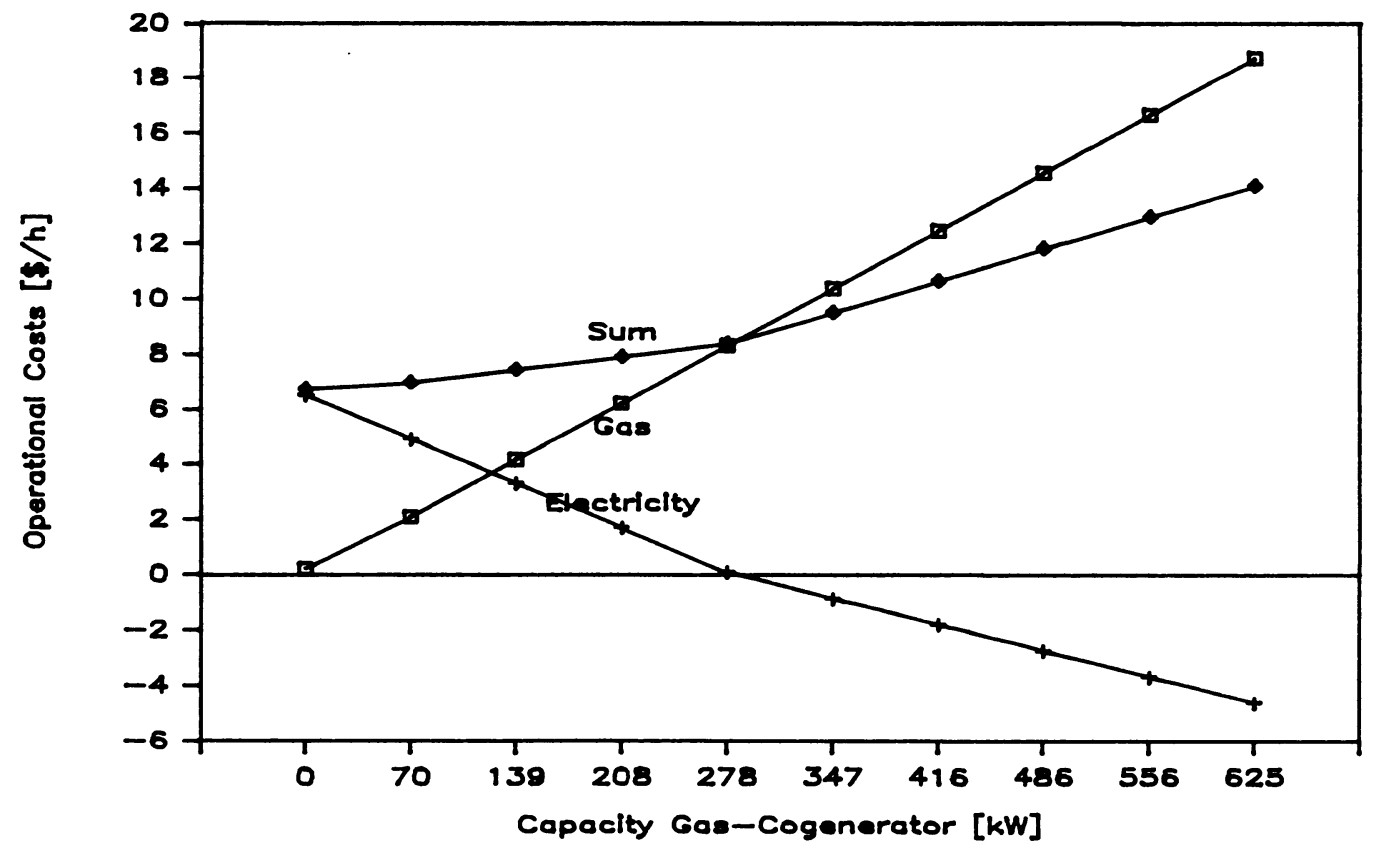

Figure 5.25 Gas, electricity, and total operational costs of Solar Mode for Sterling (500 $\mathrm{m}^{2}$ collector area) 
operation of a conventional cooling system consisting of a chiller and a cooling tower. Based on the TRNSYS chiller model used in the Chiller Mode, a constant coefficient of performance (COP) of 4.16 was assumed. Two cases were investigated:

a) An air stream of $3.4 \mathrm{~kg} / \mathrm{s}$ is dehumidified to an average humidity ratio of $0.067 \mathrm{~kg} / \mathrm{kg}$. For that purpose the air must be cooled down to $8.0^{\circ} \mathrm{C}$. It is then mixed with building return air and thereby reheated at no extra cost. This scenario compares directly to the LD simulation.

b) A total air stream of $11.2 \mathrm{~kg} / \mathrm{s}$ is dehumidified to a humidity ratio $0.095 \mathrm{~kg} / \mathrm{kg}$ which requires cooling of the air to $13.3^{\circ} \mathrm{C}$. It is assumed that reheat is available at no extra cost, supplied, for instance, by the chiller condenser. These assumptions simulate the way conventional commercial systems are often run.

Table 5.2 contains the simulation results for Cape Hatteras and Sterling conditions and electricity prices of $0.07 \$ / \mathrm{kWh}$ and $0.09 \$ / \mathrm{kWh}$.

\subsubsection{Summary}

The seasonal performance of the described LD system is dependent on the cooling load, the electricity to gas price ratio, and the available equipment. A properly-sized cogenerator can often but not always lower the costs of operation significantly. An example is the Solar Mode with collector areas that cannot supply all of the required heat. For cases, however, when the loads are relatively small 
Table 5.2. Estimation of the Operational Costs of 2 Conventional Cooling Systems

\begin{tabular}{|c|c|c|c|c|c|c|}
\hline Case & $\begin{array}{c}\text { Electr. } \\
\text { Rate } \\
\$ / \mathrm{kWh} \\
\end{array}$ & $\begin{array}{c}W_{4} \\
\mathrm{~kg} / \mathrm{s} \\
\end{array}$ & $\begin{array}{l}\mathrm{T}_{5} \\
{ }^{\circ} \mathrm{C} \\
\end{array}$ & $\begin{array}{r}\mathrm{H}_{5} \\
\mathrm{~kg} / \mathrm{kg} \\
\end{array}$ & $\begin{array}{c}\text { Costs } \\
\text { Cape H. } \\
\$ / h \\
\end{array}$ & $\begin{array}{c}\text { Costs } \\
\text { Sterling } \\
\$ / h \\
\end{array}$ \\
\hline$a$ & 0.07 & 3.4 & 8.0 & 0.067 & 7.97 & 7.50 \\
\hline b & & 11.2 & 13.3 & 0.095 & 9.73 & 8.50 \\
\hline$a$ & 0.09 & 3.4 & 8.0 & 0.067 & 10.25 & 9.65 \\
\hline$b$ & & 11.2 & 13.3 & 0.095 & 12.51 & 10.93 \\
\hline
\end{tabular}

and electricity is inexpensive, it is often cheaper not to run a gascogenerator.

The least efficient and most costly way of operation is the Chiller Mode. The use of a heat pump improves the system economics considerably by lowering the operational costs by 1 to $2 \$ / h$ compared to the Chiller Mode, depending on the load. The lowest operational costs can be obtained using solar energy. Large collector areas lower the operational costs of the system at the expense of a higher initial investment. A smaller collector area may still result in reasonable operation costs if a properly sized cogenerator is used. The sensitivity of operational costs on cogenerator capacity is stronger in the Solar Mode than in Chiller or Heat Pump Mode. 
Figure 5.1 shows that the total energy input to the LD component is about 2.5 times higher than the delivered cooling energy. That explains why the performance of the chosen configuration is generally no better than that of a conventional cooling system. The advantage of a LD system is that part of the energy input is heating rather than cooling energy. Heat is often available at low or even no extra cost. Consequently the Heat Pump and the Solar Mode show significantly better performances than the Chiller Mode and they may, if well-designed, be even less expensive to operate than a conventional system. Figures 5.26 and 5.27 summarize these results. As stated in the previous section, the Conventional Mode "a" compares best to the LD simulation. 


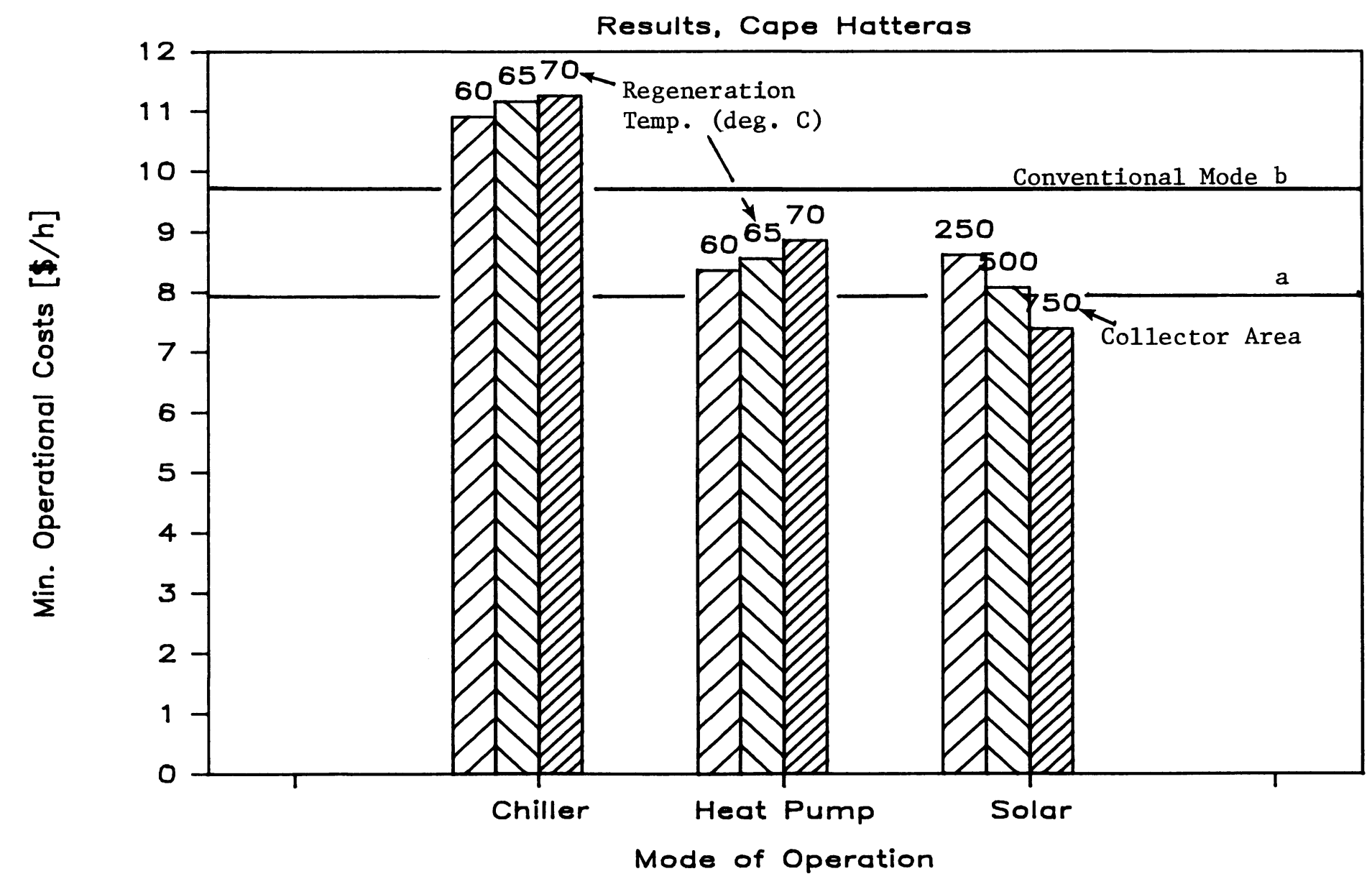

Figure 5.26 Minimum operational costs for Chiller, Heat Pump, and Solar Mode compared to 2 cost estimations for conventional cooling (Cape Hatteras) 


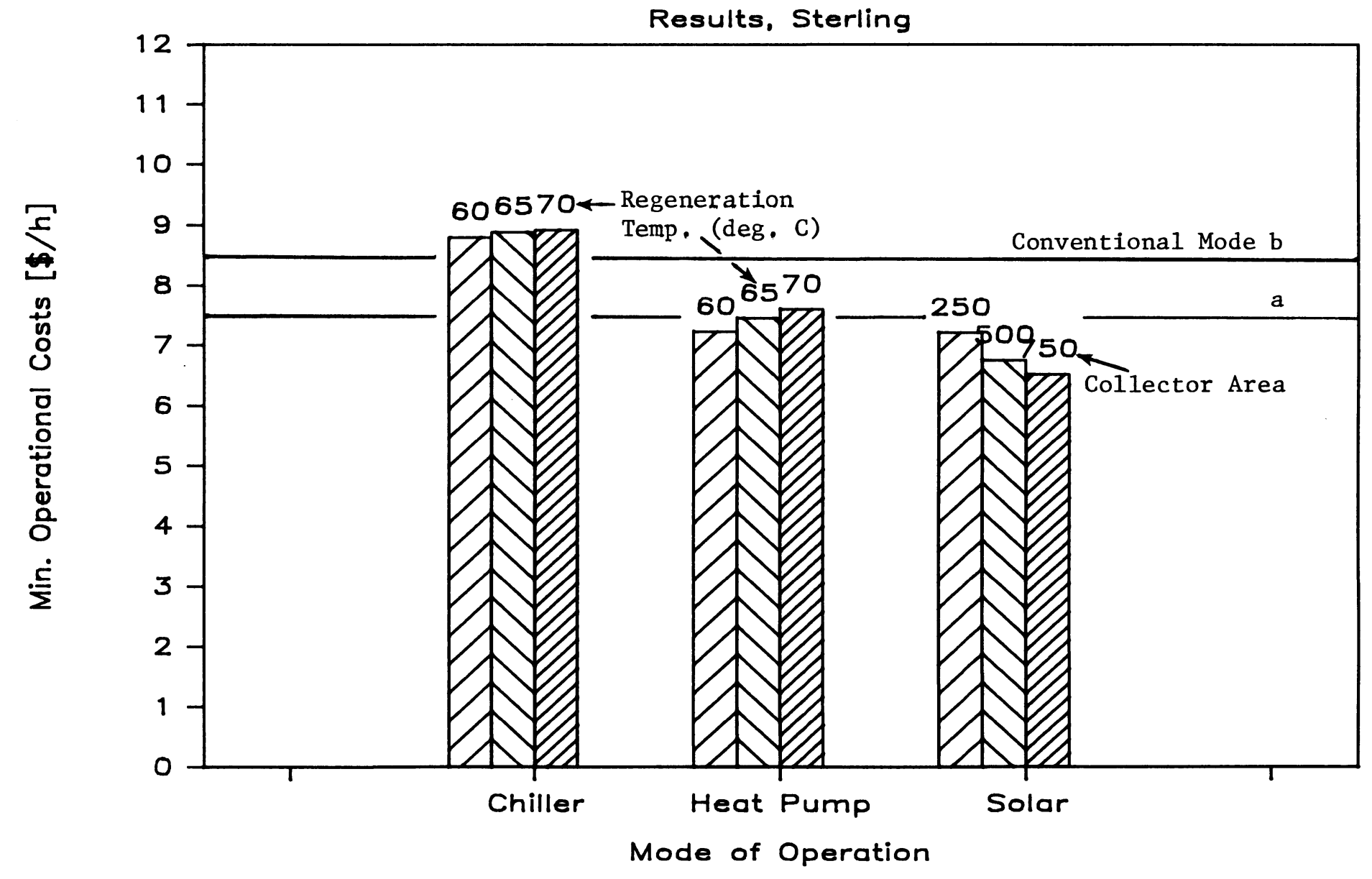

Figure 5.27 Minimum operational costs for Chiller, Heat Pump, and Solar Mode compared to 2 cost estimations for conventional cooling (Sterling) 


\section{CHAPTER 6: Conclusions and Recommendations}

This study has presented the modeling of a liquid desiccant cooling component and the simulation of several hybrid liquid desiccant air conditioning systems using the LD component model. The major results and conclusions of the study can be summarized in three parts. The first concerns model development and solution methods for the resulting equations. The second describes specific results obtained for systems like that at the Science Museum in Virginia (SMVA). The third concerns suggestions for further study, based on the results for a specific system.

1. As described in Chapter 2, the LD component model forms a system of 19 partly nonlinear algebraic equations with 19 unknowns and two differential equations. These equations must be solved during each timestep (typically 5 minutes) throughout the entire simulation period. It is thus essential to solve the system in a computationally efficient manner.

It was advantageous to partition and precedence order the system equations using the algorithm of Sargent and Westerberg $[7,8]$. The algorithm presents a fast and secure way to separate systems of linear and nonlinear algebraic equations into partitions that can be solved independently. This procedure is especially useful for large and complex systems of equations and it is of general utility. The fact that the partitions represent inseparable parts of the physical system ensures a most simple resulting solving procedure. In gene- 
ral, differential equations could be involved as well, if they have an analytical solution. In the presented case, for instance, the two differential LD component sump equations could have been combined with the algebraic system equations forming a $21 \times 21$ system. For the modeling of more complex systems, it might be worthwhile to include numerical solutions of differential equations in the algorithm, if there is a large number of differential equations or if they cannot be decoupled from the remaining equations.

2. A particular hybrid LD system was investigated for several operation modes and two locations with both different total cooling loads and different proportions of latent and sensible cooling. Average hourly operational costs were determined in order to take into account the different quality of the required energies. Although these costs represent a specific system, they allow general comparisons of different operation modes. The following conclusions can be drawn from the simulation results presented in Chapter 5:

a) The required total energy input into an air conditioning system cannot be decreased using a LD configuration as installed at the SMVA. The operating cost of such a LD system is nearly as high or higher than that of a conventional chiller system for electricity to gas price ratios of $7: 3$ and less. The larger this price ratio, the greater is the probability that the LD system is operating at lower costs than conventional systems. For example, if the electricity rate changes from $0.07 \$ / \mathrm{kWh}$ to $0.09 \$ / \mathrm{kWh}$ in the Heat Pump Mode for Cape Hatteras conditions, the minimum operational costs 
increase from $8.37 \$ / \mathrm{h}$ to $10.10 \$ / \mathrm{h}$, while the costs for a conventional cooling system increase from $7.97 \$ / \mathrm{h}$ to $10.25 \$ / \mathrm{h}$.

b) The energy inputs into a LD system consist not only of cooling energy, but also of heat, plus increased parasitic electricity demands. The potential for hybrid LD systems lies in the inexpensive supply of regeneration heat. Therefore, LD systems should be considered in applications where low temperature (less than $100^{\circ} \mathrm{C}$ ) waste heat is available. The significantly lower operating costs for the Heat Pump and the Solar Mode confirm this recommendation.

The installation of liquid desiccant air conditioning systems should be considered only for applications with a high latent load. The complexity involved in a LD system is due to efforts made for reducing the costs of the latent load.

For both the Heat Pump and especially the Solar Mode, a thorough economic analysis should be conducted before an installation decision is made. This analysis should include the initial investment and the price ratio for electricity to gas. Both the considered operation mode and a feasible conventional air conditioning system have to be investigated.

c) The Chiller Mode is an unsuitable way of operation. Its minimum average hourly costs are higher than even those of inefficiently run conventional cooling systems. The supply of the required energy demands completely from purchased sources without use of "free" heat is the reason for the poor performance. The improved thermodynamic process is negated by these additional energy needs. 
d) The Heat Pump Mode can be comparable to conventional cooling systems in the cost of operation, because regeneration heat and part of the cooling energy is supplied efficiently. For the conditions investigated in this study, the cost ratio of the optimum Heat Pump Mode to the comparable Conventional Mode is 0.97 for Sterling and 1.05 for Cape Hatteras.

e) If first costs are not considered, lower operational costs are obtained by the Solar Mode, where flat-plate collectors contribute to the regeneration heat. Sti11, the estimated operational costs are close to those of a conventional system. The cost ratio of the Solar Mode to the Conventional Mode for $500 \mathrm{~m}^{2}$ collector area is in this study 0.90 for Sterling and 1.02 for Cape Hatteras conditions.

f) The optimum cogenerator capacity is dependent on economic as well as load parameters. A high electricity to gas price ratio and high latent loads (compared to the sensible loads) favor the installation of a cogenerator. The operational costs are quite dependent on the cogenerator size, especially in the Solar Mode. Therefore, the choice of a suitable capacity is crucial.

g) Relatively low regeneration temperatures of $60^{\circ} \mathrm{C}$ or less result in lower operating cost. The explanation for this behavior is that a higher hot water temperature not only improves the regeneration, but also heats the desiccant in the entire system. Consequently, more solution cooling is required to obtain the conditioned air set temperature. To improve the system performance it is desirable 
to lower the temperature difference of the desiccant between regenerator and conditioner cycle.

3. The results obtained in the investigation of a system resembling the SMVA design suggest that other system configurations should be studied. Promising alternatives to the presented configuration are ways of operation comparable to those used in solid desiccant air conditioning systems [16]. A general proposed schematic for a modified LD system is given in Figure 6.1. Such a system would operate as follows:

The LD component overdries the air at a hot water temperature which is optimal for the regeneration. Cooling energy is supplied by the LD component only to maintain the dehumidification process. The set temperature does not have to be reached. The dehumidified and heated air is blown through heat exchangers where it is cooled by outside and/or building return air to a temperature close to the initial air state. Evaporative coolers then cool the air to the desired set point and add an appropriate amount of moisture. It is recommended to conduct an investigation of a LD system configuration as described above.

Hopefully, this study has contributed to the understanding of the performance of hybrid liquid desiccant cooling systems and will encourage further investigation to evaluate the prospects of these systems. 


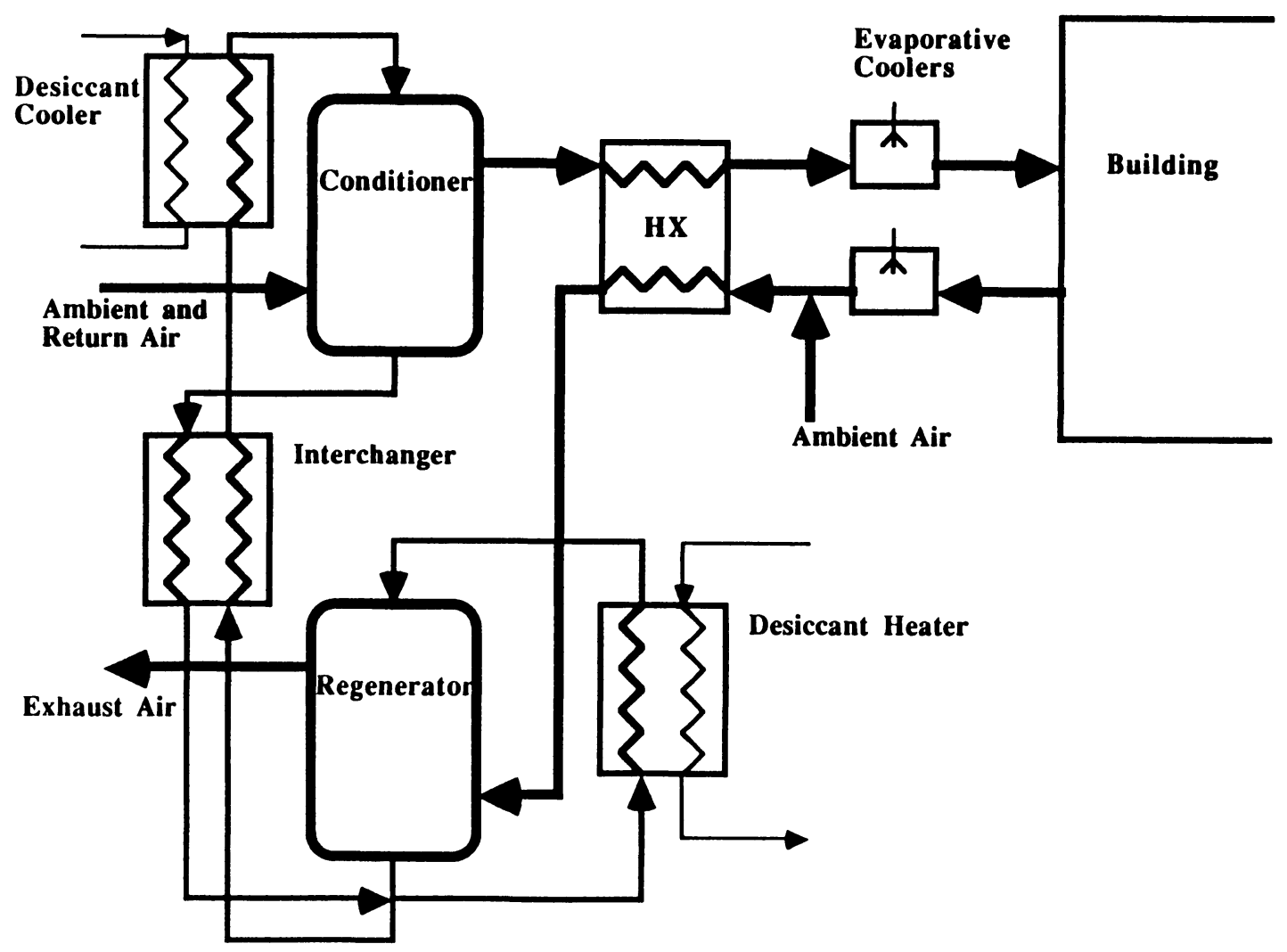

Figure 6.1 Schematic of a modified liquid desiccant cooling system 


\section{APPENDICES}

Appendix A.1 contains the computer code listings for the TRNSYS components TYPE42 and TYPE43. TYPE42 models the liquid desiccant component and TYPE43 provides additional output. 
SUBROUTINE TYPE42 (TIME,XIN,OUT, T,DTDT,PAR, INEO)

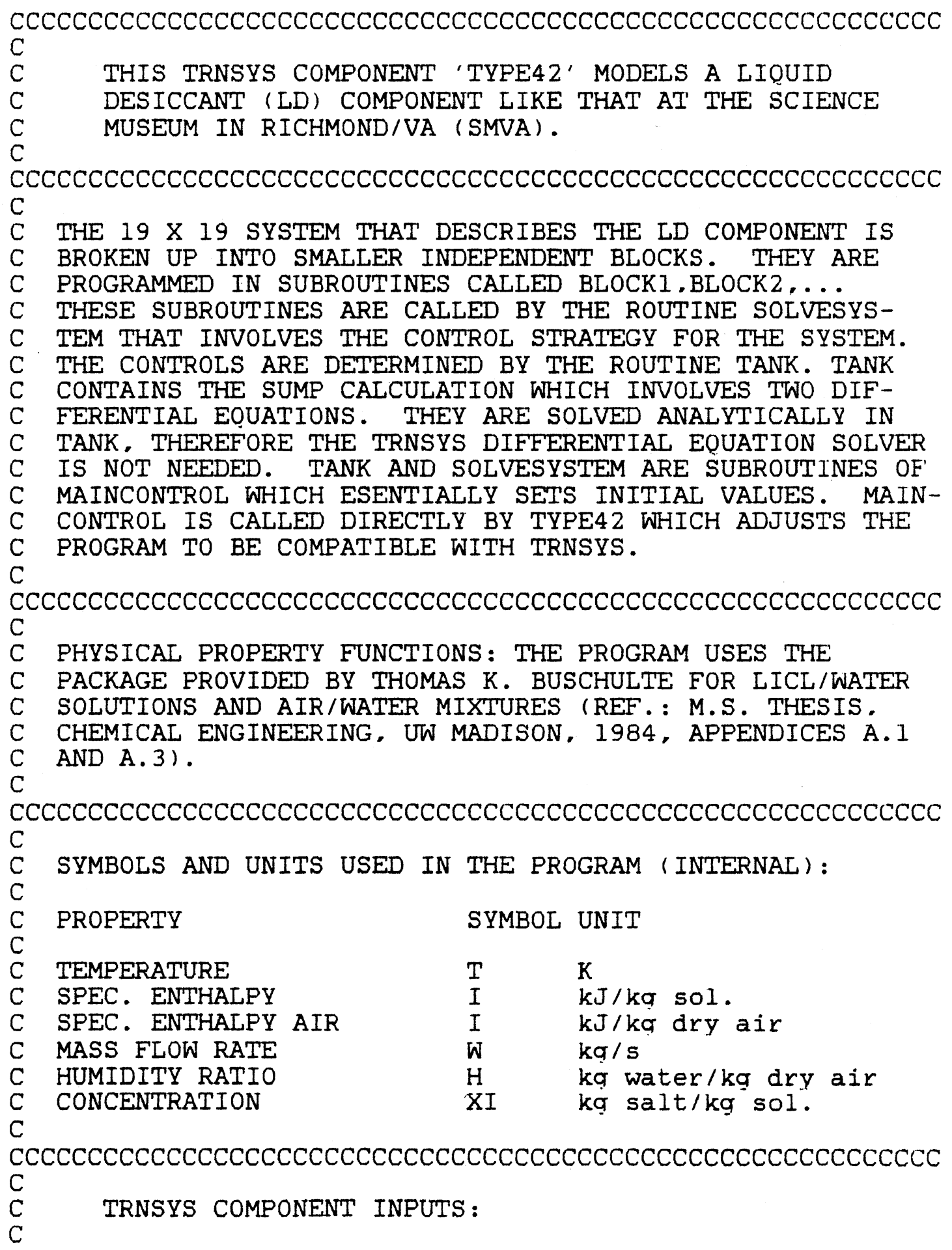




\begin{tabular}{|c|c|c|c|}
\hline 1 & AIR TEMP. IN REG. & $\mathrm{Tl}$ & DEG C \\
\hline 2 & AIR TEMP. IN COND. & T4 & DEG C \\
\hline 3 & AIR TEMP. OUT COND. (SET PT.) & T5 & DEG C \\
\hline 4 & HOT WATER SOURCE TEMP. & T11 & DEG C \\
\hline 5 & COLD WATER SOURCE TEMP. & T13 & DEG C \\
\hline 6 & HUMIDITY AT REG. INLET & $\mathrm{HI}$ & $\mathrm{ka} / \mathrm{ka}$ \\
\hline 7 & HUMIDITY AT COND. INLET & $\mathrm{H} 4$ & $\mathrm{kq} / \mathrm{kq}$ \\
\hline 8 & AIR FLOW RATE THROUGH REG. & WI & $\mathrm{kg} / \mathrm{s}$ \\
\hline 9 & AIR FLOW RATE THROUGH COND. & W4 & $\mathrm{kg} / \mathrm{s}$ \\
\hline 10 & HOT WATER MASS FLOW RATE & W12 & $\mathrm{kq} / \mathrm{s}$ \\
\hline 11 & AMBIENT PRESSURE & PAMB & $\mathrm{Pa}$ \\
\hline PF & \multicolumn{3}{|c|}{ PARAMETERS : } \\
\hline 1 & OVERALL HEAT TR. COEFF, COOLER & UAC & $\mathrm{kW} / \mathrm{K}$ \\
\hline 2 & OVERALL HEAT TR. COEFF. HEATER & $\mathrm{UAH}$ & $\mathrm{kW} / \mathrm{K}$ \\
\hline 3 & OVERALL HEAT TR. COEFF. INTERCH. & UAI & $\mathrm{kW} / \mathrm{K}$ \\
\hline 4 & SPECIFIC HEAT OF WATER & CPW & $\mathrm{kJ} / \mathrm{k} \propto \mathrm{K}$ \\
\hline 5 & KATHABAR CONSTANT CONDITIONER & $\mathrm{KC}$ & $\mathrm{kaK} / \mathrm{kJ}$ \\
\hline 6 & KATHABAR CONSTANT REGENERATOR & $\mathrm{KR}$ & $\mathrm{kqK} / \mathrm{kJ}$ \\
\hline 7 & INITIAL WATER MASS & MWATER & $\mathrm{kg}$ \\
\hline 8 & INITIAL SALT MASS & MSALT & $\mathrm{kg}$ \\
\hline 9 & INITIAL TANK TEMPERATURE & T7I & $\mathrm{K}$ \\
\hline 10 & LOWER BOUND TANK MASS & ML & $\mathrm{ka}$ \\
\hline 11 & UPPER BOUND TANK MASS & MU & $\mathrm{kq}$ \\
\hline 12 & SOLUTION MASS FLOW RATE REG. & พ3 & $\mathrm{kg} / \mathrm{s}$ \\
\hline 13 & SOLUTION MASS FLOW RATE COND. & W6 & $\mathrm{ka} / \mathrm{s}$ \\
\hline 14 & SOL. MASS FLOW RATE REG. $\Rightarrow$ COND. & W15 & $\mathrm{kg} / \mathrm{s}$ \\
\hline 15 & MAX. ERROR FOR ITERATIONS & EPS & $\%$ \\
\hline 16 & UPPER MARGIN FOR COND. CONTROL & PERU & $k a$ \\
\hline 17 & LOWER MARGIN FOR COND. CONTROL & PERL & $k q$ \\
\hline & \multirow{2}{*}{\multicolumn{3}{|c|}{ OUTPUTS : }} \\
\hline & & & \\
\hline 1 & INT. FLAG COND & ICOND & $(I=O N)$ \\
\hline 2 & INT. FLAG REGENERATOR & IREG & $(I=O N)$ \\
\hline 3 & TEMP. AIR OUT REG. & T2 & DEG C \\
\hline 4 & TEMP. SOLUTION REG. IN & T3 & DEG C \\
\hline 5 & TEMP. SOL. COND. IN & T6 & DEG C \\
\hline 6 & TEMP. SOL. SUMP & T7 & DEG C \\
\hline 7 & TEMP. SOL. COOLER IN & T8 & DEG C \\
\hline 8 & TEMP. SOL. SUMP IN & T9 & DEG C \\
\hline 9 & TEMP. WATER HEATER OUT & T12 & DEG C \\
\hline 10 & TEMP. WATER COOLER OUT & T14 & DEG C \\
\hline 11 & TEMP. SOL. INTERCH. OUT $\Rightarrow$ COND. & T15 & DEG C \\
\hline 12 & TEMP. SOL. COND. OUT & T40 & DEG C \\
\hline 13 & TEMP. SOL. REG. OUT & T41 & DEG C \\
\hline 14 & HUMIDITY REG. OUT & $\mathrm{H} 2$ & $\mathrm{kq} / \mathrm{kq}$ \\
\hline 1 & HUMIDITY COND. OUT & H5 & $\mathrm{kq} / \mathrm{kg}$ \\
\hline
\end{tabular}




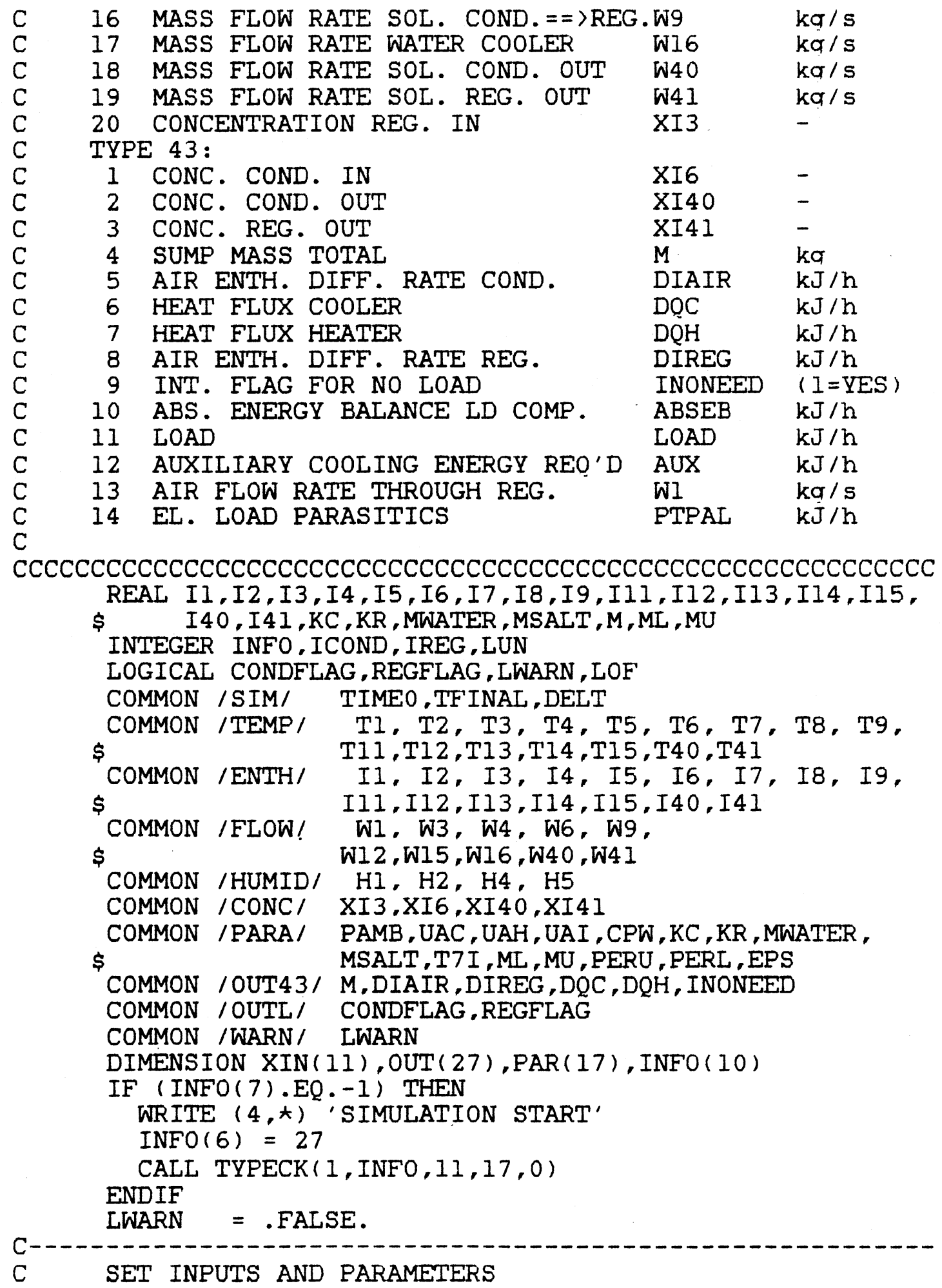




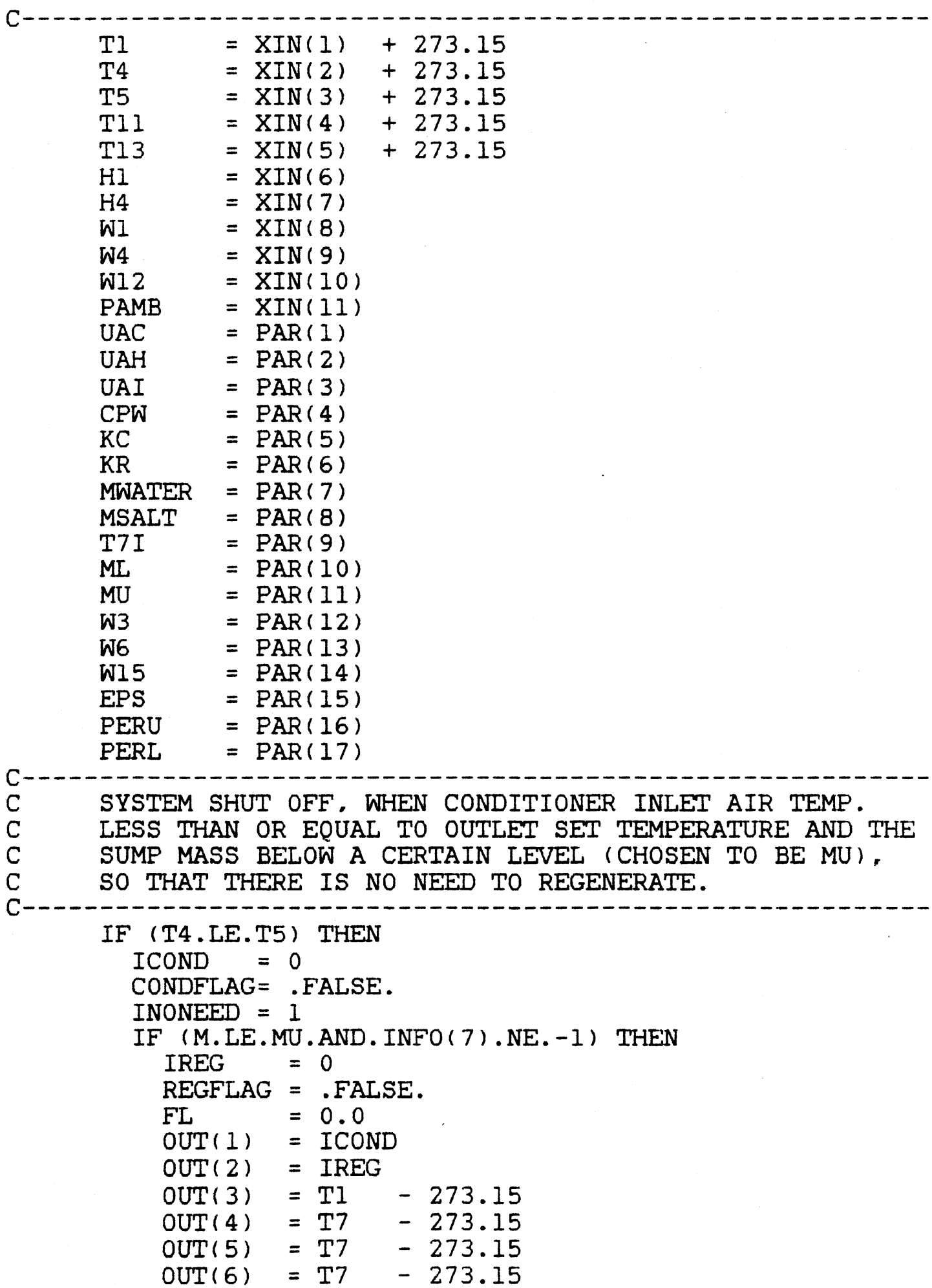



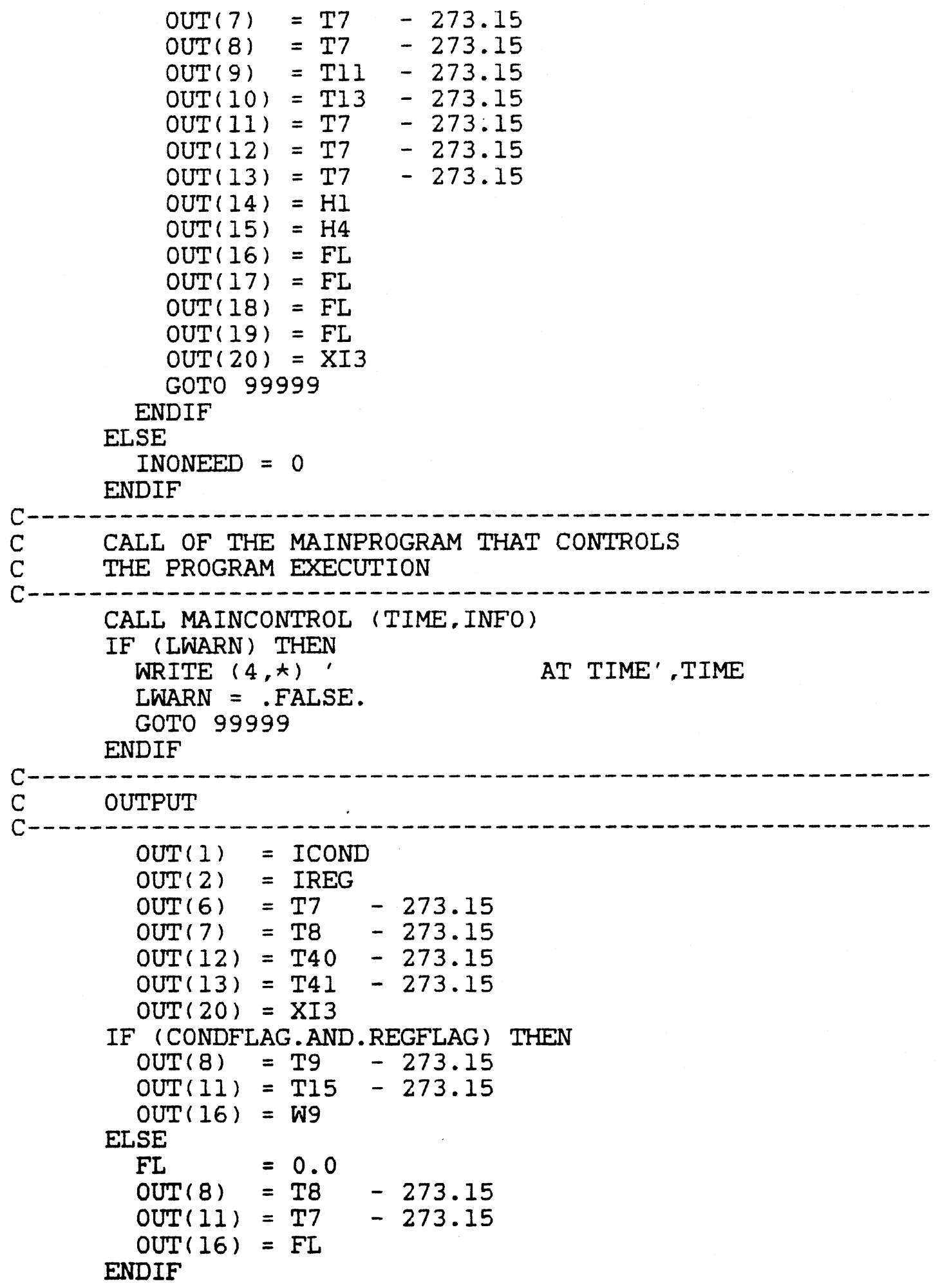


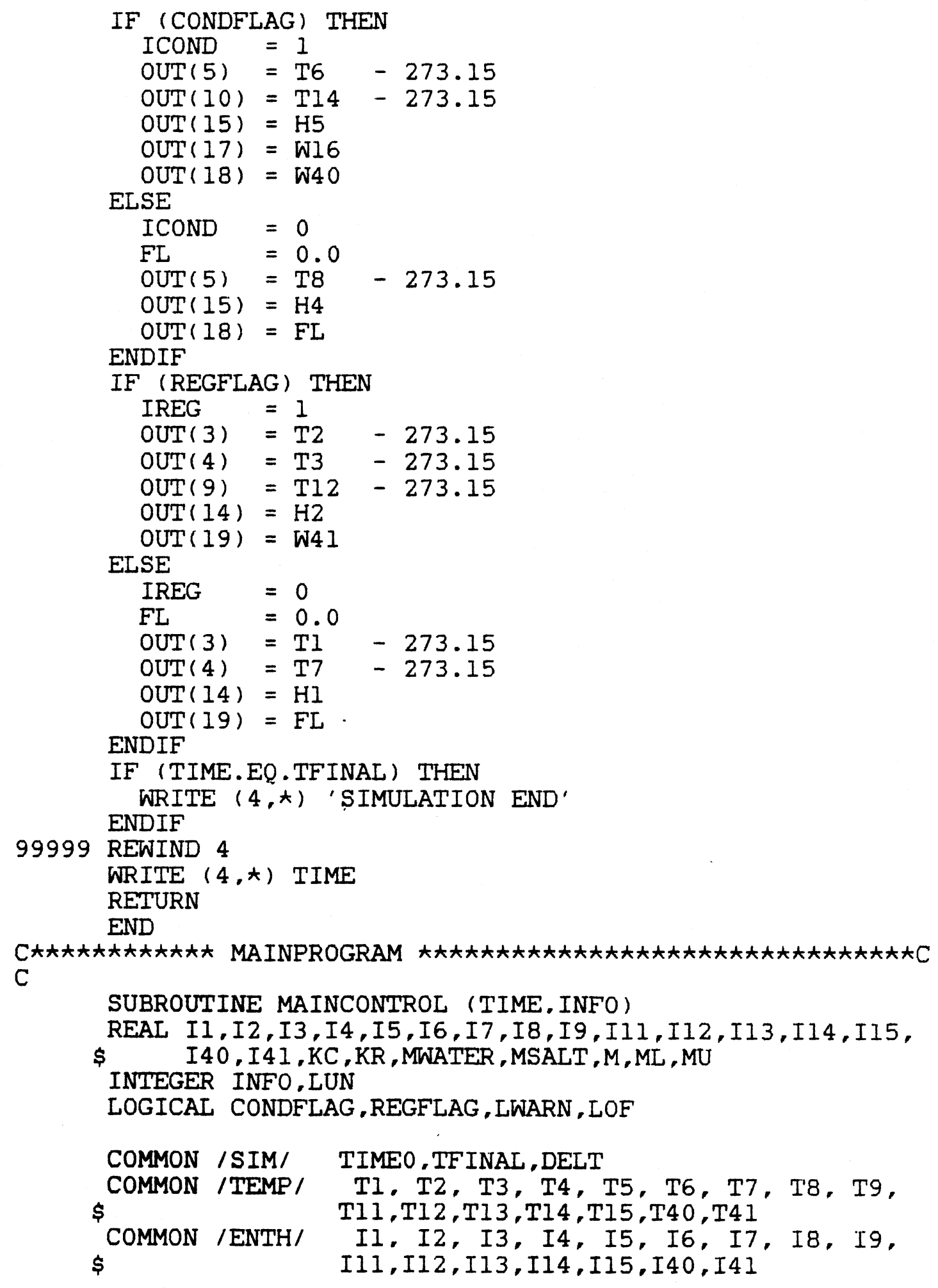




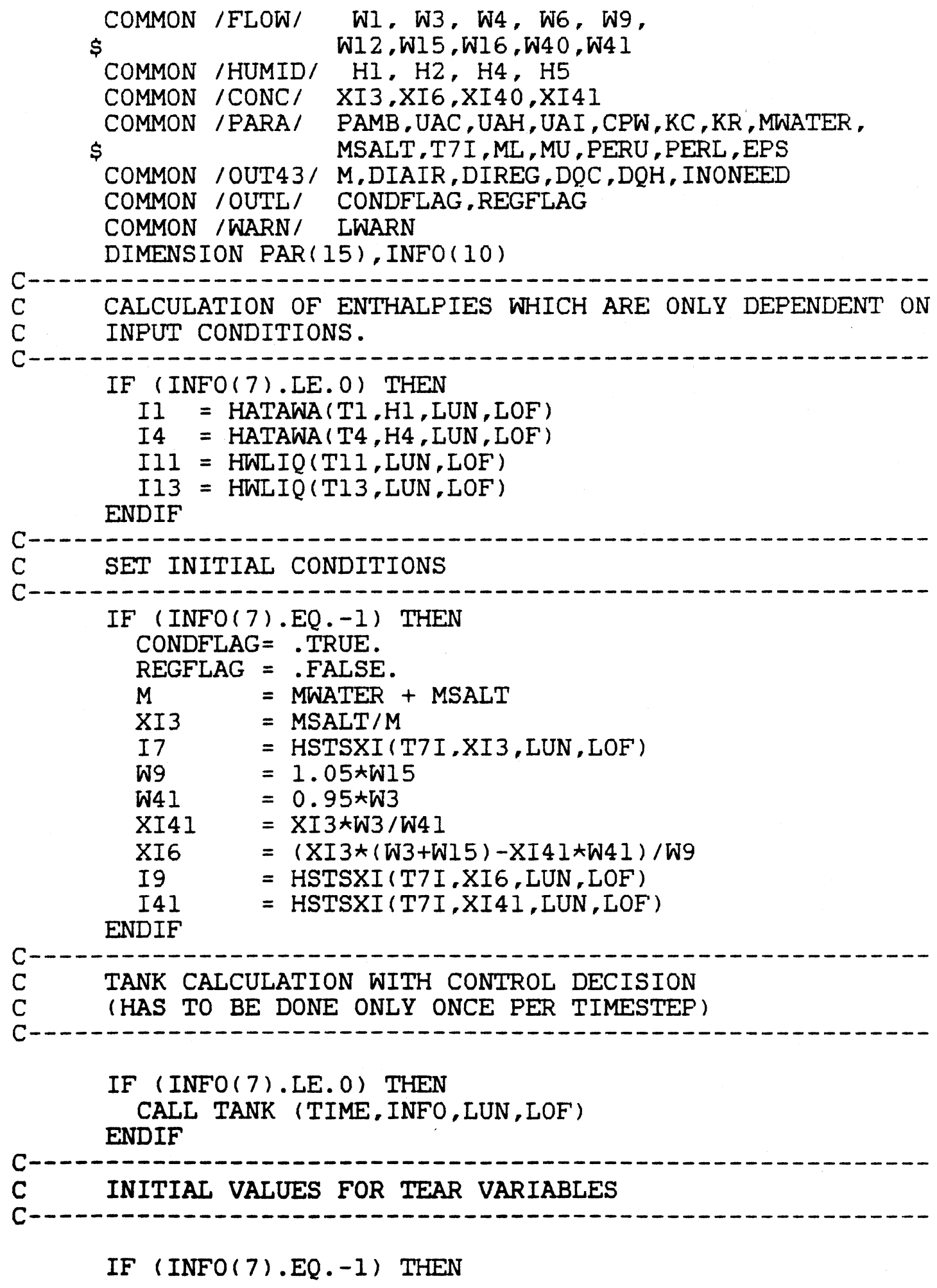




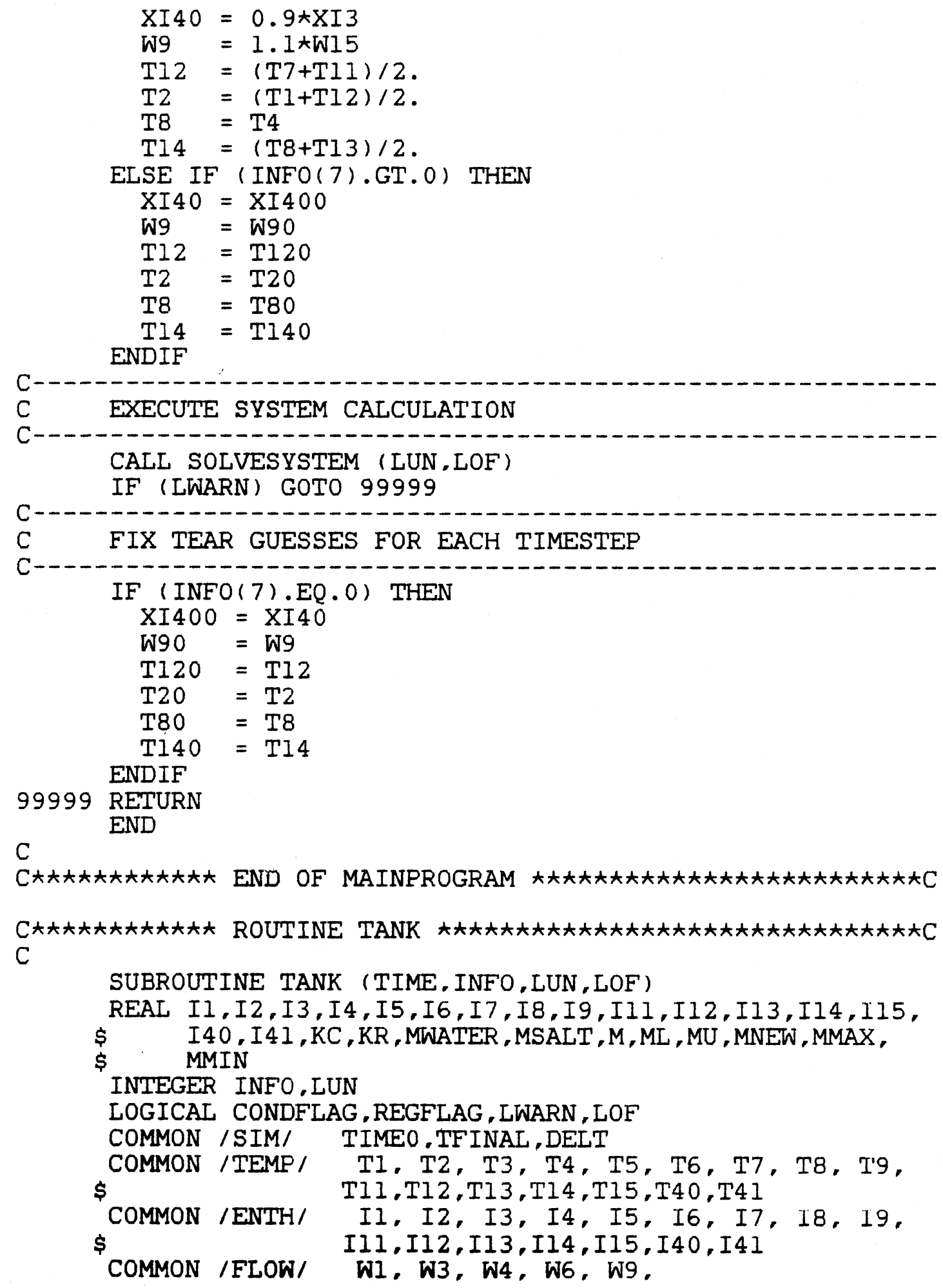




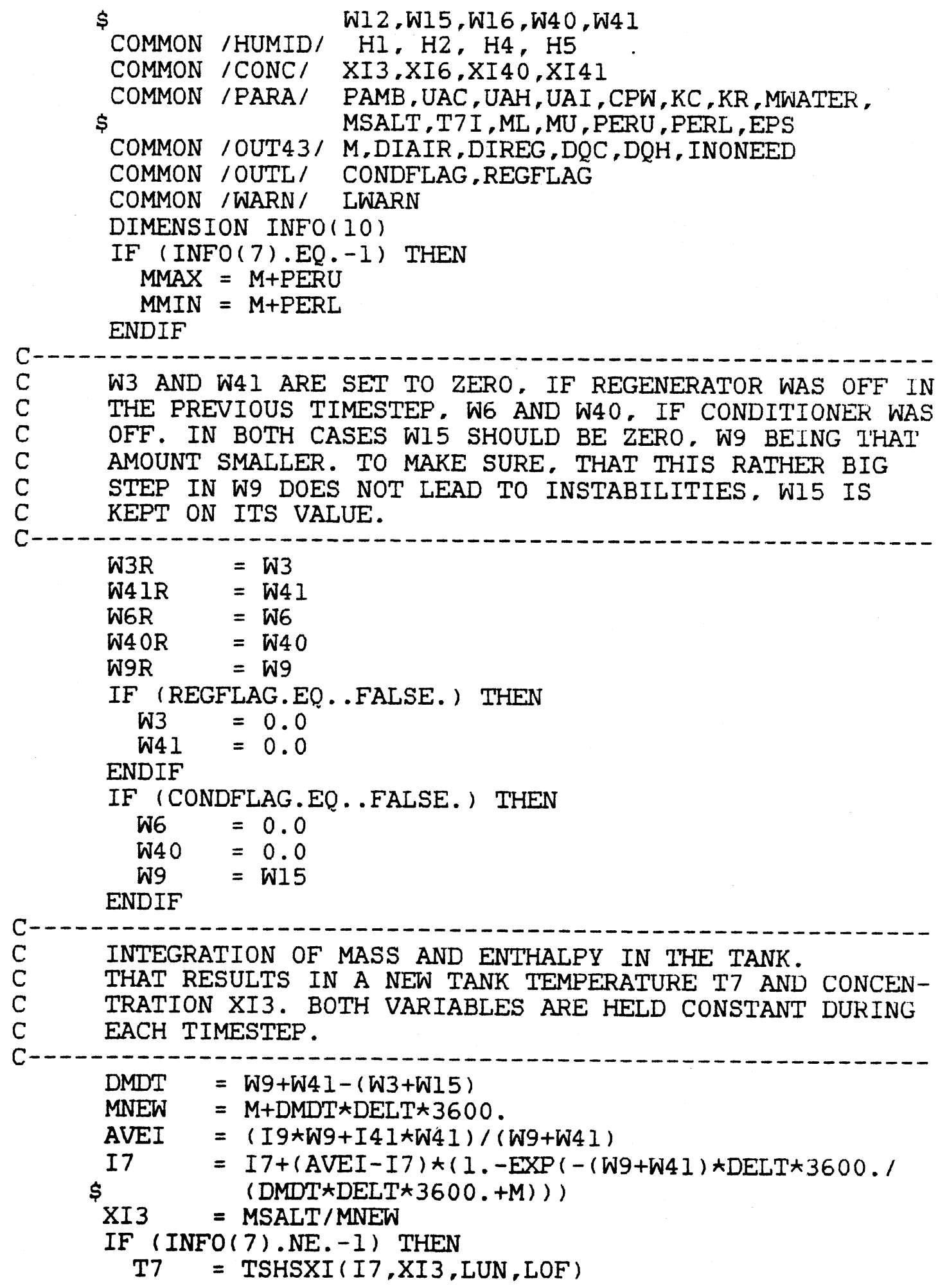




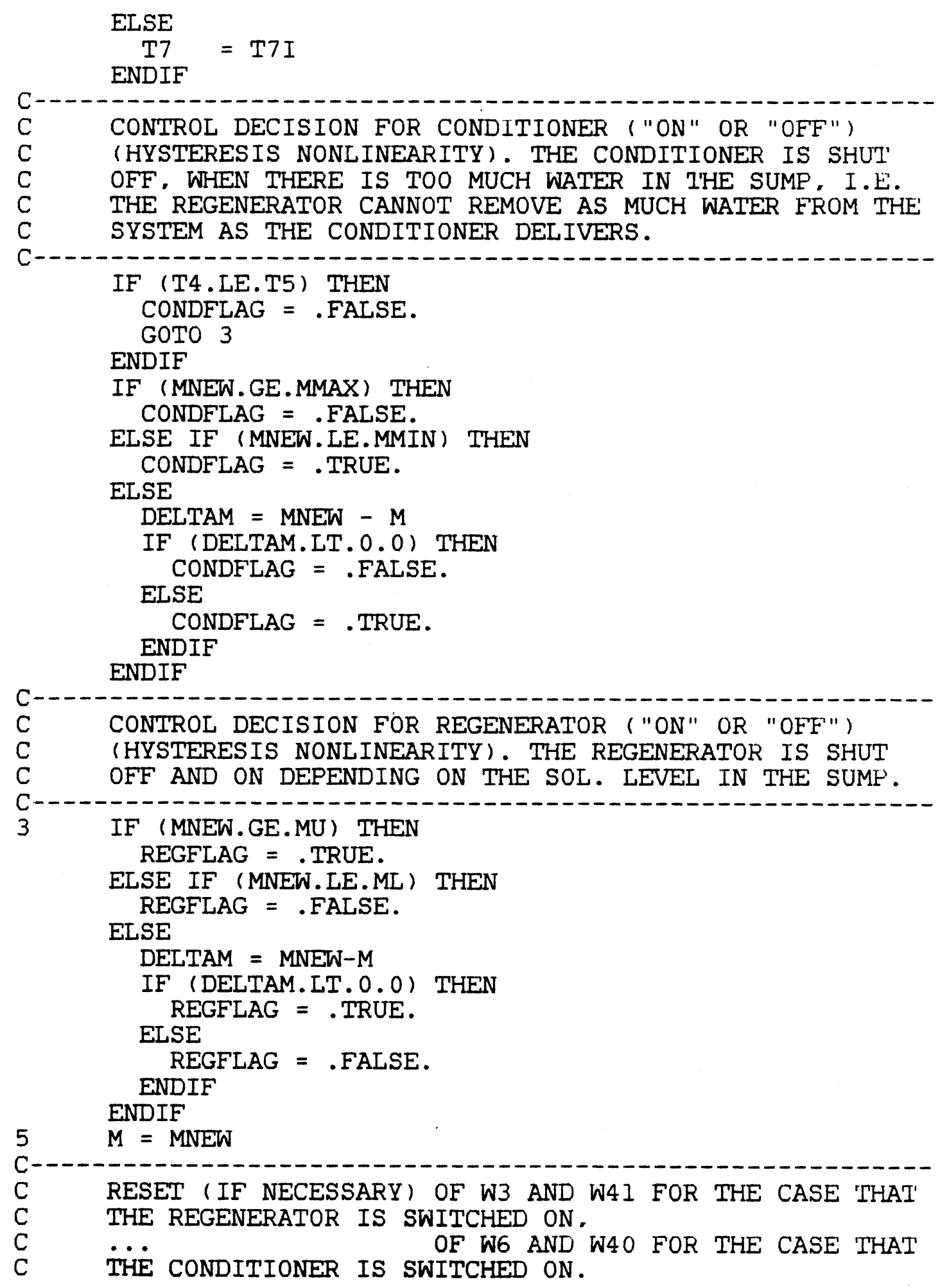




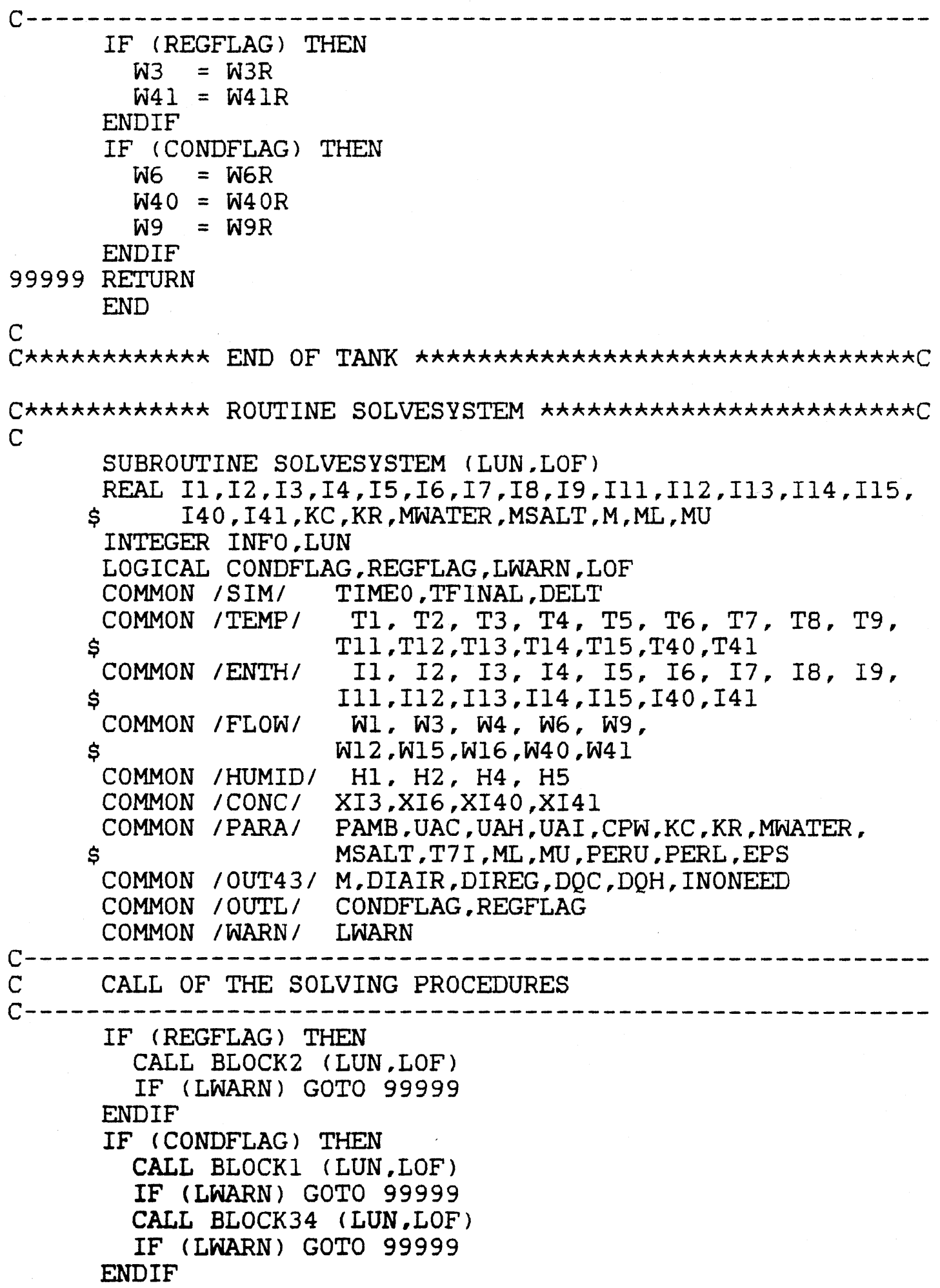




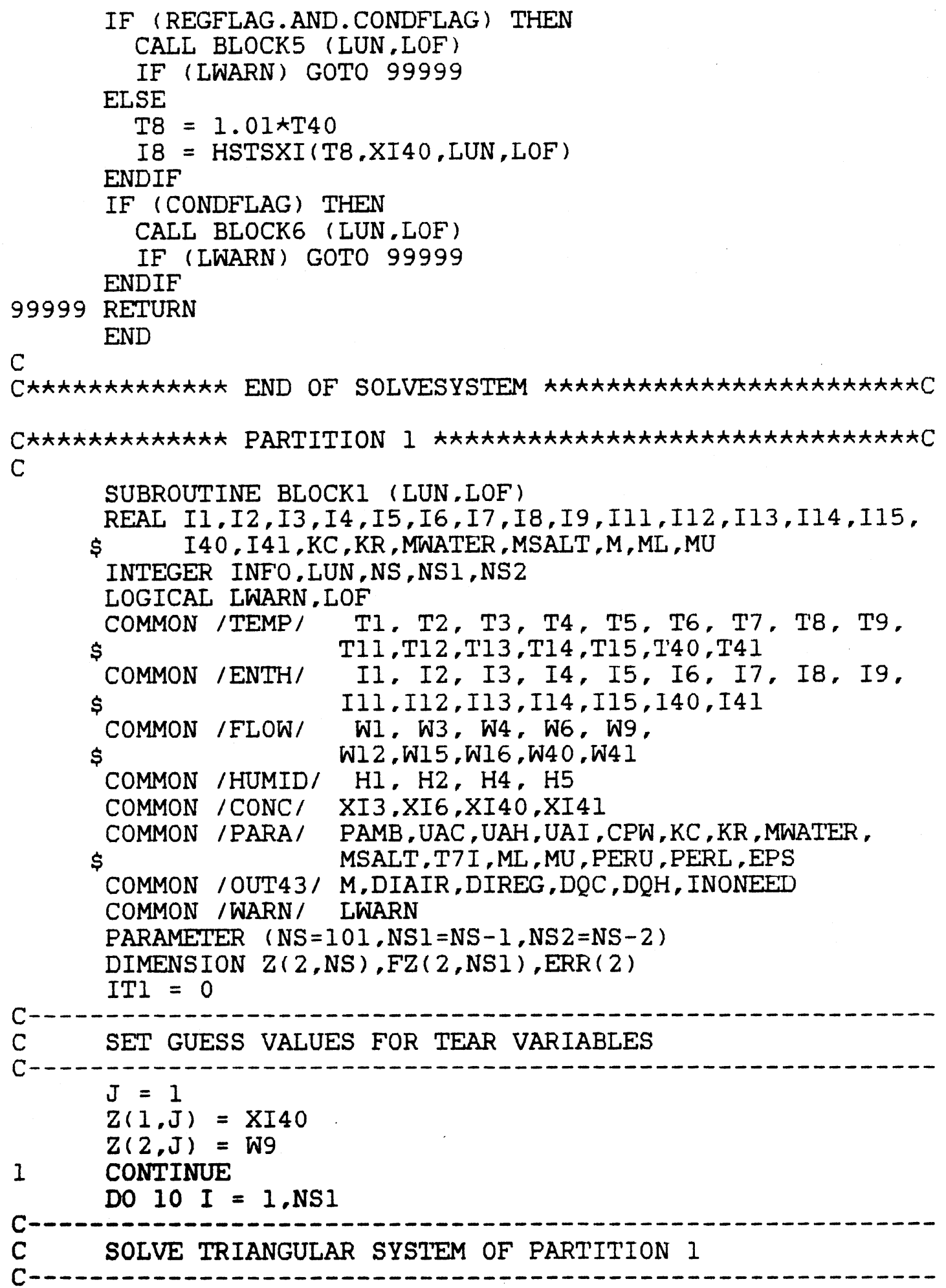




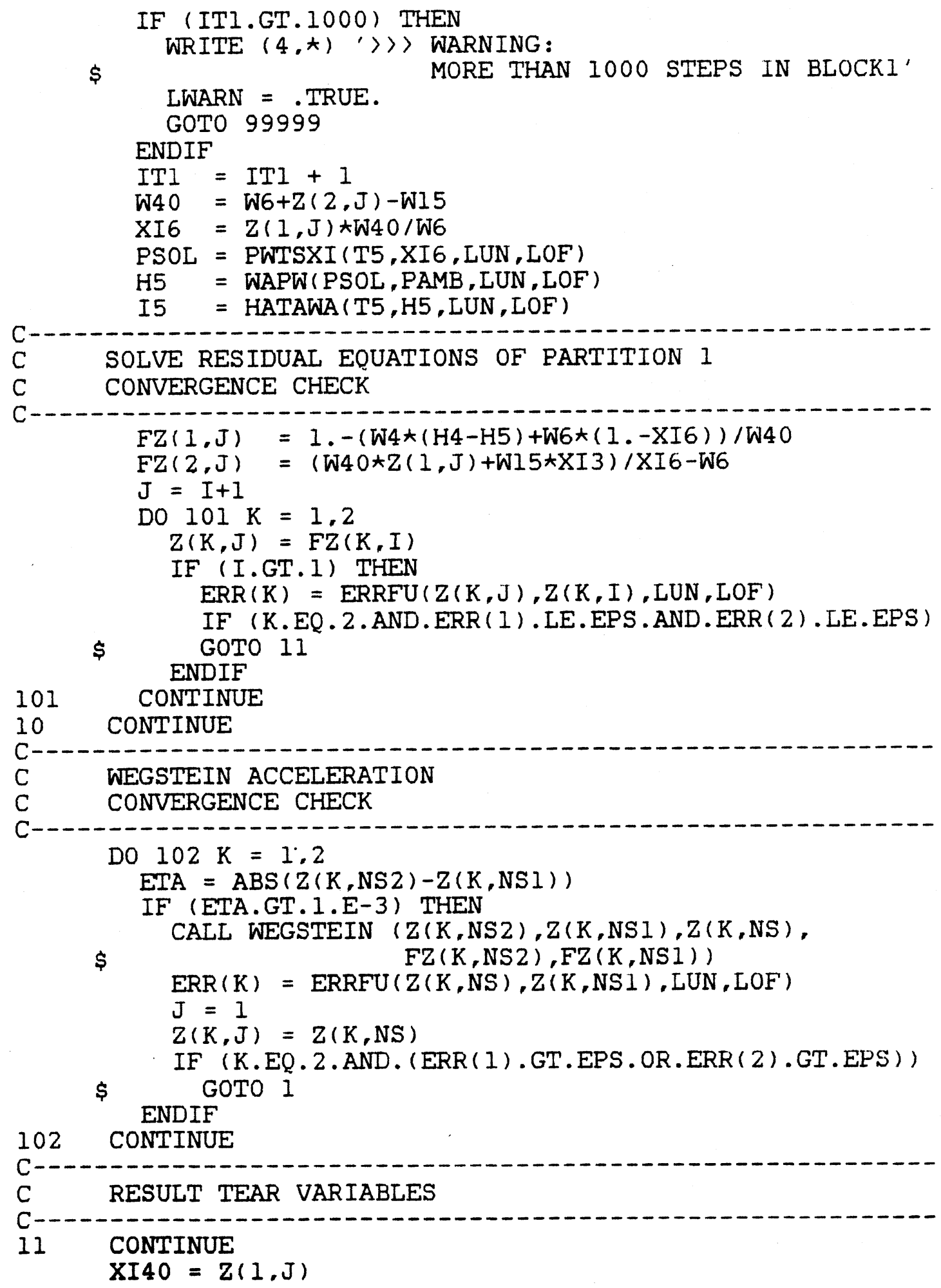




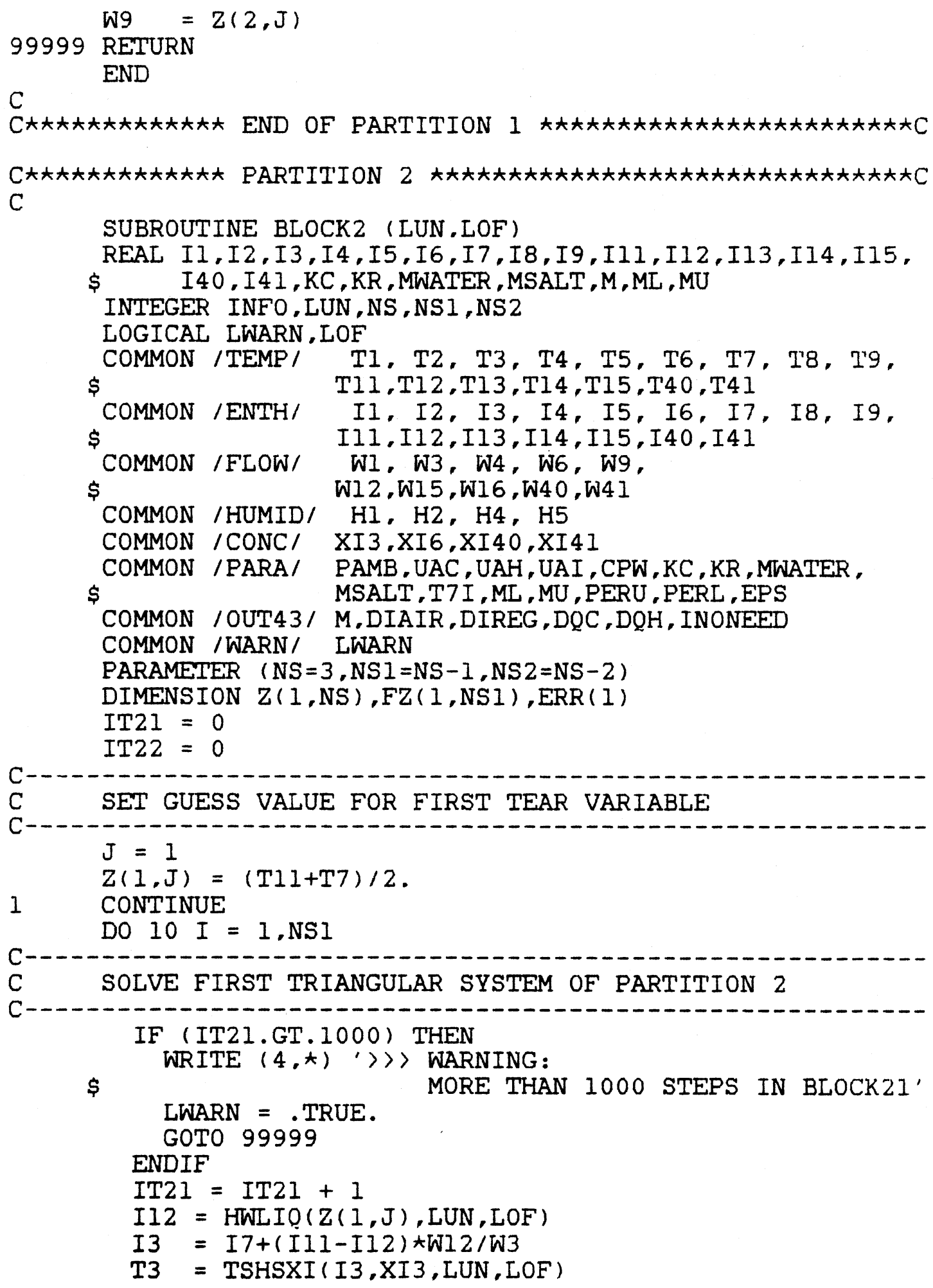




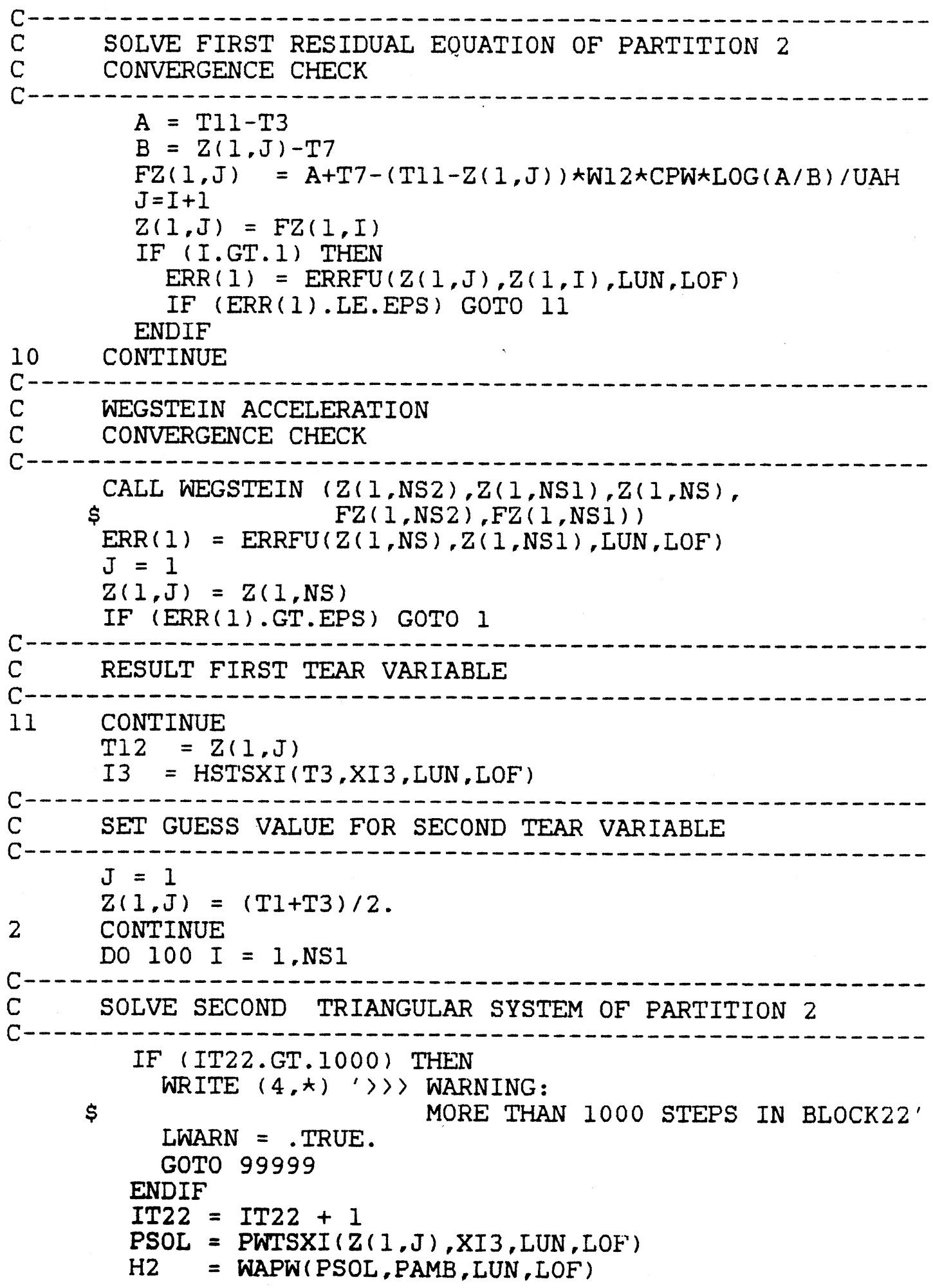




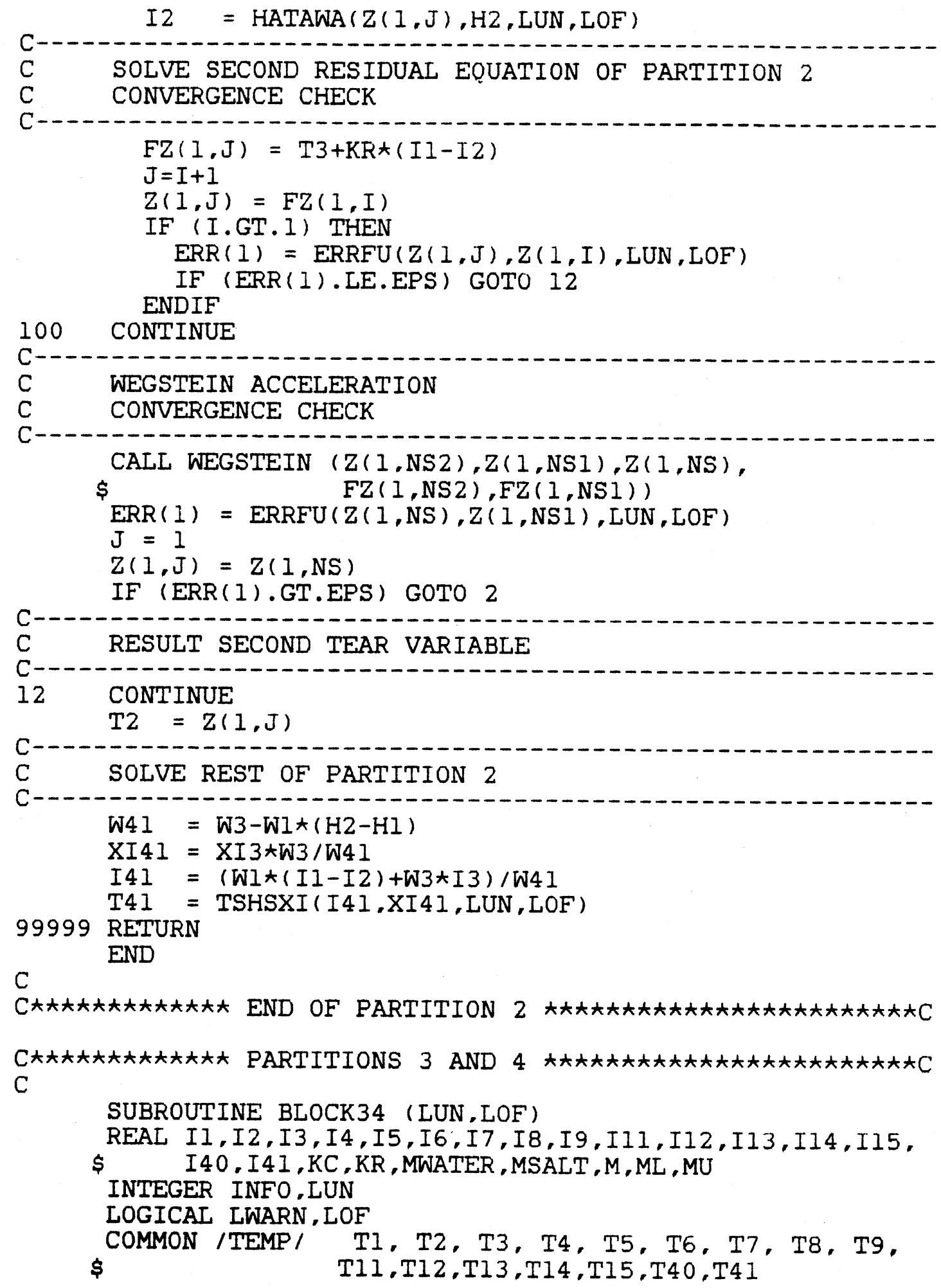




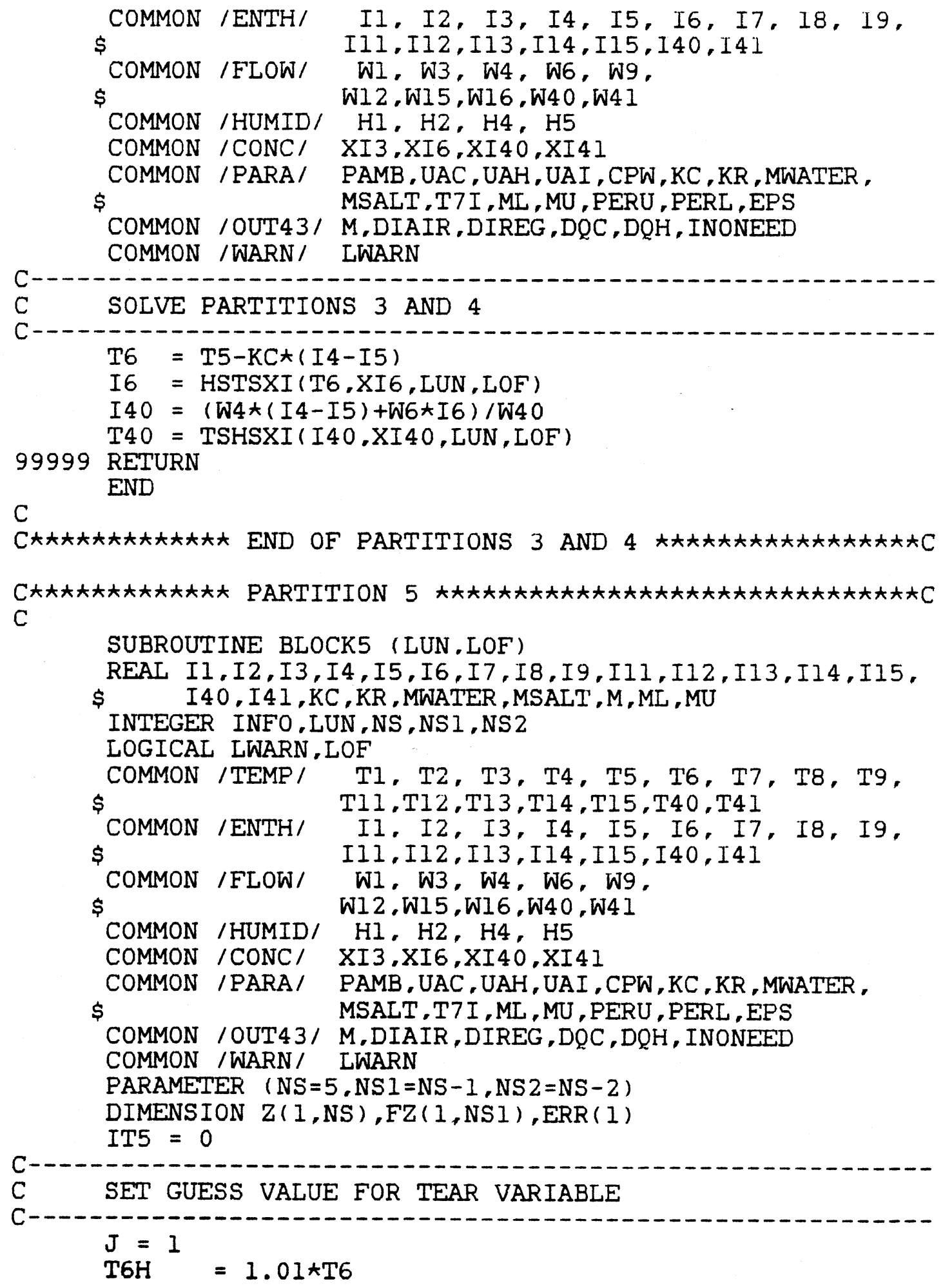




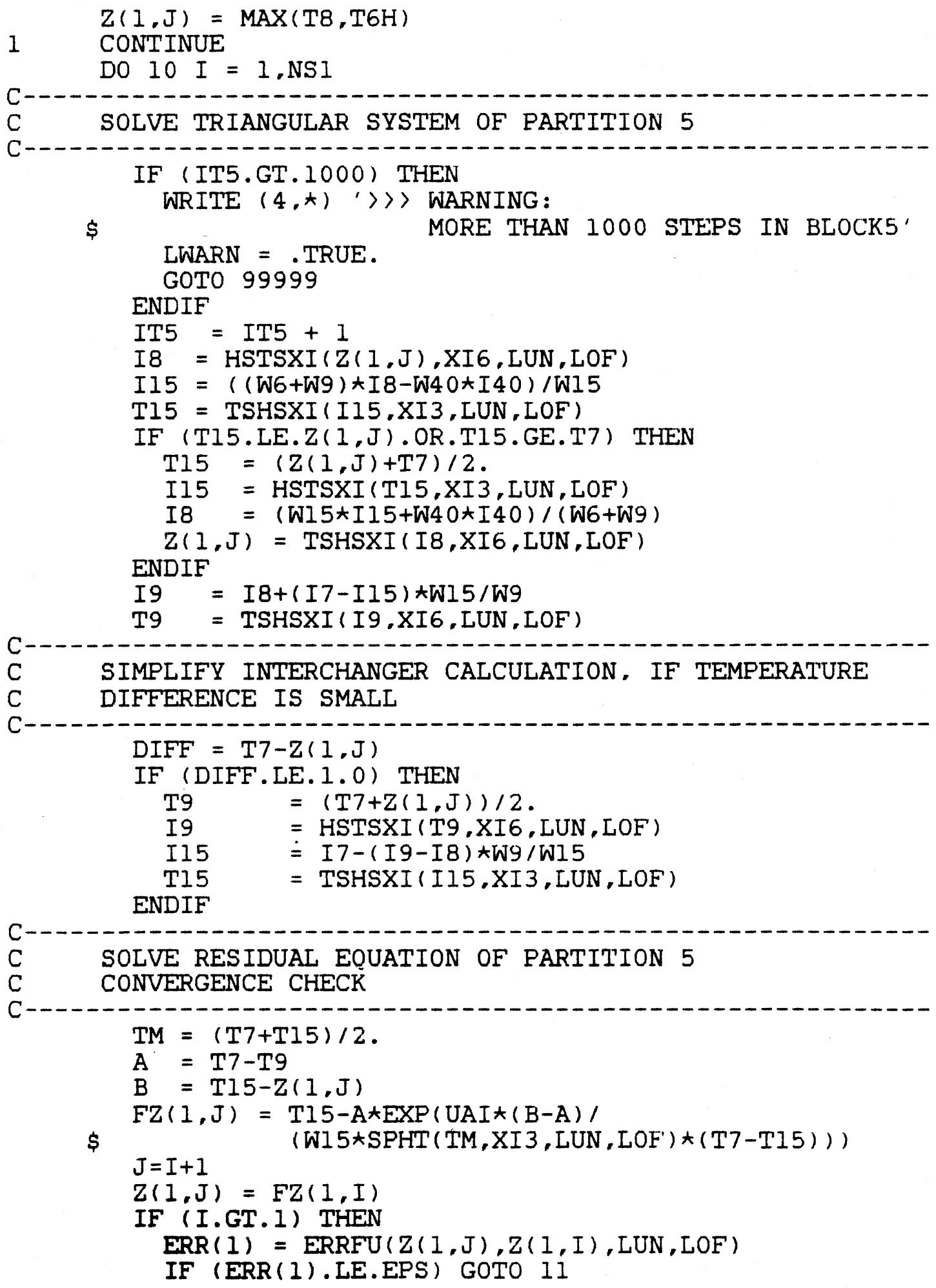




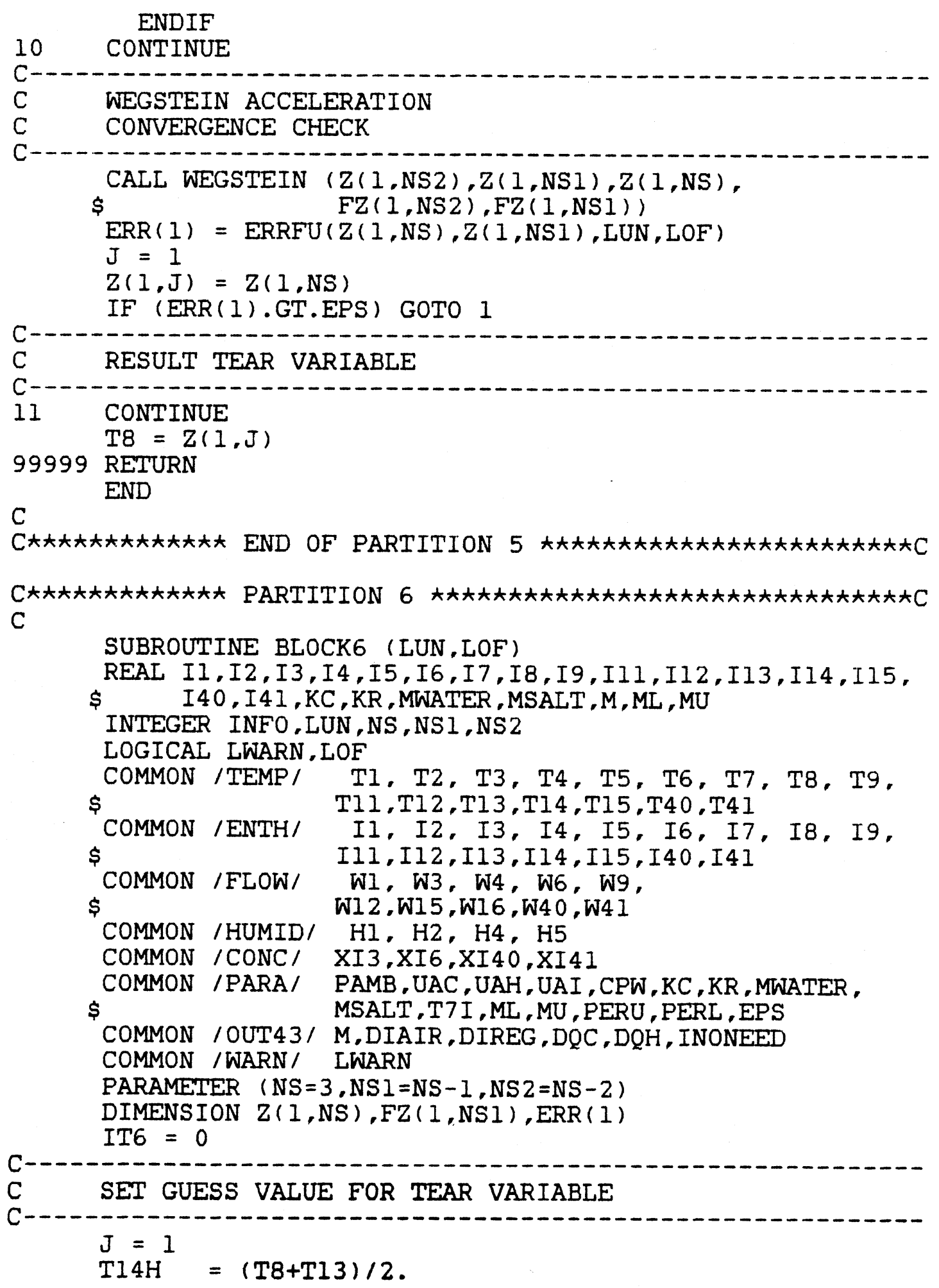




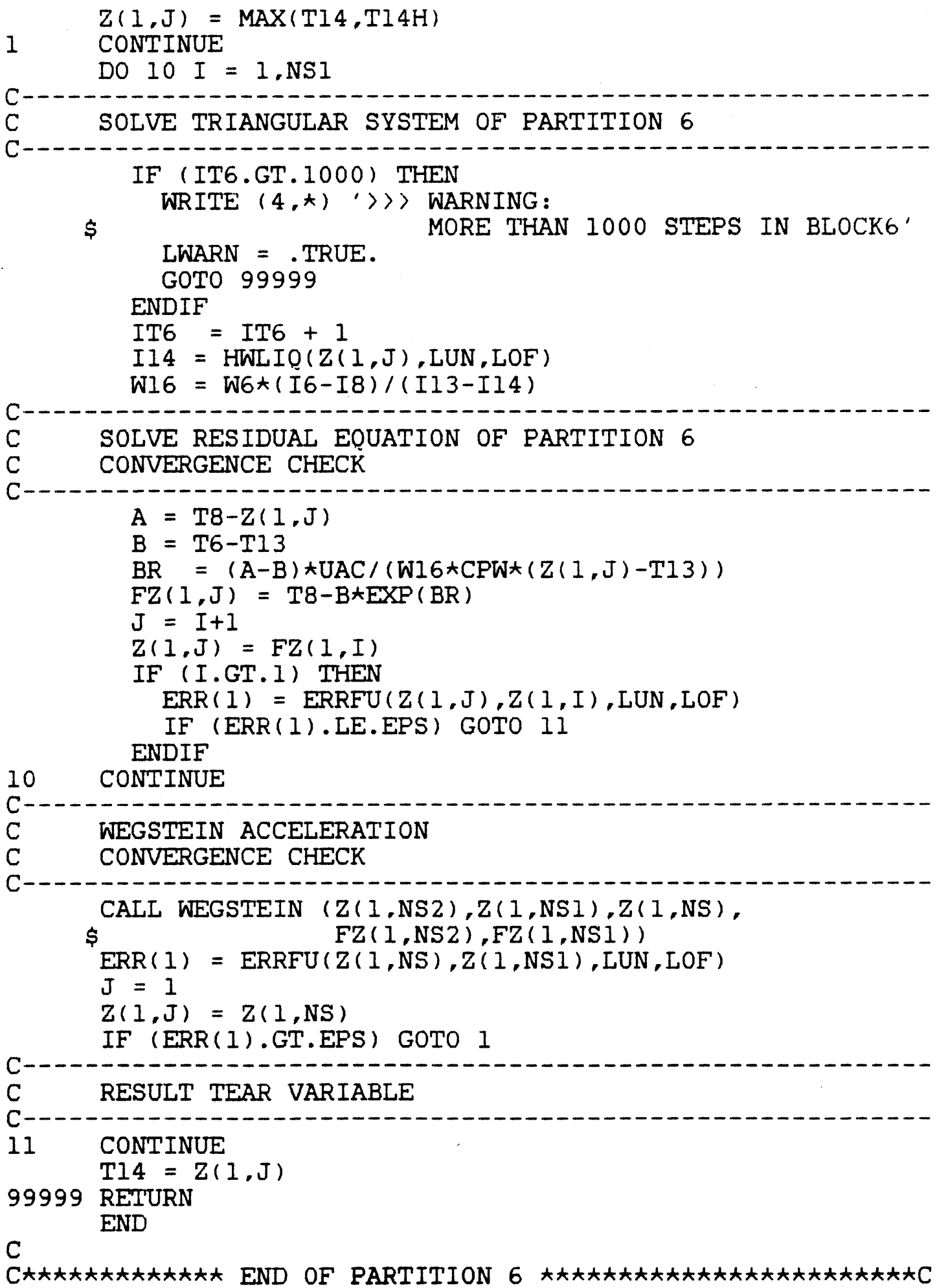




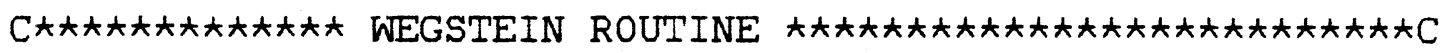
$\mathrm{C}$

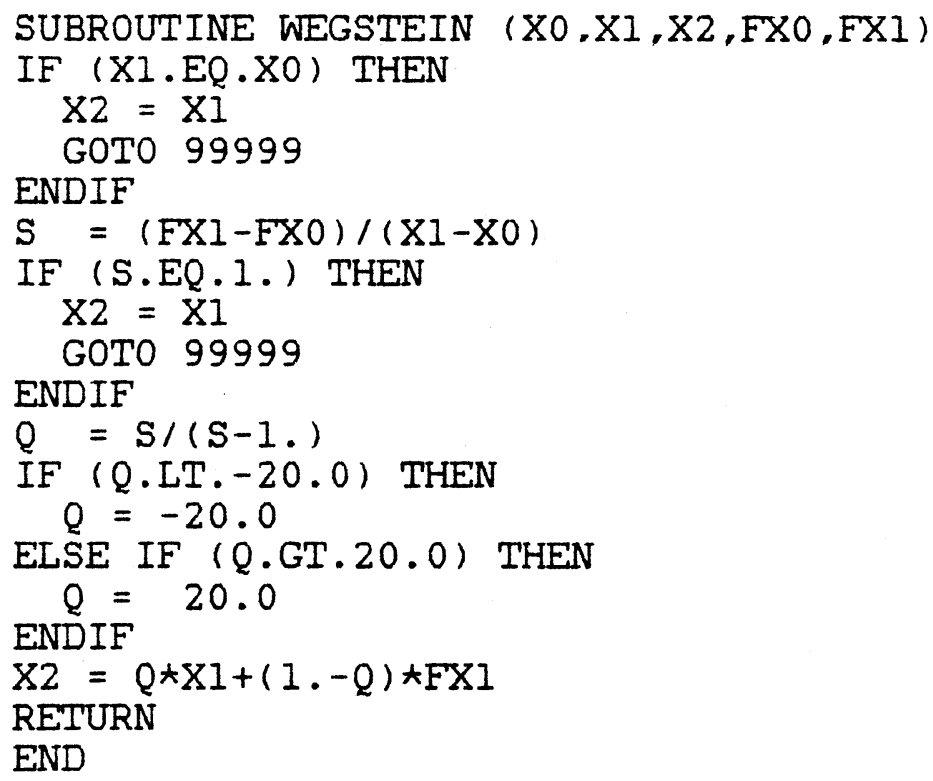




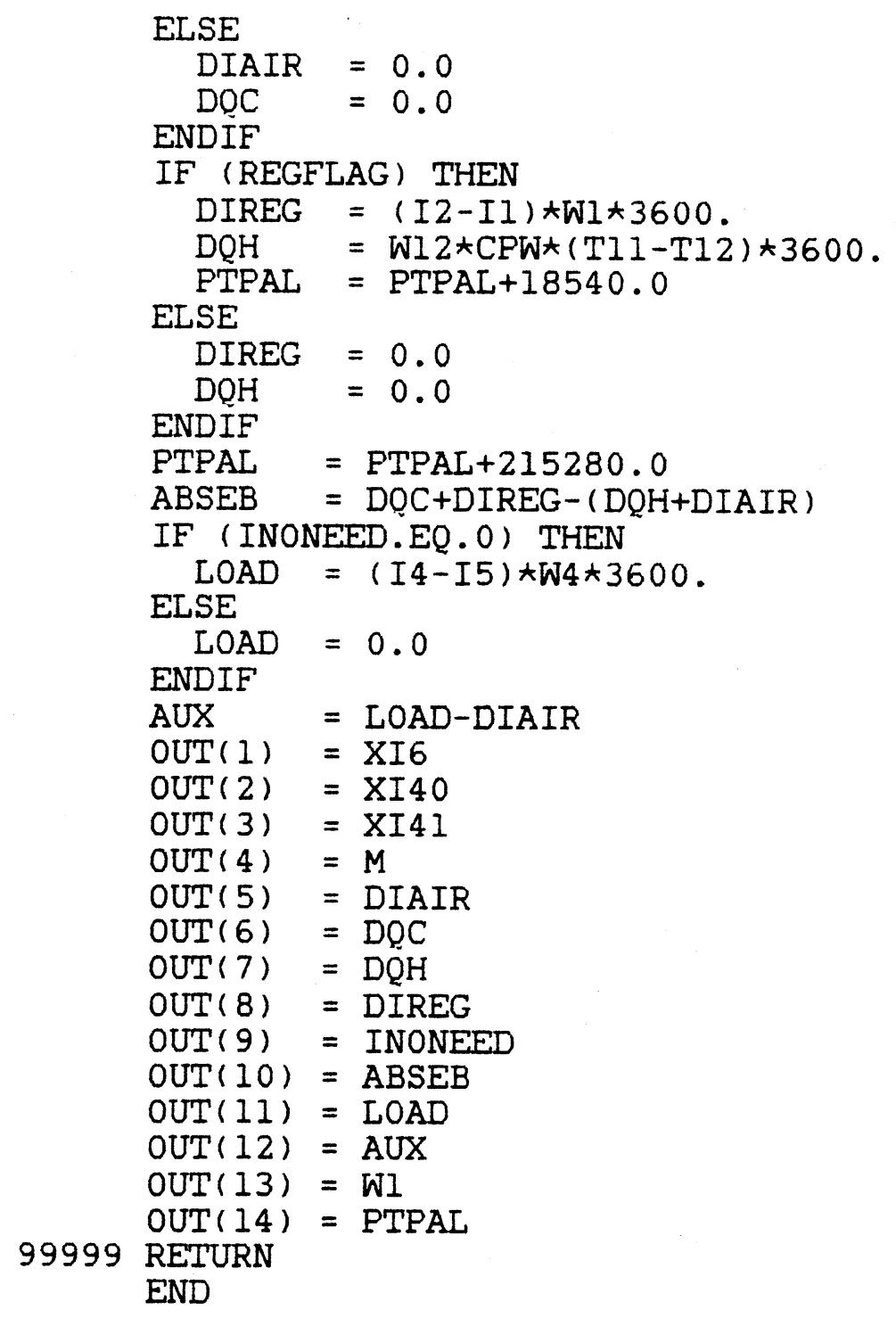


Appendix A.2 containes the energy supply control component TYPE47 for the Chiller Mode. It distributes the energy demands of the LD component to the available energy sources according to the desired control. 
SUBROUTINE TYPE47(TIME,XIN, OUT, T,DTDT, PAR, INFO)

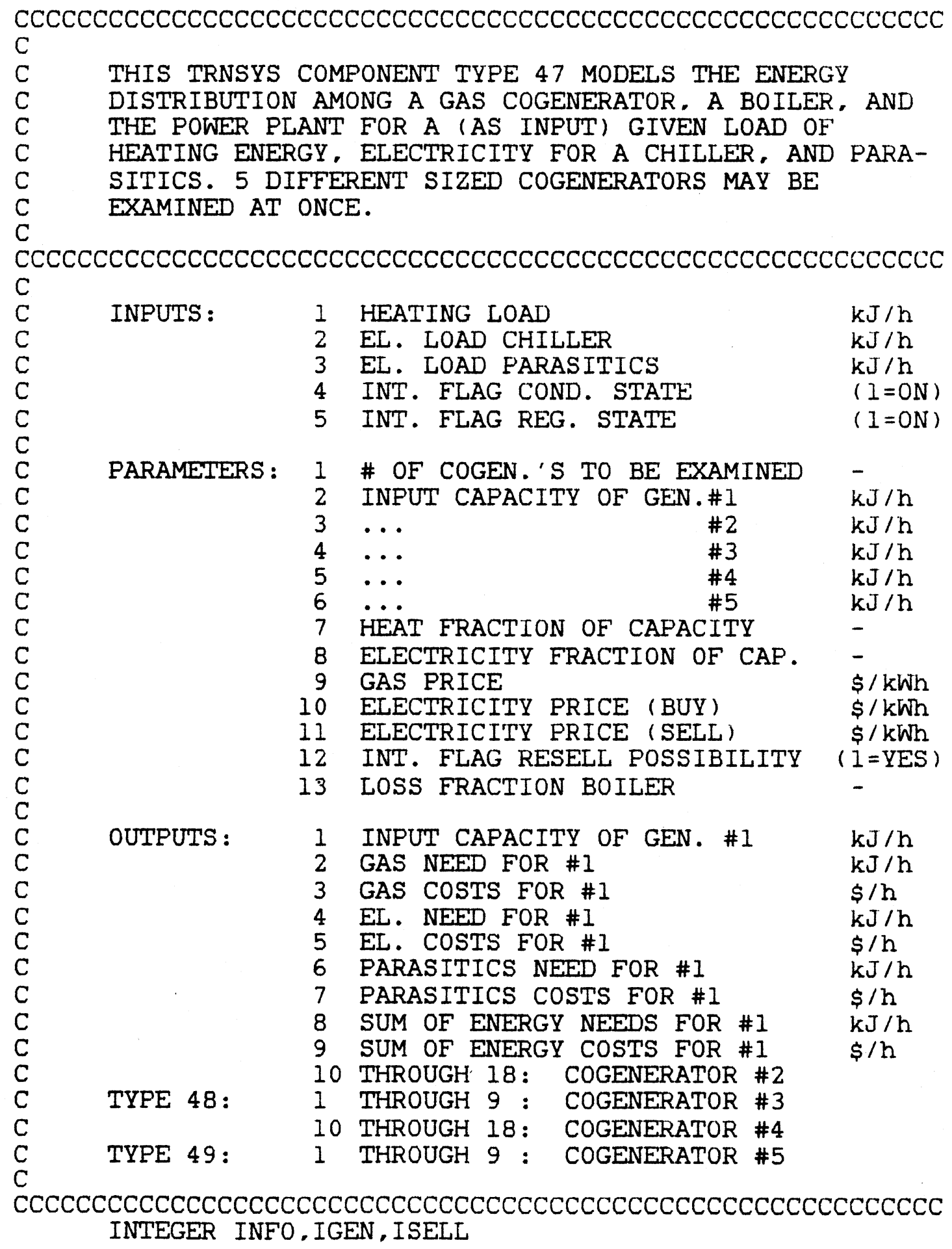




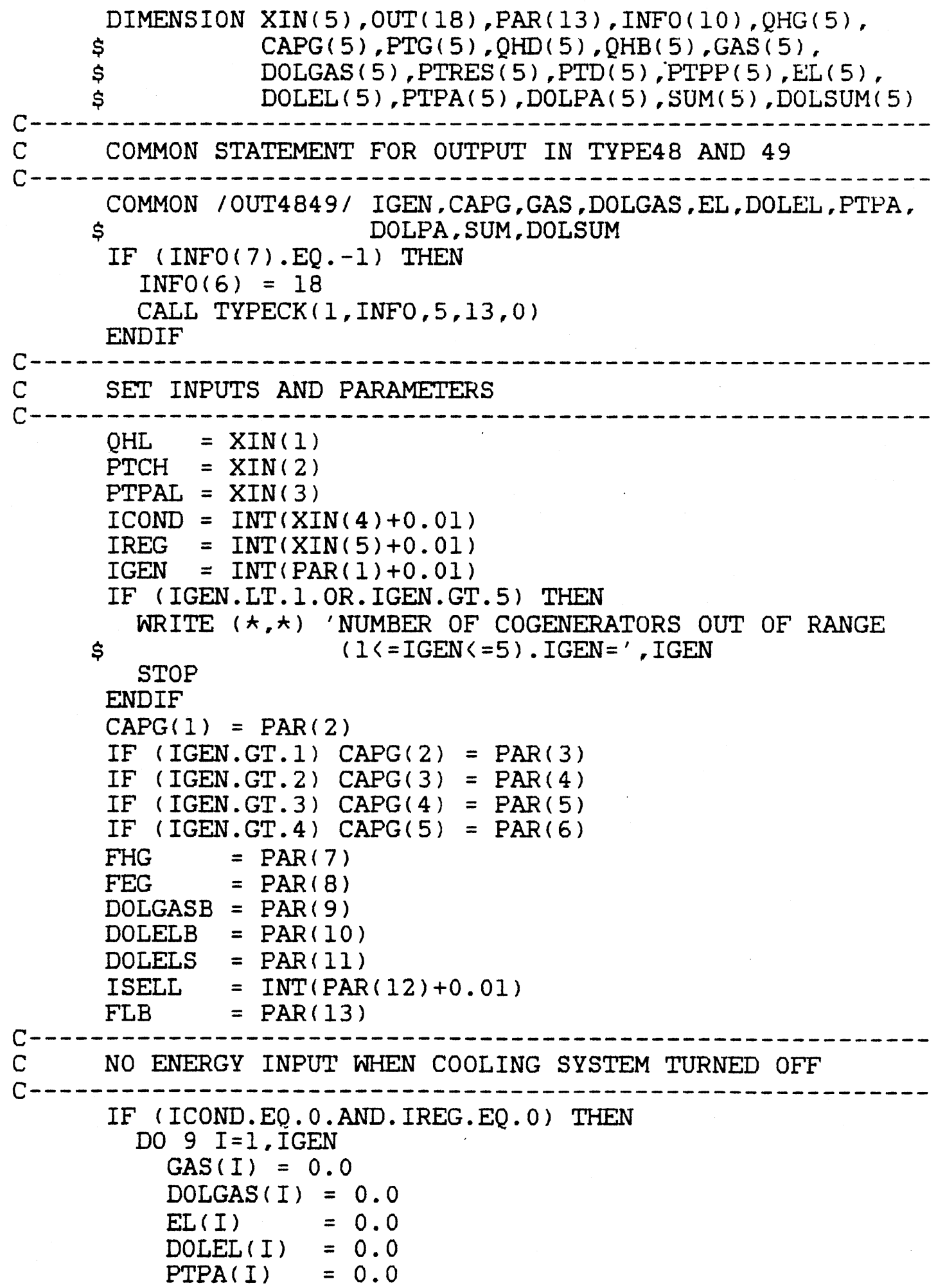




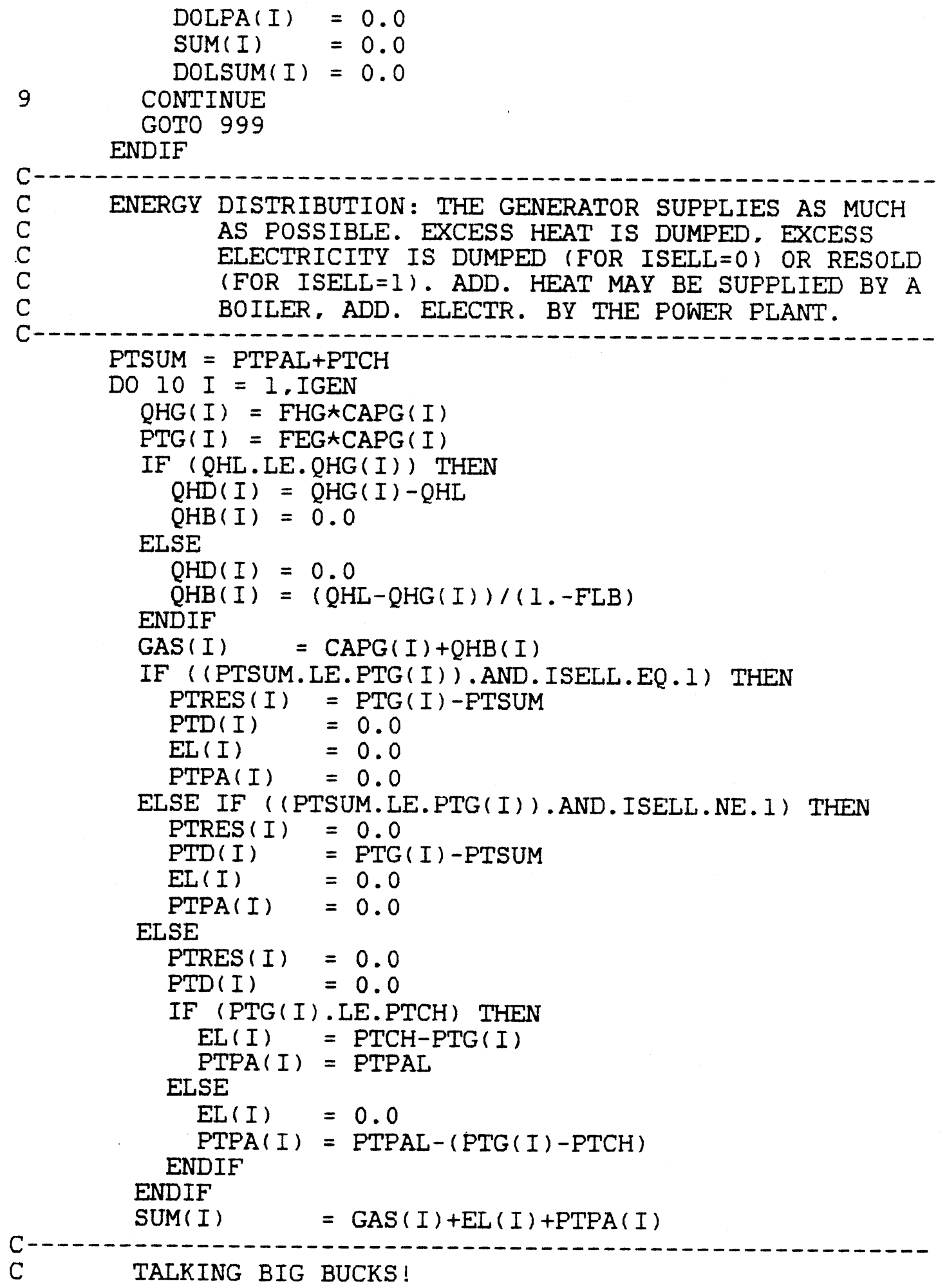




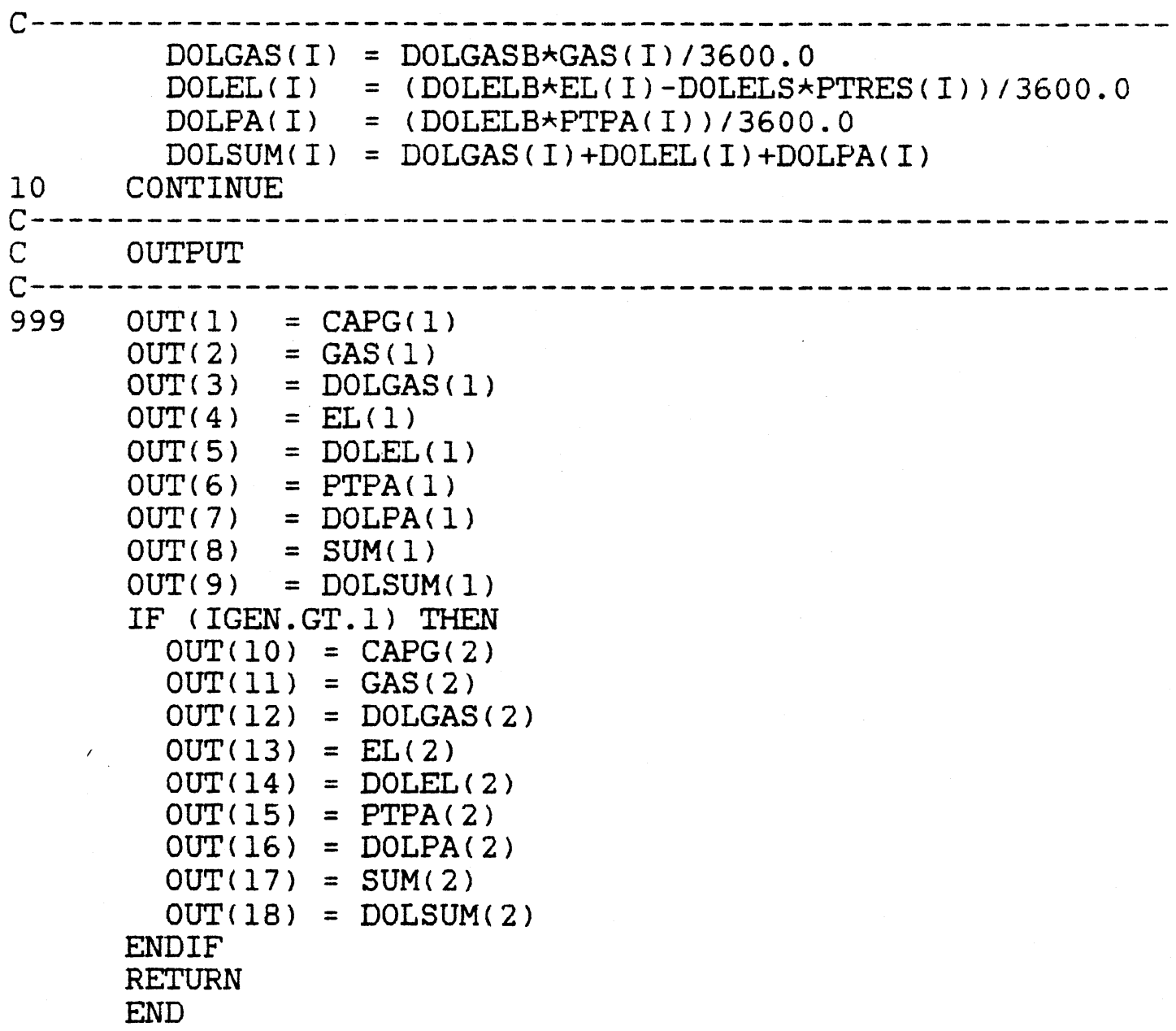


Appendix B contains a sample data sheet with experimental test data as supplied by the Tennessee Valley Authority (TVA). It shows the data collected on August 19, 1985. The units are as follows:

$$
\begin{array}{ll}
\text { T001 - T015: } & { }^{\circ} \mathrm{F} \\
\text { W001 - W016: } & \text { gal/h or cfm } \\
\text { H001 - H005: } & \% \text { RH } \\
\text { R001 - R005: } & \text { grains/1b }
\end{array}
$$

Note: In this thesis, the symbol $H$ rather than $R$ was used to designate humidity ratios. 
Sclence Museum of Virginta: Date 08/19/85

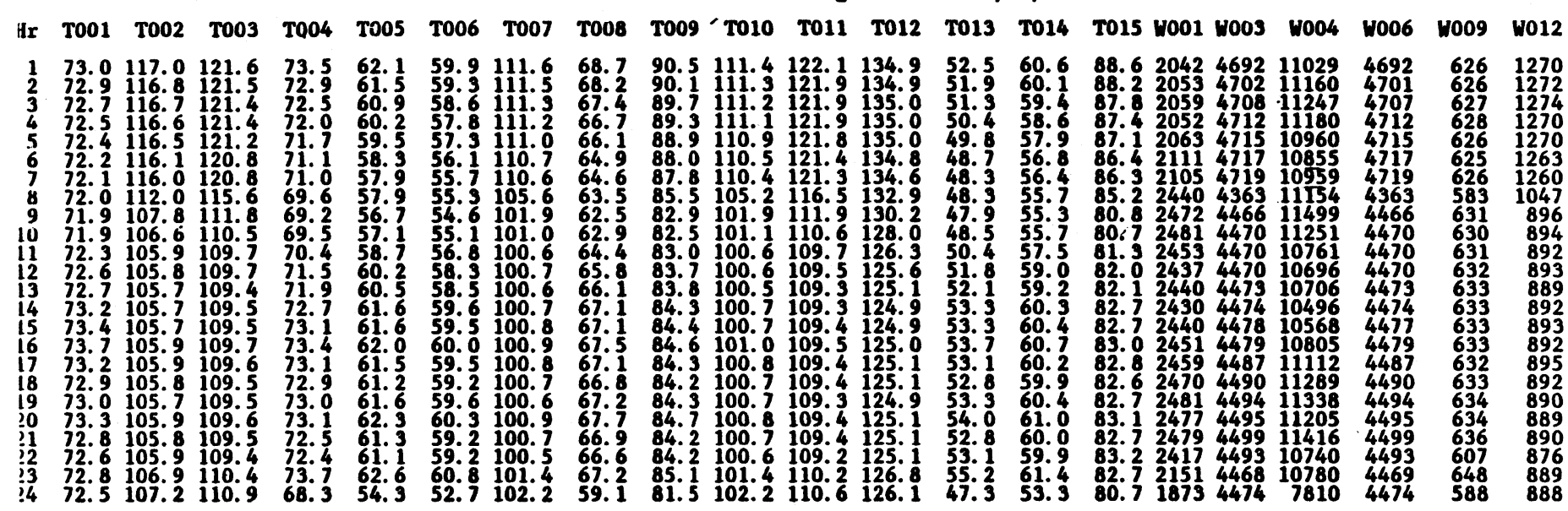

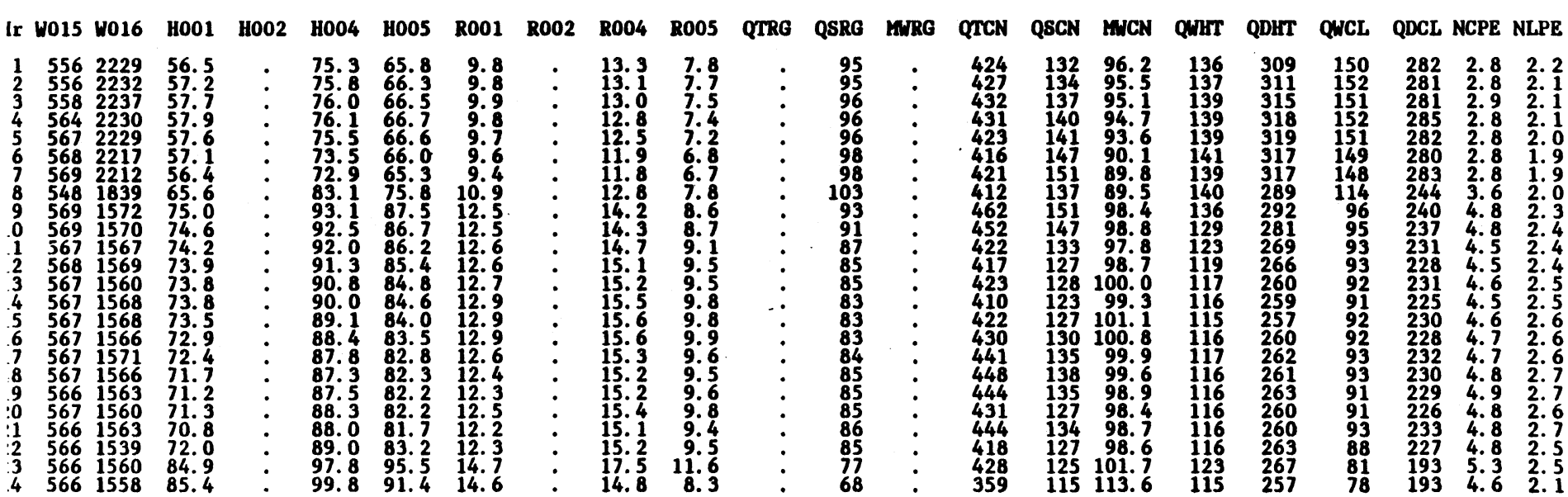


Appendix C.1 contains the TRNSYS deck for the Chiller Mode. 
NOLIST

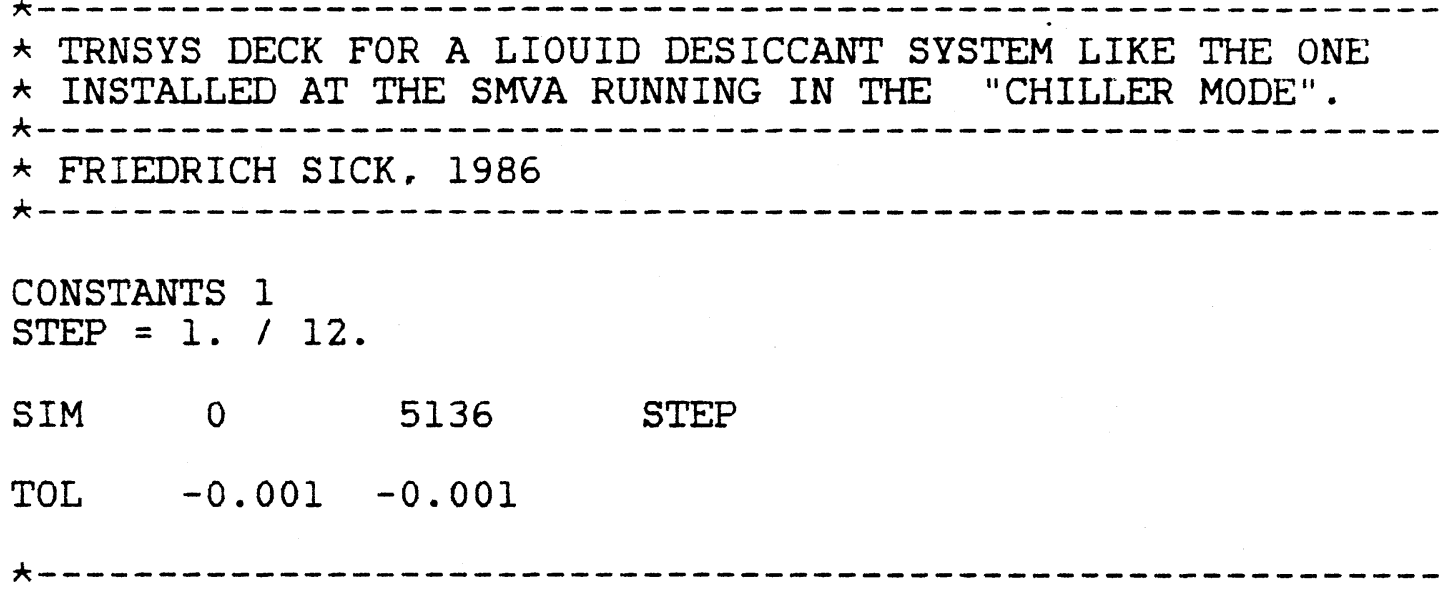
UNIT 1 TYPE 2 PROVIDES CONSTANT GENERAL DATA

PARAMETERS 9

$\begin{array}{lllllllll}\text { T1 } & \text { T5 } & \text { TI1 } & \text { T13 } & \text { H1 } & \text { WI } & \text { W4 } & \text { WI2 } & \text { PAMB }\end{array}$

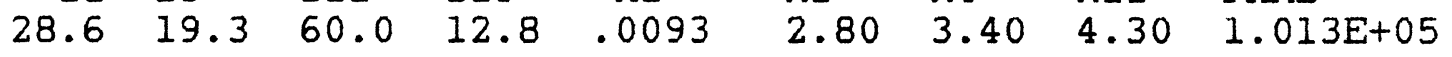
INPUTS 0

UNIT 10 TYPE 9 DATA READER TMY DATA

PARAMETERS 10

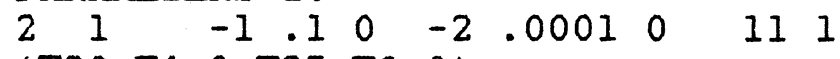

$(\mathrm{T} 20, \mathrm{~F} 4.0, \mathrm{~T} 25, \mathrm{~F} 6.0)$

UNIT 2 TYPE 42 SMVA SYSTEM

PARAMETERS 17

* UAC UAH UAI CPW KC KR MWATER MSALT

$\star T 7 I[K]$ ML MU W3 W6 W15 EPS DMU DML

$22.667 \quad 11.231 \quad 1.58 \quad 4.194 \quad 4.013 E-2 \quad 1.911 E-2 \quad 3333.33 \quad 1374.76$

$\begin{array}{lllllllll}312.4 & 4598.1 & 4618.1 & 8.3 & 8.18 & .55 & 1 . E-3 & 500 . & 15 .\end{array}$ INPUTS 11

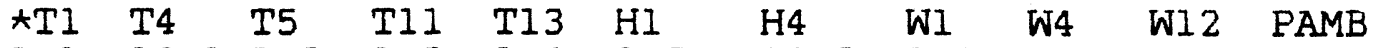
$\begin{array}{lllllllllll}1,1 & 10,1 & 1,2 & 1,3 & 1,4 & 1,5 & 10,2 & 1,6 & 1,7 & 1,8 & 1,9\end{array}$

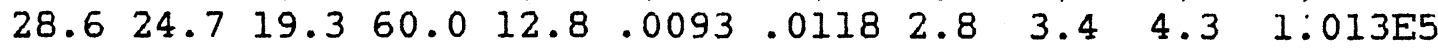

UNIT 3 TYPE 43

PARAMETERS 0

INPUTS 0

UNIT 9 TYPE 15 ALG. CONVERTER $\mathrm{kg} / \mathrm{s}=\Rightarrow \mathrm{kg} / \mathrm{h}$

PARAMETERS 1

1 


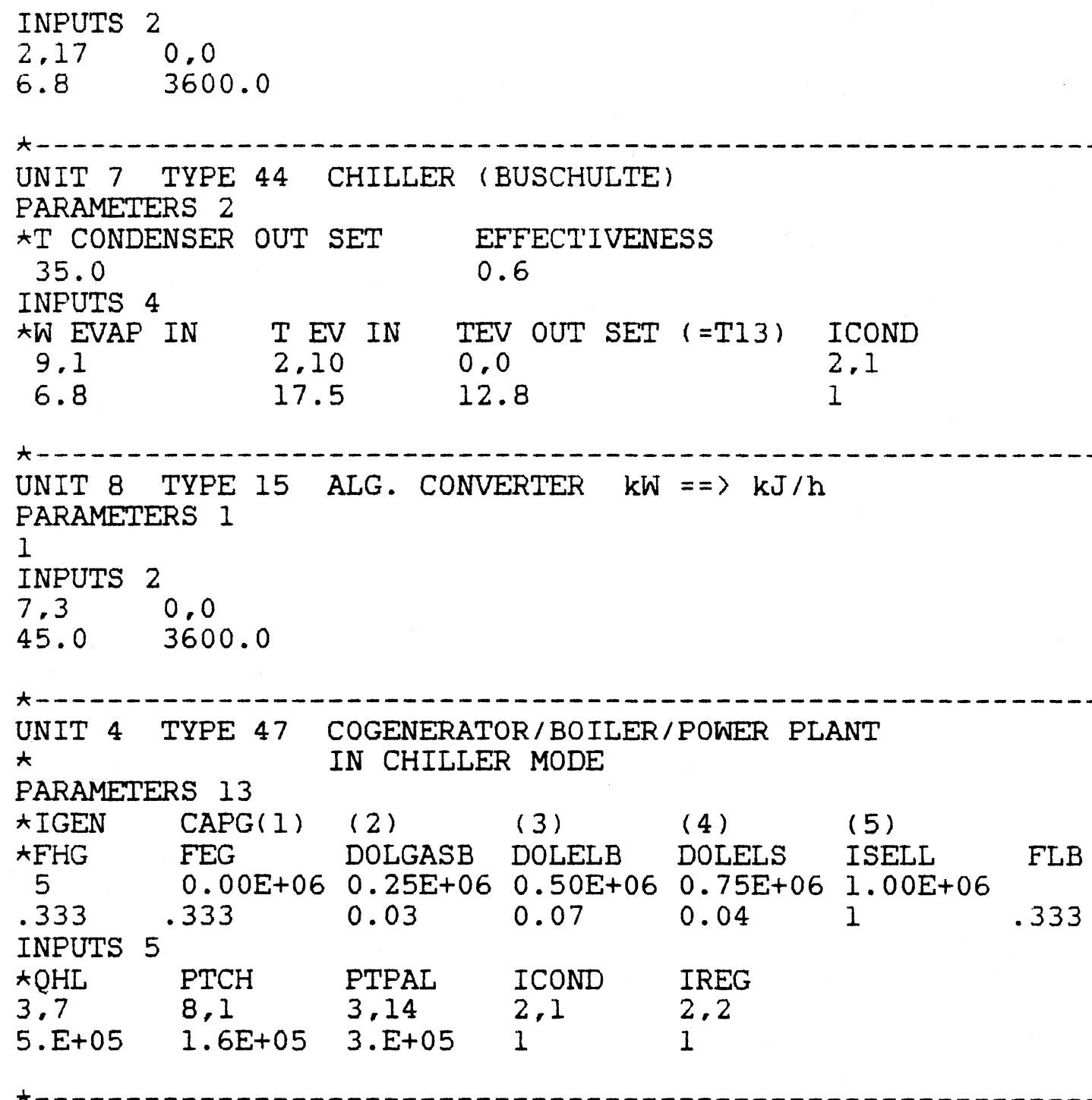

UNIT 5 TYPE 48 ADD. OUTPUT SPACE FOR COGENERATORS \#3, \#4 PARAMETERS 0

INPUTS 0

UNIT 6 TYPE 49 ADD. OUTPUT SPACE FOR COGENERATOR \#5 PARAMETERS 0 INPUTS 0

UNIT 20 TYPE 28 OUTPUT COGENERATOR \# I PARAMETERS 25

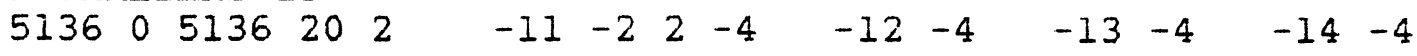


INPUTS 9

4.1

$$
\begin{array}{lllllllllll}
-15 & -4 & -16 & -4 & -17 & -4 & -18 & -4 & -19 & -4
\end{array}
$$

LABLES 9

$4,24,34$,

CAPGI

GAS

ET

4,6

4,7

$4.8 \quad 4.9$

CAE

UNIT 21 TYPE 28 OUTPUT COGENERATOR \# 2

PARAMETERS 25

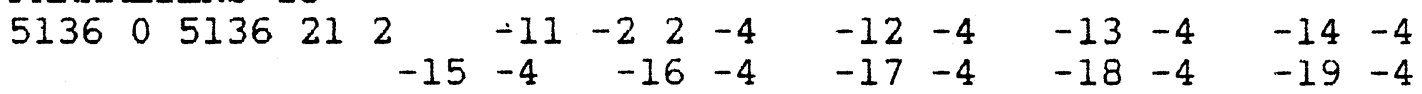

INPUTS 9

$\begin{array}{lllllllll}4,10 & 4,11 & 4,12 & 4,13 & 4,14 & 4,15 & 4,16 & 4,17 & 4,18\end{array}$

LABLES 9

CAPG2 GAS \$GAS EL \$EL PAR \$PAR SUM \$SUM

UNIT 22 TYPE 28 OUTPUT COGENERATOR \# 3

PARAMETERS 25

$\begin{array}{lllllllllllllll}5136 & 0 & 5136 & 22 & 2 & -11 & -2 & 2 & -4 & -12 & -4 & -13 & -4 & -14 & -4\end{array}$

INPUTS 9

$\begin{array}{lllllllll}5.1 & 5.2 & 5,3 & 5.4 & 5.5 & 5,6 & 5,7 & 5,8 & 5,9\end{array}$

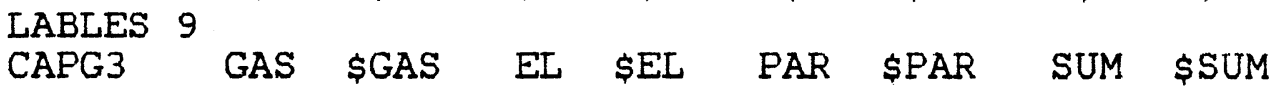

UNIT 23 TYPE 28 OUTPUT COGENERATOR \# 4

PARAMETERS 25

$\begin{array}{llllllllllllllll}5136 & 0 & 5136 & 23 & 2 & & -11 & -2 & 2 & -4 & -12 & -4 & -13 & -4 & -14 & -4\end{array}$

INPUTS 9

$\begin{array}{lllllllll}5,10 & 5,11 & 5,12 & 5,13 & 5,14 & 5,15 & 5,16 & 5,17 & 5,18\end{array}$

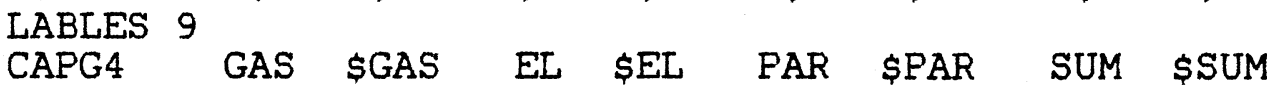

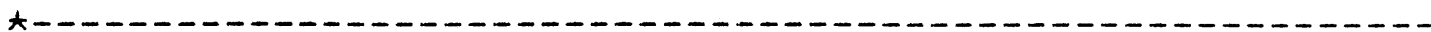

UNIT 24 TYPE 28 OUTPUT COGENERATOR \# 5

PARAMETERS 25

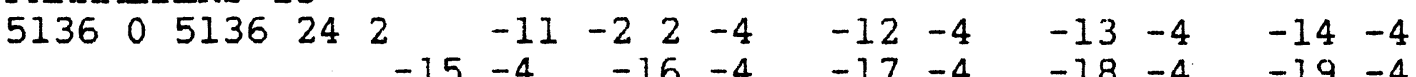

INPUTS 9

$\begin{array}{lllllllll}6,1 & 6,2 & 6,3 & 6,4 & 6,5 & 6,6 & 6,7 & 6,8 & 6,9\end{array}$

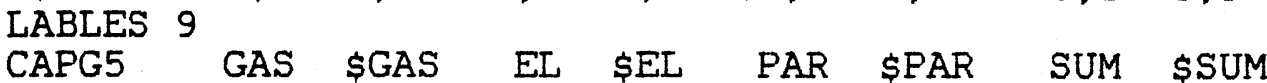


$3,11 \quad 3,5 \quad 3,7 \quad 3,6 \quad 3,12$

400.400 .400 .400 .0 .0

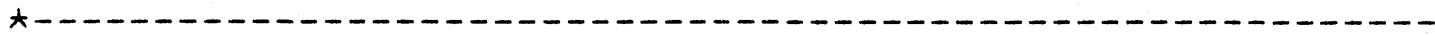

UNIT 26 TYPE 25 PRINTER FOR LD COMPONENT LOADS

PARAMETERS 4

$5136 \quad 0 \quad 5136 \quad 25$

INPUTS 5

$25,1 \quad 25,2 \quad 25,3 \quad 25,4 \quad 25,5$

LOAD DEL QHL QCL AUX

$\star--$ END OF TRNSYS DECK

END 
Appendix C.2 contains the TRNSYS deck for the Solar Mode. 
NOLIST

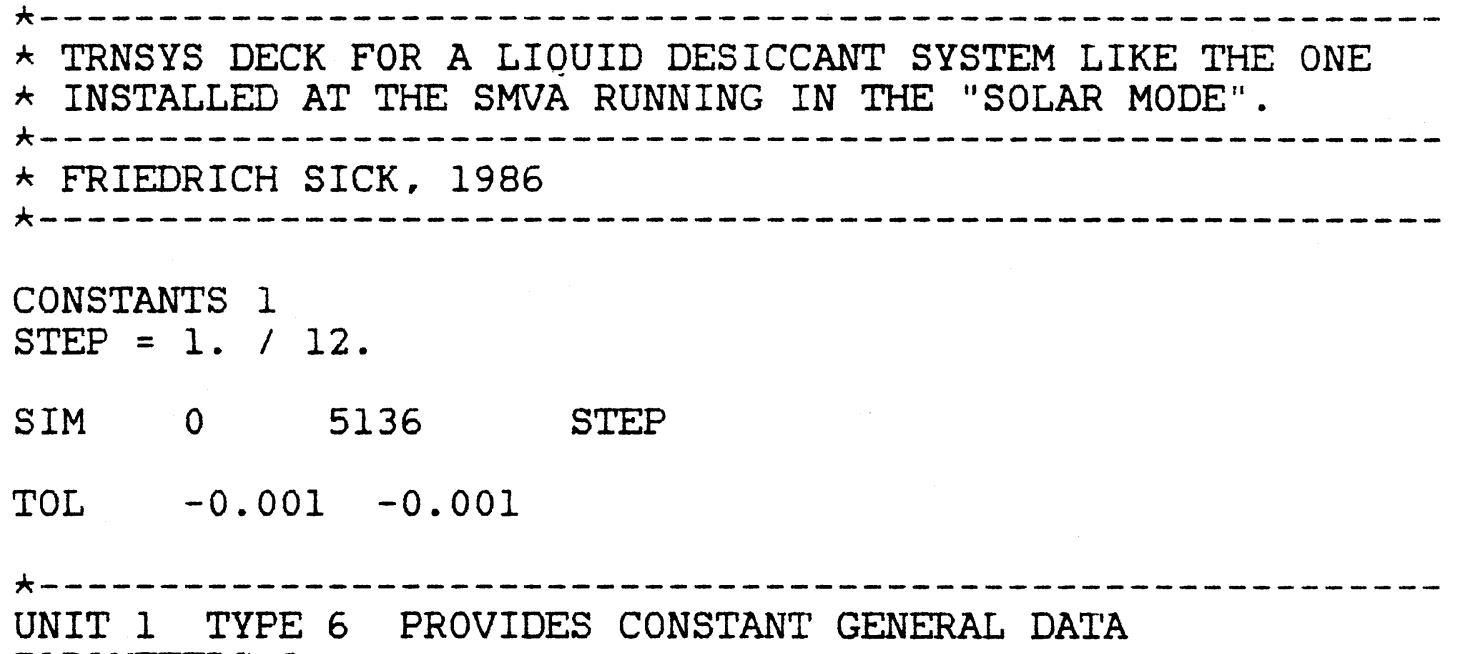

PARAMETERS 9

$\begin{array}{lllllllll}\text { TI T5 } & \text { Tl1 } & \text { T13 } & \text { HI } & \text { Wl W4 W12 PAMB }\end{array}$

$\begin{array}{lllllllll}28.6 & 19.3 & 60.0 & 12.8 & .0093 & 2.80 & 3.40 & 4.30 & 1.013 \mathrm{E}+05\end{array}$

INPUTS 0

\section{UNIT 10 TYPE 9 TMY DATA}

PARAMETERS 13

$\begin{array}{llllllllllllllll}3 & 1 & -1 & 1 & 0 & -2 & .1 & 0 & -3 & .0001 & 0 & 11 & 1\end{array}$

(T15,F4.0,T20,F4,0,T25,F6.0)

UNIT 7 TYPE 2 PUMP CONTROLLER

PARAMETERS 3

$3 \quad 11$

INPUTS 3

$\begin{array}{lll}12.1 & 13,1 & 7,1 \\ 20 & 20 & 0\end{array}$

UNIT 8 TYPE 3 PUMP

PARAMETERS 1

10000

INPUTS 3

$13.10,007,1$

A-1-

UNIT 11 TYPE 16 RADIATION PROCESSOR

PARAMETERS 7

$\star$ ERBS FIXED SURF. $4 / 1$ LAT. SOL.CONST. TIMESHFT SOLARTIME $\begin{array}{lllllll}3 & 1 & 91 & 35.16 & 4871 & 0 & -1\end{array}$ 


$\begin{array}{llllll}\text { INPUTS } & 6 & & & & \\ \star I & \text { TD1 } & \text { TD2 } & \text { RHOG } & \text { SLOPE } & \text { AZIMUTH } \\ 10.1 & 10.19 & 10.20 & 0.0 & 0.0 & 0.0 \\ 0 & 0 & 0 & 0.2 & 35.16 & 0\end{array}$

\begin{tabular}{|c|c|c|c|c|c|c|c|c|c|c|}
\hline \multicolumn{11}{|c|}{ PARAMETERS 12} \\
\hline $\begin{array}{l}\star M O D E \\
\star E F F H X\end{array}$ & $\begin{array}{l}\# \mathrm{CO} \\
\mathrm{CPh}\end{array}$ & $L^{\prime} \mathrm{S}$ & $\begin{array}{l}\text { AREA } \\
\text { OP.MODE }\end{array}$ & $\begin{array}{l}\text { CFW } \\
\text { BO }\end{array}$ & EFF.M & ODE & GTEST & FR & TAUALF & FRUL \\
\hline $\begin{array}{c}1 \\
-1 \\
\text { INPUTS }\end{array}$ & $\begin{array}{l}10 \\
4.1 \\
10\end{array}$ & & $\begin{array}{l}500 \\
1\end{array}$ & $\begin{array}{l}4.194 \\
.1\end{array}$ & 1 & & 20.0 & 0 . & & 17. \\
\hline $\begin{array}{c}\text { ATIN } \\
8.1 \\
20\end{array}$ & $\begin{array}{l}\mathrm{MDC} \\
8,2 \\
0\end{array}$ & $\begin{array}{l}M D F \\
8,2 \\
0\end{array}$ & $\begin{array}{l}\text { TAMB } \\
10,2 \\
20\end{array}$ & $\begin{array}{l}\text { IT } \\
11,6 \\
0\end{array}$ & $\begin{array}{l}I \\
11,4 \\
0\end{array}$ & $\begin{array}{l}\text { ID } \\
11 \\
0\end{array}$ & $\begin{array}{l}\text { RH } \\
0, \\
0 .\end{array}$ & & $\begin{array}{l}\text { THETA } \\
11.9 \\
0\end{array}$ & $\begin{array}{l}\text { SLOPE } \\
11.10 \\
35.16\end{array}$ \\
\hline
\end{tabular}

$\begin{array}{llllll}\text { UNIT } 13 & \text { TYPE } & \text { TANK } & & & \\ \text { PARAMETERS } 6 & & & & \\ \text { AMODE VOL } & \text { CPW } & \text { RHO } & \text { UT } & \text { HEIGHT } \\ 1 & 19 . & 4.194 & 1000 . & 1.7 & -2.5 \\ \text { INPUTS } 5 & & & & & \\ \text { ATH MDH } & \text { TL } & \text { MDL } & \text { TENV } & \\ 12.1 & 12.2 & 16.1 & 16.2 & 0.0 & \\ 20 & 0 & 50 & 15480 . & 20 .\end{array}$

UNIT 14 TYPE 15 ALG. CONVERTER $\mathrm{KG} / \mathrm{H} \Rightarrow \mathrm{KG} / \mathrm{S}$

PARAMETERS 1

2

INPUTS 2

$0.0 \quad 13.4$

3600 . 15480 .

UNIT 2 TYPE 42 SMVA SYSTEM

PARAMETERS 17

* UAC UAH UAI CPW KC KR MWATER MSALT $\star T 7 I[K] \mathrm{ML} M U$ W3 W6 W15 EPS DMU DML $\begin{array}{llllllll}22.667 & 11.231 & 1.58 & 4.194 & 4.013 E-2 & 1.911 E-2 & 3333.33 & 1374.76\end{array}$

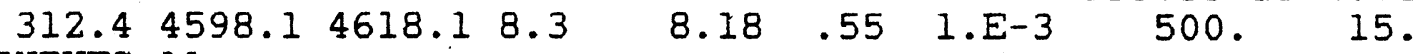
INPUTS 11

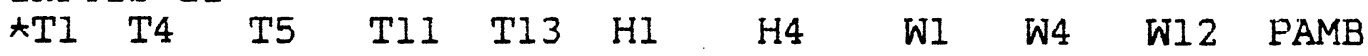
$\begin{array}{llllllllllll}1.1 & 10,2 & 1.2 & 0,0 & 1,4 & 1,5 & 10,3 & 1,6 & 1,7 & 0,0 & 1,9\end{array}$ $\begin{array}{lllllllllll}28.6 & 24.7 & 19.3 & 60.0 & 12.8 & .0093 & .0118 & 2.8 & 3.4 & 4.3 & 1.013 E 5\end{array}$ 


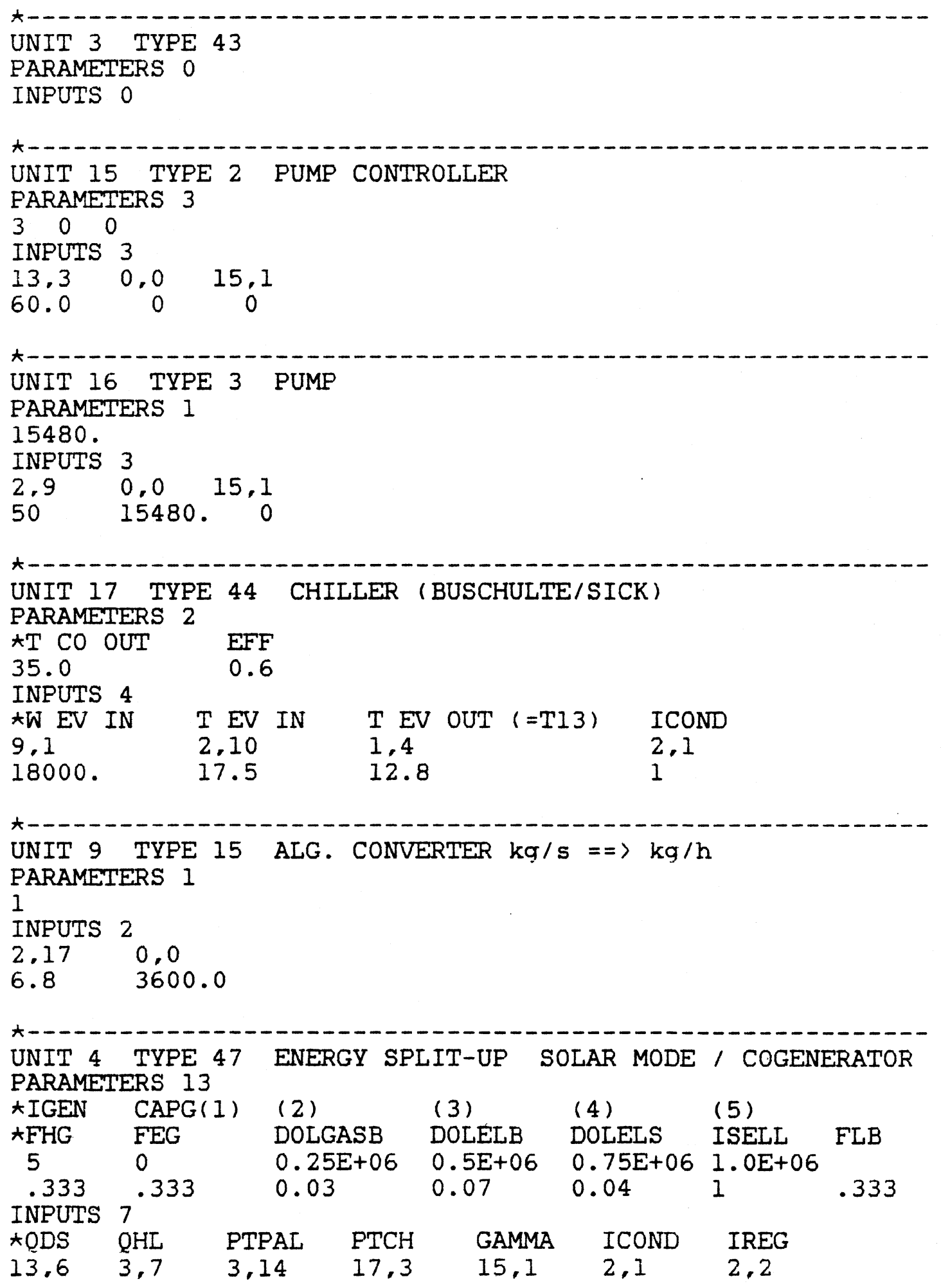


$\begin{array}{lllllll}5 . E 05 & 5 . E 05 & 3 . E 05 & 1.6 \mathrm{E} 05 & 1 & 1 & 1\end{array}$

UNIT 5 TYPE 48 ADD. OUTPUT SPACE FOR COGENERATORS \#3, \#4 PARAMETERS 0

INPUTS 0

UNIT 6 TYPE 49 ADD. OUTPUT SPACE FOR COGENERATOR \#5

PARAMETERS 0

INPUTS 0

UNIT 20 TYPE 28 OUTPUT COGENERATOR \# 1

FARAMETERS 25

$\begin{array}{llllllllllllllll}5136 & 0 & 5136 & 20 & 2 & -11 & -2 & 2 & -4 & -12 & -4 & -13 & -4 & -14 & -4\end{array}$

INPUTS 9

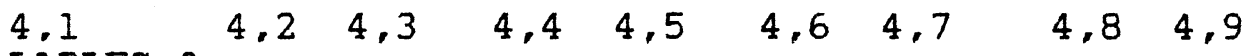

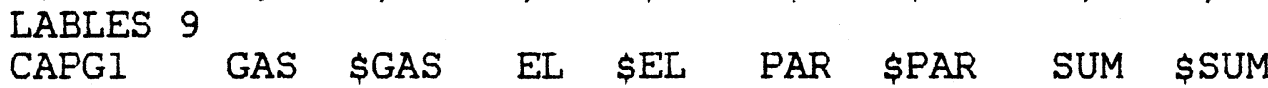

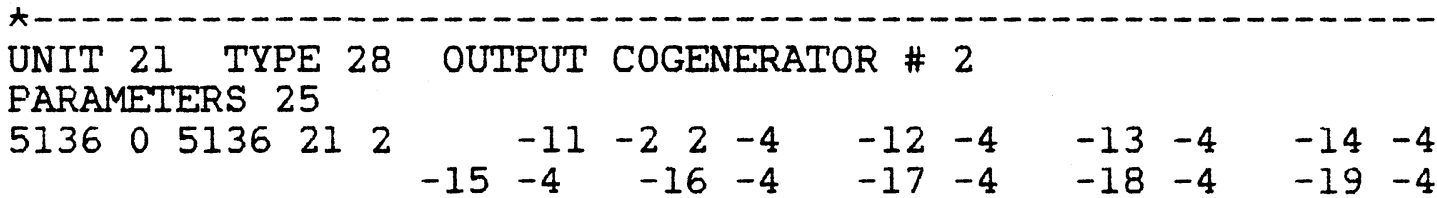

INPUTS 9

$\begin{array}{lllllllll}4.10 & 4.11 & 4,12 & 4,13 & 4,14 & 4,15 & 4,16 & 4.17 & 4,18\end{array}$

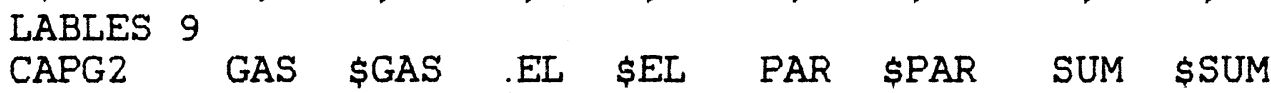

ה-1-

UNIT 22 TYPE 28 OUTPUT COGENERATOR \# 3

PARAMETERS 25

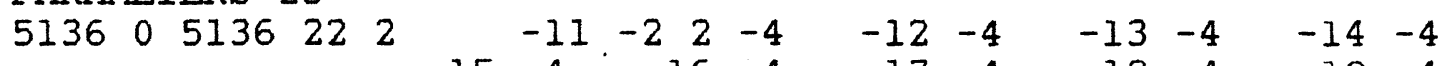

INPUTS 9

$\begin{array}{lllllllll}5.1 & 5.2 & 5.3 & 5.4 & 5.5 & 5.6 & 5,7 & 5.8 & 5.9\end{array}$

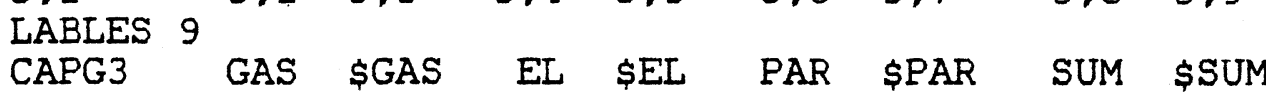

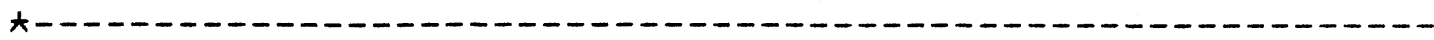

UNIT 23 TYPE 28 OUTPUT COGENERATOR \# 4

PARAMETERS 25

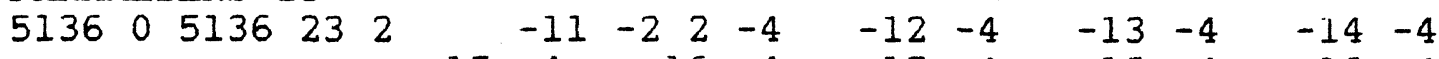

INPUTS 9

\begin{tabular}{|c|}
\hline-4 \\
\hline
\end{tabular}


$\begin{array}{lllllllll}5,10 & 5,11 & 5,12 & 5,13 & 5,14 & 5,15 & 5,16 & 5,17 & 5,18\end{array}$ LABLES 9

CAPG4 GAS \$GAS EL \$EL PAR \$PAR

UNIT 24 TYPE 28 OUTPUT COGENERATOR \# 5

PARAMETERS 25

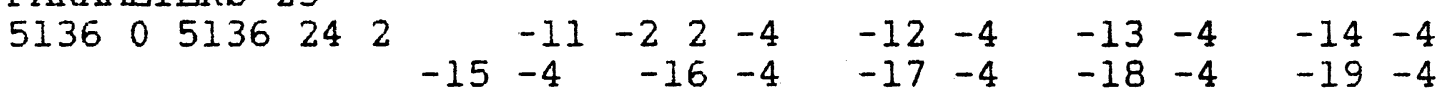

INPUTS 9

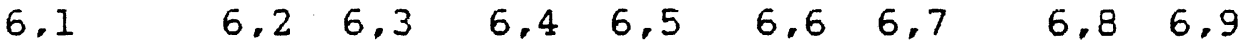

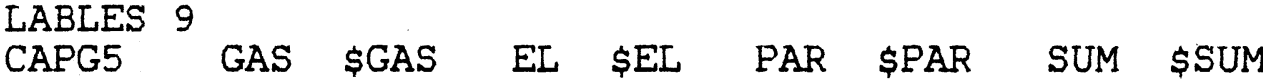

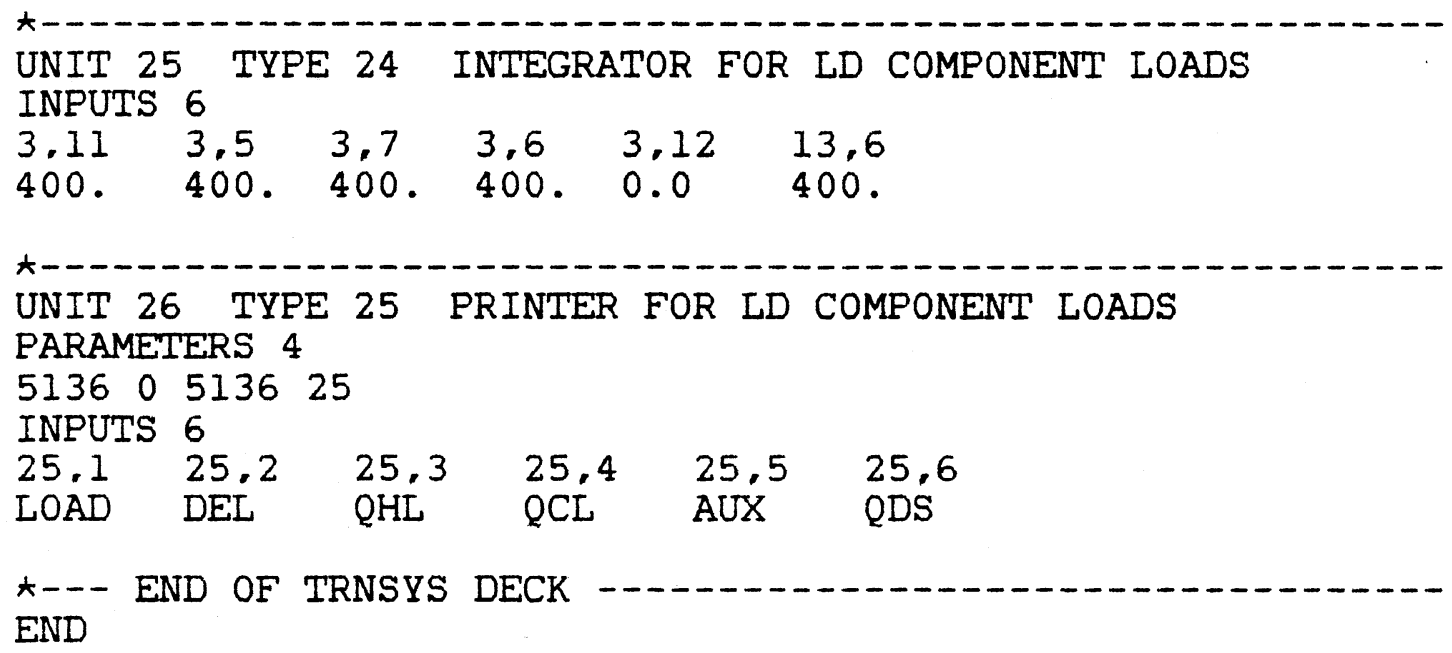




\section{REFERENCES}

1. Buschulte, T.K., "Analysis of Hybrid Liquid Desiccant Cooling Systems", M.S. Thesis in Chemical Engineering, University of Wisconsin-Madison, (1984).

2. Meckler, G., "Designing Energy Integrated HVAC Systems Based on Thermodynamic Efficiency (Science Museum, Richmond, VA)", Proceedings of the Designing and Managing Energy Conscious Commercial Buildings Workshop, Denver, C0, (1982).

3. Meckler, G., "Energy-Integrated Desiccant HVAC System Applications". DOE/SERI Desiccant Cooling Workshop, Chattanooga, TN, (1986).

4. Meckler, G., "Data Collection and Model Development of Liquid Desiccant Integrated HVAC System", Science Museum of Virginia, Richmond, VA, $(1984,1985)$

5. Klein, S.A., et. al., "TRNSYS - A Transient Simulation Program", Version 12.1, Solar Energy Laboratory, University of WisconsinMadison, (1983).

6. Northey, P., "Modeling Liquid Desiccant Air Conditioning Systems", Research Paper, University of Wisconsin-Madison, (1985).

7. Westerberg, A.W., Hutchison, H.P., Motard, R.L., and Winter, P., Process Flowsheeting, Cambridge University Press, (1979).

8. Sargent, R.W.H. and Westerberg, A.W., "'SPEED-UP' in Chemical Engineering Design", Trans. Inst. Chem. Eng. (London), 42, 190197, (1964).

9. Hall, I.J., et. al., "Generation of a Typical Meteorological Year", Proceedings of 1978 Annual Meeting, American Section of ISES, $2,669,(1978)$.

10. "ASHRAE Handbook, 1981 Fundamentals", American Society of Heating, Refrigerating and Air-Conditioning Engineers, Atlanta, GA, (1981).

11. Samuel Crothers Assoc./01iver, Smith, Cooke and Linder, "Virginia Science Museum Planetarium, Richmond, VA", Mechanical Drawing No. C954-80046-1XI, (1981).

12. "McQuay Centrifugal. Single Compressor Packaged Water Chillers", Catalog 950, McQuay Group, Minneapolis, MN, (1983). 
13. "McQuay Templifier. Heat Recovery Water Heaters", Catalog 1200, McQuay Group, Minneapolis, MN, (1982).

14. Duffie, J.A. and Beckman, W.A., Solar Engineering of Thermal Processes, Wiley, New York, (1980).

15. Wuestling, M.D., "Investigation of Promising Control Alternatives for Solar Water Heating Systems", M.S. Thesis in Mechanical Engineering, University of Wisconsin-Madison, (1983).

16. Crum, D.R., "Open Cycle Desiccant Air Conditioning Systems", M.S. Thesis in Mechanical Engineering, University of WisconsinMadison, (1986). 